\title{
ANALYSIS OF STABLE SULFUR ISOTOPES AND TRACE COBALT ON \\ SULFIDES FROM THE TAG HYDROTHERMAL MOUND
}

by

Carrie T. Friedman

B.A. Earth Science

University of California at Berkeley, 1994

SUBMITTED TO THE MASSACHUSETTS INSTITUTE OF TECHNOLOGY AND

THE WOODS HOLE OCEANOGRAPHIC INSITUTION JOINT PROGRAM IN MARINE GEOLOGY AND GEOPHYSICS IN PARTIAL FULFILLMENT OF THE

REQUIREMENTS FOR THE DEGREE OF

\section{MASTER OF SCIENCE}

\author{
at the \\ MASSACHUSETTS INSTITUTE OF TECHNOLOGY \\ and the \\ WOODS HOLE OCEANOGRAPHIC INSTITUTION
}

February 1998

(C) 1998 Carrie T. Friedman. All rights reserved.

The author hereby grants to MIT and WHOI permission to reproduce paper and electronic copies of this thesis in whole or in part, and to distribute them publicly.

Signature of Author

Joint Program in Marine Geology and Geophysics

Massachusetts Institute of Technology/Woods Hole Oceanographic Institution

Certified by

Susan E. Humphris
Research Specialist, Marine Geology and Geophysics
Thesis Co-Supervisor

Certified by

Margaret K. Tivey Assocklte Scientist, Marine Chemistry and Geochemistry Thesis Co-Supervisor

Accepted by

Deborah Smith

Chair, Joint Committee for Marine Geology and Geophysics, Massachusetts Institute of Technology/Woods Hole Oceanographic Institution 


\title{
ANALYSIS OF STABLE SULFUR ISOTOPES AND TRACE COBALT ON SULFIDES FROM THE TAG HYDROTHERMAL MOUND
}

by

\author{
Carrie T. Friedman
}

Submitted to the Massachusetts Institute of Technology and the Woods Hole Oceanographic Institution on January 16, 1998 in partial fulfillment of the requirements for the Degree of Master of Science in Oceanography

\begin{abstract}
Stable sulfur isotopes $\left(\delta^{34} \mathrm{~S}\right)$ and trace Co are analyzed in sulfide and sulfate minerals from six sample types collected from the TAG active mound, $26^{\circ} \mathrm{N}$ Mid-Atlantic Ridge. $\delta^{34} \mathrm{~S}$ values range from 2.7 to $20.9 \%$, with sulfate minerals isotopically indistinguishable from seawater $(21 \%$ ) , and sulfide minerals reflecting input of $\sim 1 / 3$ seawater and $\sim 2 / 3$ basaltic sulfur $(\sim 0 \%)$. Co concentrations in pyrite analyzed by ion microprobe primarily reflect depositional temperatures. The $\delta^{34} \mathrm{~S}$ and Co data are combined to provide information regarding the sources and temperatures of parent fluids, the genetic relationships among sample types, and the circulation of hydrothermal fluids and seawater in the mound. $\delta^{34} \mathrm{~S}$ values and Co concentrations vary by sample type. Chalcopyrite from black smoker samples exhibits invariant $\delta^{34} \mathrm{~S}$ values, indicating direct precipitation from black smoker fluids. Crust samples contain chalcopyrite with a mean $\delta^{34} \mathrm{~S}$ indistinguishable from that of black smoker samples, and pyrite with some light $\delta^{34} \mathrm{~S}$ and moderately high Co values, consistent with crust samples precipitating from cooled black smoker fluids. Massive anhydrite samples are a mixture of anhydrite with high $\delta^{34} \mathrm{~S}$, and pyrite with variable $\delta^{34} \mathrm{~S}$ and Co values, indicative of deposition from disequilibrium mixing between black smoker fluids and seawater. White smoker samples contain chalcopyrite and sphalerite with high $\delta^{34} \mathrm{~S}$, and pyrite with low Co values, reflecting deposition from cooler fluids formed from mixtures of seawater and black smoker fluid, with some reduction of sulfate. Mound samples contain chalcopyrite with a mean $\delta^{34} \mathrm{~S}$ indistinguishable from that of black smoker and crust samples, and pyrite with low Co values, suggesting deposition from a fluid isotopically similar to black smoker fluid at temperatures similar to those of white smoker fluid. Massive sulfide samples exhibit pyrite with high $\delta^{34} \mathrm{~S}$ values and very high Co, indicating deposition from and recrystallization with very hot fluids contaminated with seawater-derived sulfate. The data demonstrate that direct precipitation from black smoker fluids, conductive cooling, disequilibrium mixing with entrained seawater, sulfate reduction, and recrystallization all contribute to the formation of the TAG mound deposit. The successful preliminary Co analyses demonstrate that ion microprobe analyses are a viable technique for measuring trace elements in sulfides.
\end{abstract}




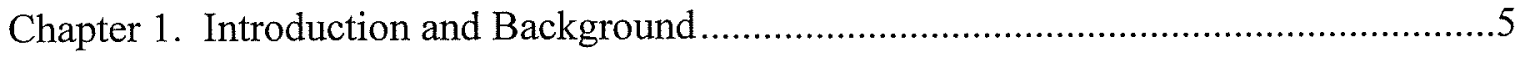

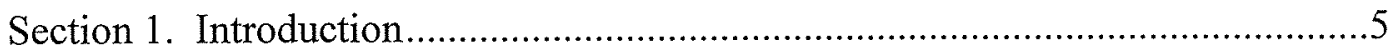

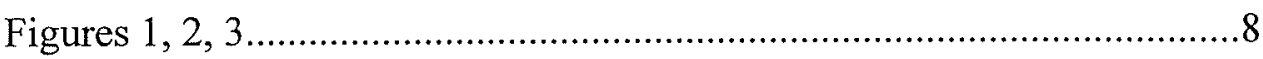

Section 2. The TAG Active Mound ............................................................... 10

Geologic Setting..................................................................... 10

Previous Studies.......................................................................... 11

Sample Description .................................................................. 12

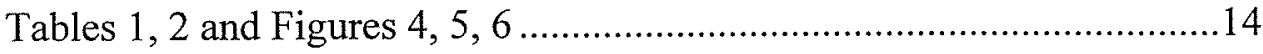

Chapter 2. Stable Sulfur Isotopes Study …......................................................19

Section 1. Sulfur Isotope Analysis of Surficial Samples from the TAG Mound..19 Introduction and Background ..................................................19

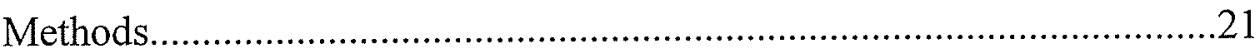

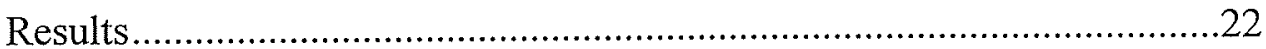

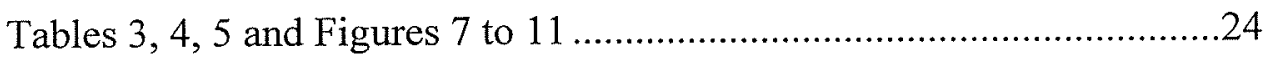

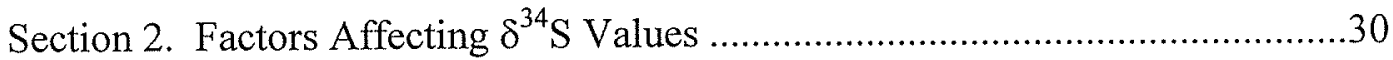

Variations in the $\delta^{34} \mathrm{~S}$ Value of End-Member Hydrothermal Fluid ...........30

Seawater Entrainment ................................................................ 32

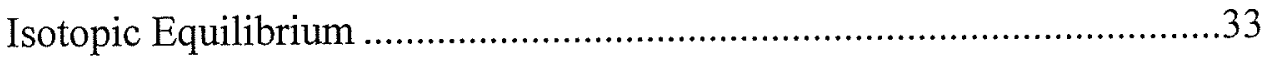

Isotopic Relationships of Coexisting Minerals ......................................35

Isotopic Relationship of Black Smoker Fluids and Sulfides ...................37

Post-depositional Reworking ........................................................... 38

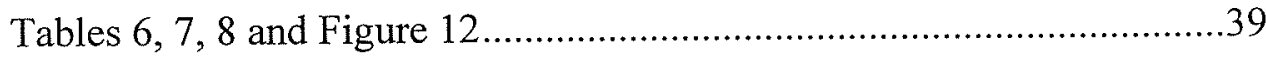

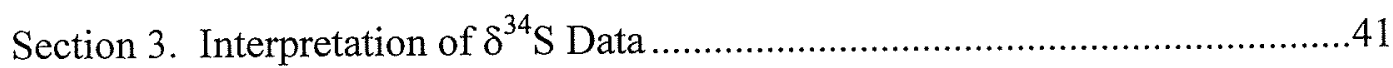

Black Smoker, Crust, and Massive Anhydrite Samples .......................41

White Smoker Samples...............................................................44

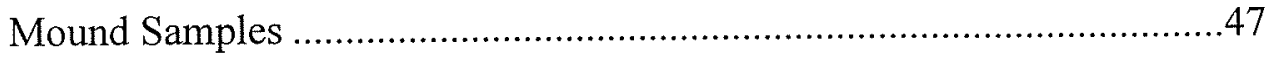

Massive Sulfide Samples ..........................................................49 


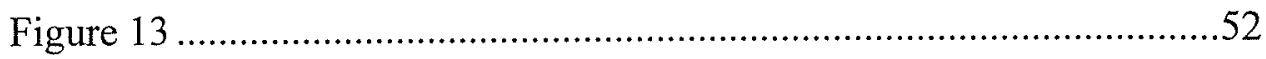

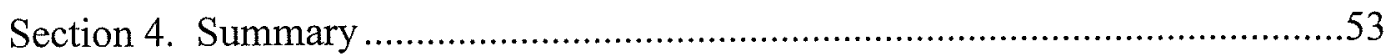

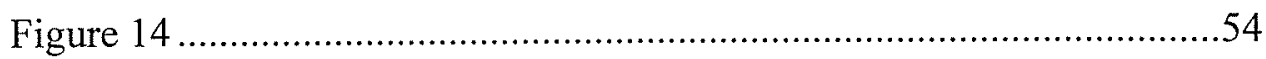

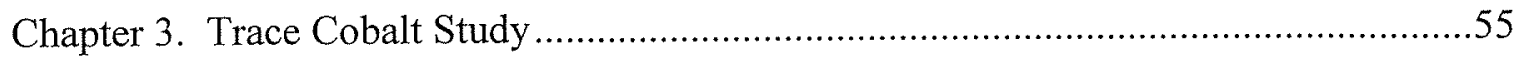

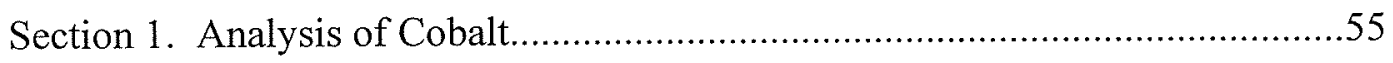

Introduction and Background ...................................................55

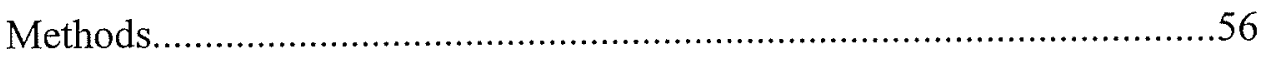

General Parameters ...........................................................58

Development of Standards .................................................58

Development of Analytical Techniques...................................58

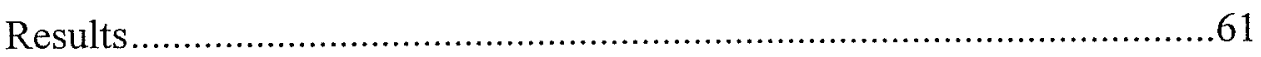

Tables 9 to 18 and Figures 15 to 22 ..............................................63

Section 2. Interpretation of Cobalt Data .................................................. 74

Crust and Massive Anhydrite Samples .............................................75

White Smoker and Mound Samples ..............................................76

Massive Sulfide Sample.............................................................78

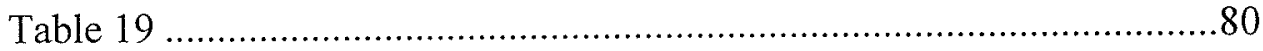

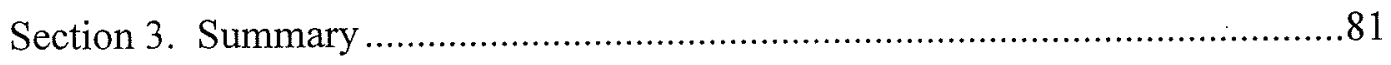

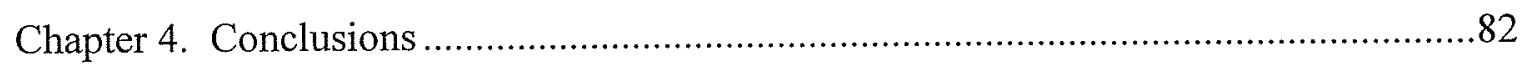

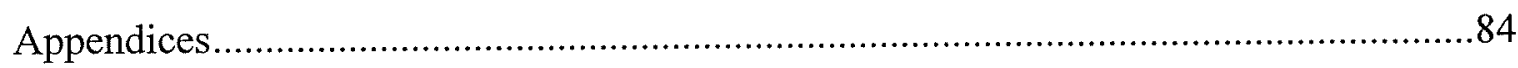

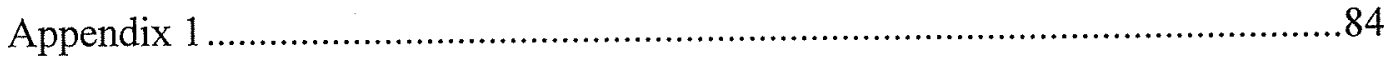

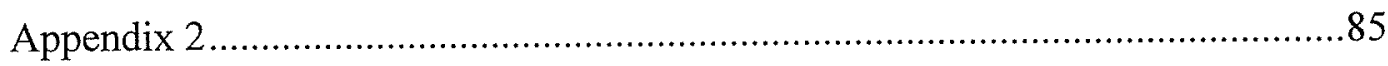

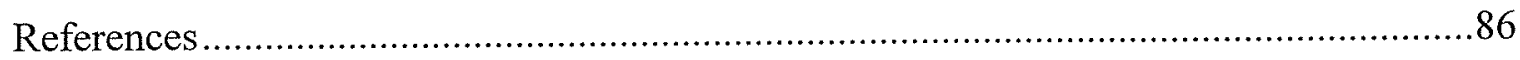

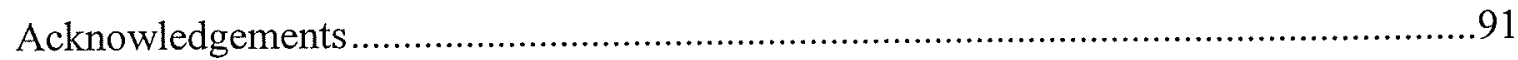




\section{Chapter 1. INTRODUCTION AND BACKGROUND}

\section{Section 1. INTRODUCTION}

The convection of seawater through mid-ocean ridges and ridge flanks affects heat transport, influences the chemistry of the oceans and ocean crust, and controls the formation of seafloor massive sulfide deposits. High and low temperature reactions between seawater and crustal rock account for $25 \%$ of global heat loss (Stein and Stein, 1994) and regulate ocean chemistry on an 8-10 Myr cycle (Edmond et al., 1982). Chemical reactions modify the composition of the crust, particularly at the surface and shallow subsurface of a vent where metals leached out of crustal rock by circulating seawater can accumulate as massive sulfide deposits as great as 9 million tons (Zierenberg et al., in press). Large seafloor sulfide deposits are believed to be the modern analogues to economic orebodies such as those in Cyprus (Constantinou and Govett, 1972).

Seafloor sulfide deposits form when a heat source in the crust supplies energy that drives the circulation of seawater through oceanic rocks on both the axis and flanks of a mid-ocean ridge. Considering only processes which occur at the ridge axis, the system can be separated into recharge, reaction, and discharge zones (Figure 1). The recharge zone is defined as the zone where seawater enters permeable volcanic rocks and heats by conduction. As summarized in Figure 2 by Alt (1995), oxidizing seawater grows increasingly hotter, and a series of water-rock reactions take place that initially fix alkalis into basalt (Seyfried and Bischoff, 1979). This is followed by uptake of $\mathrm{Mg}$ into basalt (Bischoff and Seyfried, 1978; Mottl, 1983) and precipitation of retrograde soluble anhydrite (Blount and Dickson, 1969; Bischoff and Seyfried, 1978), and finally mobilization of alkalis back out of basalt (Seyfried and Bischoff, 1979). As modified seawater penetrates close to the heat source and reaches temperatures $>350^{\circ} \mathrm{C}$, it enters the reaction zone. Here, seawater leaches metals and $\mathrm{S}$ out of surrounding rock (Alt, 
1995; Seyfried and Bischoff, 1977) before increasing temperatures drive the buoyancy of the fluid to the point where it is hydrostatically unstable. Once the reaction zone fluid becomes unstable, it rises up through the discharge zone to the seafloor (Alt, 1995).

Ascending fluid may either pass directly through the shallow subsurface of a vent to exit at the seafloor or may undergo additional processes within the shallow subsurface prior to emission. Directly exiting fluid is termed "end-member fluid," and it is defined as the highest temperature, $\mathrm{Mg}$-free hydrothermal fluid. Fluid which does not directly exit at the seafloor may mix in the shallow subsurface with entrained seawater, cool conductively, reduce velocity, precipitate anhydrite and sulfides, or remobilize metals out of previously deposited minerals (Janecky and Shanks, 1988). These shallow subsurface processes are thought to be responsible for the formation of non-end-member fluids such as "white smoker fluid," for influencing the chemistry and size of near surface deposits, and for creating a variety of surface precipitates with diverse mineralogies and morphologies (Koski et al., 1984; Shanks and Seyfried, 1987; Tivey et al., 1995).

Shallow subsurface discharge zone processes play a major role in altering depositional environments at the actively venting TAG hydrothermal mound on the MidAtlantic Ridge (Tivey et al., 1995). Cores recovered during the recent drilling of the active mound are composed of sulfide-sulfate-silica breccias and altered basalt (Figure 3; Humphris et al., 1995). The presence, in particular, of the sulfate mineral, anhydrite, in drill cores confirms that seawater has been entrained into the active mound (Humphris et al., 1995), and indicates the presence of shallow subsurface processes more complex than the simple emission of end-member fluid.

To examine the processes which affect the TAG active mound, this study combines analyses of sulfur isotopes and trace cobalt from a suite of surficial mound samples. Sulfur isotopes can provide information on the relative contributions of isotopically heavy seawater and isotopically light basalt to the formation of hydrothermal fluids and vent sulfides. Sulfur isotope data are useful for determining the extent of reactions between seawater and basalt, but sulfur isotopes alone do not yield a unique solution to describe which reactions occur and in what part of a hydrothermal vent system. Additional information may be garnered through analysis of trace elements such 
as cobalt. Trace elements can help characterize a source fluid and depositional conditions as well as potentially provide information on precipitation and remobilization reactions. Because the trace element analytical techniques used in this study are relatively new, the methodology is still being developed. Cobalt is the only trace element for which the analytical techniques were resolved, and, consequently, cobalt is the only trace element for which data are presented. Combined with the sulfur isotope data, the trace cobalt studies of surface precipitates can provide insight into the chemical reactions in the shallow subsurface of the TAG active mound. The aim of this study is to use the sulfur isotope and cobalt data to help identify the processes that form and modify the TAG active mound, to determine the relationships among samples, and to understand the pattern of fluid circulation inside the mound. 


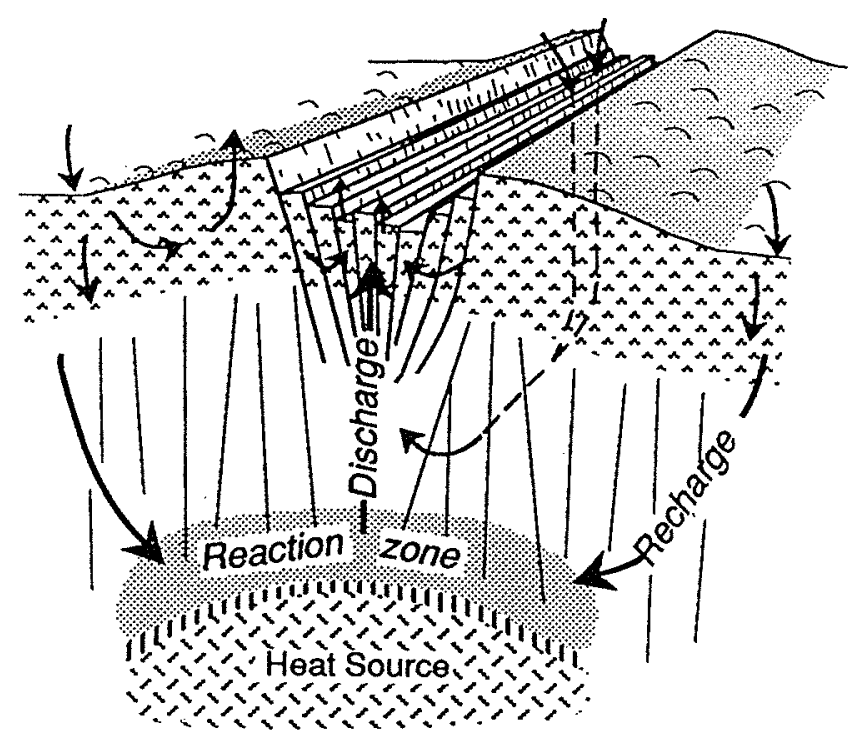

Figure 1. Schematization of ridge axis hydrothermal system. Hydrothermal circulation begins at recharge zones where seawater enters the ocean crust. As it progresses closer to a heat source, seawater reacts with crustal rocks. Upon entering the reaction zone, high temperature reactions produce a hydrostatically unstable, chemically evolved fluid. The buoyant fluid rises rapidly through the discharge zone and exits at the seafloor. Figure from Alt, 1995.

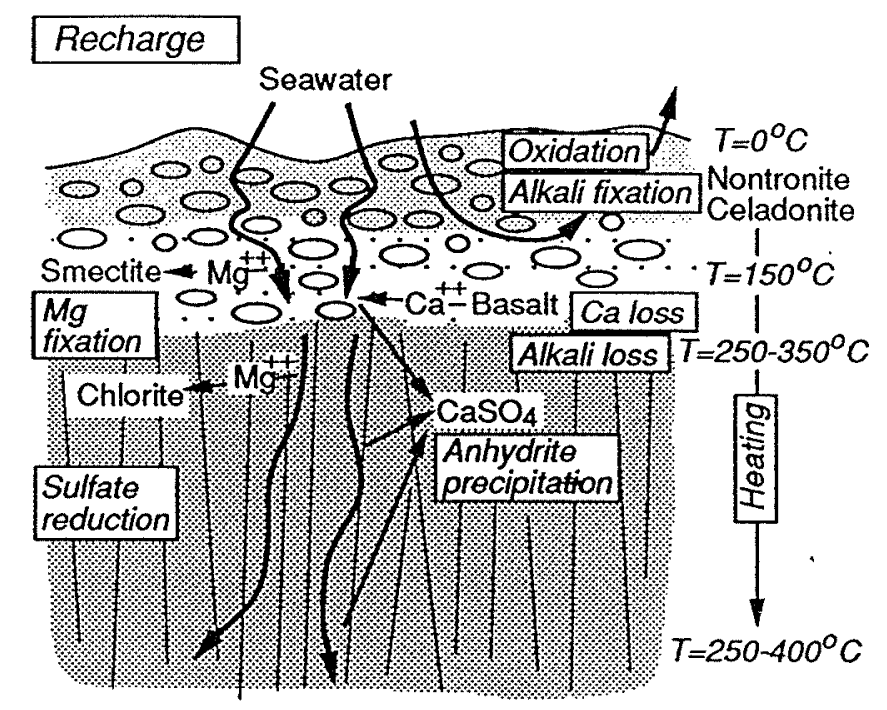

Figure 2. Schematization of recharge zone processes Seawater enters permeable volcanic rocks and heats by conduction. As oxidizing seawater grows increasingly hotter, it fixes alkalis, then fixes $\mathrm{Mg}$ and precipitates anhydrite, and finally mobilizes alkalis back out of basalt. Figure from Alt, 1995. 


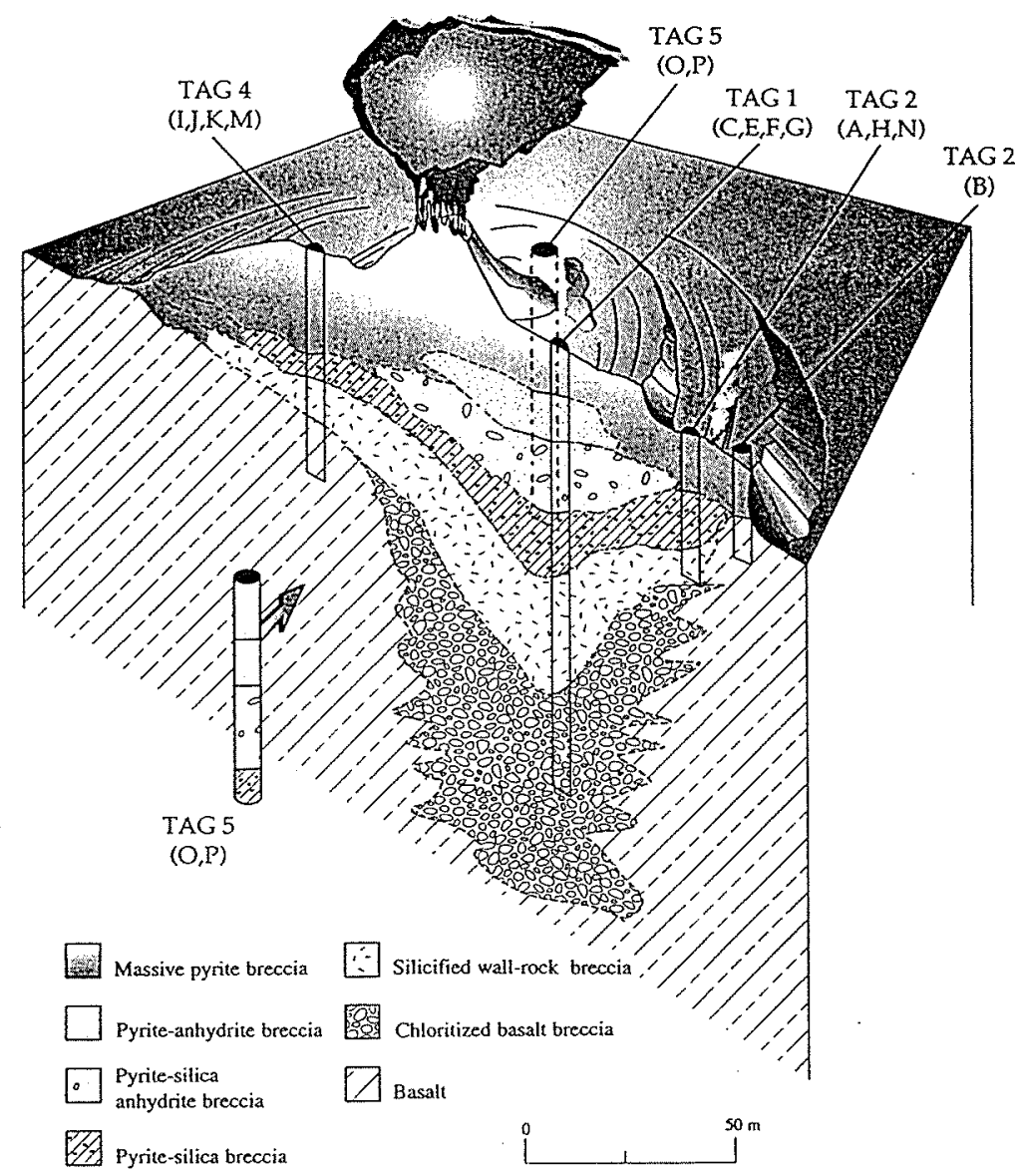

Figure 3. Cross-section of the TAG active mound showing simplified internal structure based on the results from drilling. TAG 1-5 refer to drilling sites at each of 5 locations, and letters in brackets refer to individual holes drilled at each location. The presence of anhydrite indicates entrainment of seawater into the active mound. Figure from Humphris et al. (1995) and drawn by E. P. Oberlander. 


\section{Section 2. THE TAG ACTIVE MOUND}

\section{Geologic Setting}

As early as the mid-1970's, surface ships started investigating the TAG area for hydrothermal activity (summary in Rona, 1980). Dives by submersible began in 1986 (Thompson et al., 1988) and made it possible to precisely document the location and morphology of seafloor sulfide samples, as well as determine whether the samples were collected from an active or inactive vent. The TAG field is now known to cover a $5 \mathrm{~km}^{2}$ area along the floor and eastern wall of the rift valley (Rona and Von Herzen, 1996; Tivey et al., 1995), and includes the currently venting TAG active mound, relict mounds in the ALVIN and MIR zones, and an active low-temperature zone (Figure 4).

Located at $26^{\circ} 08.2 \mathrm{~N} 44^{\circ} 49.6^{\prime} \mathrm{W}$ and $3670 \mathrm{~m}$ depth, the TAG active mound is $\sim 200 \mathrm{~m}$ diameter and 50m high (Thompson et al., 1988; Tivey et al., 1995). The mound is topped by a $20 \mathrm{~m}$ diameter, 10-20 $\mathrm{m}$ high cone covered with up to $15 \mathrm{~m}$ tall "black smoker" chimneys termed the "black smoker complex" (Figure 5; Tivey et al., 1995; Humphris et al., 1995). Black smokers form when discharging high temperature $\left(>350^{\circ} \mathrm{C}\right)$ fluids mix with cold ambient seawater, depositing minerals that build chimneylike structures composed of outer walls of anhydrite $\left(\mathrm{CaSO}_{4}\right)$ and inner channels of mainly chalcopyrite $\left(\mathrm{CuFeS}_{2}\right)$ (Goldfarb et al., 1983). The surface of the cone supporting the black smoker chimneys is composed of "crust" samples, which are $2-10 \mathrm{~cm}$ thick platy surface layers consisting primarily of chalcopyrite and pyrite/marcasite $\left(\mathrm{FeS}_{2}\right)$ and exhibiting a porous textured underside (Tivey et al., 1995). Crusts are believed to form when the same fluid responsible for the precipitation of black smoker chimneys fails to rise rapidly to discharge at the seafloor and instead pools below the cone supporting the black smoker complex. Pooled fluid subsequently flows slowly up through debris to the surface to form crusts (Tivey et al., 1995). On the sides of the cone sit talus blocks of anhydrite and minor pyrite, called "massive anhydrite" (Tivey et al., 1995). Massive anhydrites are thought to form inside the base of the cone when entrained seawater and black smoker fluid mix, precipitating anhydrite, pyrite, and minor chalcopyrite (Tivey et 
al., 1995).

Located 70m southeast of the black smoker complex, 1-2 m tall "white smoker" chimneys group in a 20-50 m diameter region named the "Kremlin area" (Thompson et al., 1988). White smoker chimneys form from lower temperature $\left(260-300^{\circ} \mathrm{C}\right)$ fluids, and are composed dominantly of low-Fe sphalerite $(\mathrm{ZnS})$ with small amounts of pyrite and chalcopyrite (Tivey et al., 1995; Edmond et al., 1995).

Much lower temperature fluids $\left(<46^{\circ} \mathrm{C}\right)$ percolate out of many areas of the active mound (Mills and Elderfield., 1995; Mills et al., 1996; James and Elderfield, 1996). Large bulbous "mound" samples containing variable proportions of sphalerite, pyrite, and chalcopyrite all coated with a $<1$ to $2 \mathrm{~mm}$ thick outer layer of amorphous red-orange $\mathrm{Fe}$ oxide are found on the mound surface (Tivey et al., 1995). These samples display neither the well developed channels of smoker samples nor the layered, planar morphology of crust samples. On the steep outer slopes of the mound are dense, unfriable "massive sulfide" samples consisting primarily of pyrite/marcasite with lesser amounts of chalcopyrite (Tivey et al., 1995). As suggested by Th/U age dates (Lalou et al., 1993) and replacement and recrystallization textures (Tivey et al., 1995), these massive sulfide samples were initially precipitated as much as 10,000 years ago and have undergone extensive post-depositional reworking.

\section{Previous Studies}

The TAG active mound has been the subject of numerous studies. Radiometric dating has constrained active venting at the TAG mound to a minimum of four pulses over the past 18,000 to 4000 years (Lalou et al., 1990; 1993). Current activity at TAG is believed to have begun in the last 50 years (Lalou et al., 1990; 1993).

Variability in activity on the TAG mound on a shorter time scale was investigated in measurements of conductive heat flow taken on and around the mound. During submersible dives in 1993, 1994, and 1995, heat flow measurements yielded extremely variable results in the region surrounding the black and white smoker areas, consistently high results on the southern and southeastern slopes of the mound and in the surrounding sedimented floor, and consistently low results in a zone to the west of the black smoker 
complex (Becker et al., 1996). Consistently low heat flow was interpreted to indicate a zone of seawater entrainment (Becker et al., 1996). In another study, instruments emplaced on the mound surface from August 1994 to February 1995 continuously measured temperatures. Temperatures were found to fluctuate and to not always match the measurements of Becker et al. (1996), but they nevertheless supported seawater entrainment into the area of the mound (Kinoshita et al., 1996).

Time series studies of TAG active mound fluid samples collected in 5 years during the period 1986 to 1995 determined that end-member fluids had a major ion chemistry and $\mathrm{pH}$ which remained relatively constant on the order of a decade (Table 1; Edmonds et al., 1996; Gamo et al., 1996). Because there were no time series measurements of sulfur isotopes and trace elements, it is not known whether they also remained constant in end-member fluid.

Analyses of surface precipitates formed from end-member and other fluids indicated that chemistry varied among sample types. The mineralogy and bulk chemistry of a range of surface samples was detailed in several studies (Thompson et al., 1985, 1988; Tivey et al., 1995), and described in the previous section. Analyses of gold enrichment in white smoker deposits indicated that lower temperature white smokers fluids precipitate gold in seafloor sulfides (Hannington et al., 1995). Measurements of gold concentrations in massive sulfide samples also demonstrated that post-depositional reworking locally concentrates gold (Hannington et al., 1995).

Geochemical modeling has demonstrated that white smoker fluids can be formed from a mixture of black smoker fluid and entrained seawater, coupled with anhydrite, pyrite, and chalcopyrite precipitation and sphalerite dissolution (Tivey et al., 1995; Edmond et al., 1995). These results were supported by data from a series of 17 cores taken during Leg 158 of the Ocean Drilling Program (ODP) in 1994.

\section{Sample Description}

The method employed for classifying TAG mound surface samples is based on macroscopic texture and mineralogy, and has been adapted from Tivey et al. (1995). In this study, 4 different minerals (pyrite, chalcopyrite, sphalerite, and anhydrite) from 6 
different sample types (black smoker, crust, massive anhydrite, white smoker, mound, massive sulfide) were analyzed for stable sulfur isotopes, trace cobalt, or both. Most samples were retrieved in 1990 by the U.S. submersible DSV ALVIN, with the exceptions of sample ODP-6-2894 (named for ODP marker 6), which was collected by DSV ALVIN in 1995, and sample MIR2-75, which was collected by the Russian MIR submersibles in 1991. Figure 6 shows the sites from which each sample used in this study was collected. A list of all samples analyzed in this study for stable sulfur isotopes and trace cobalt is provided in Table 2 . 


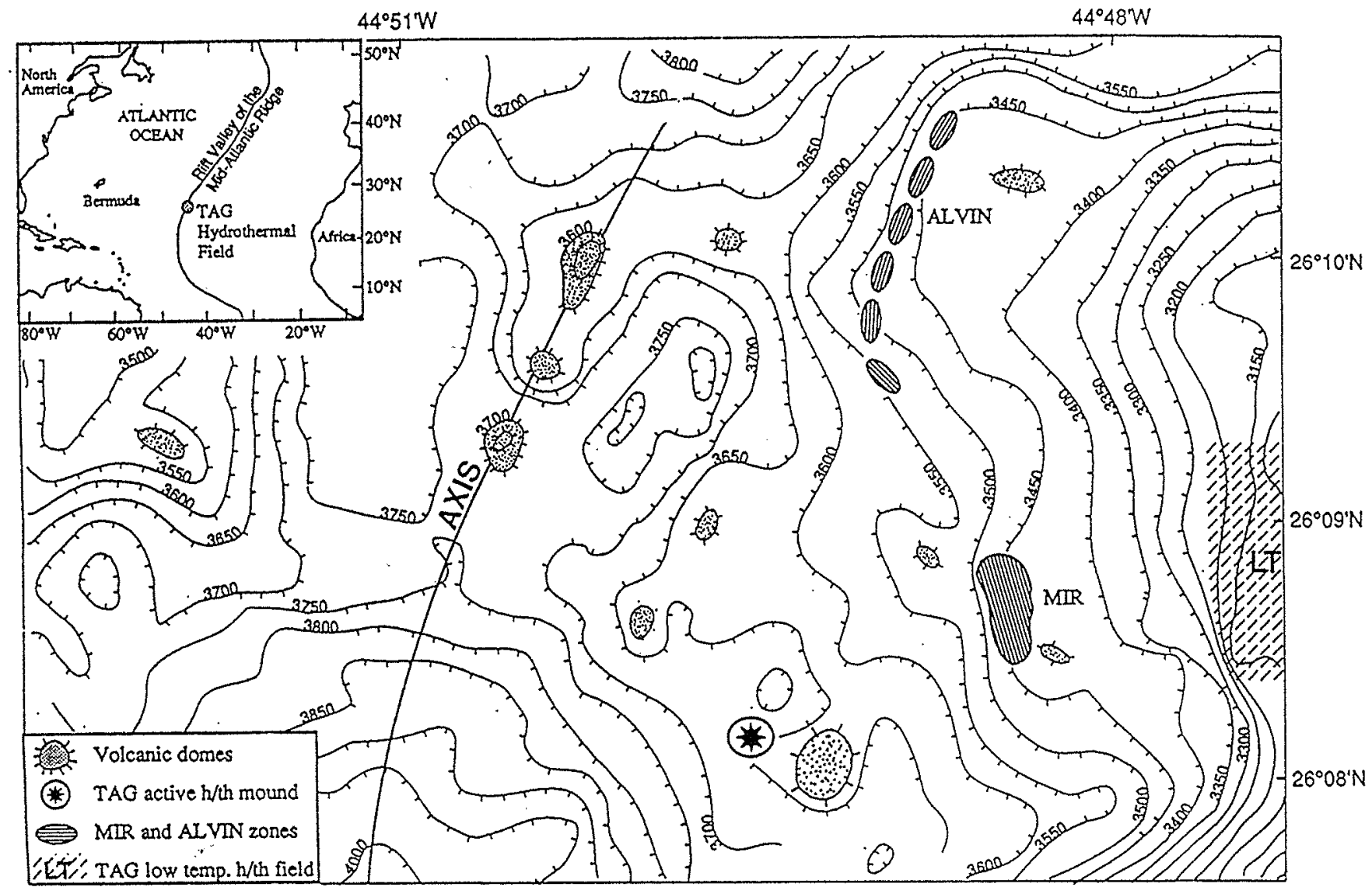

Figure 4. Bathymetric map of the TAG hydrothermal field showing the currently venting TAG active mound, relict mounds in the ALVIN and MIR zones, and an active low-temperature zone. Figure from Tivey et al. (1995) and based on Rona et al. (1993).

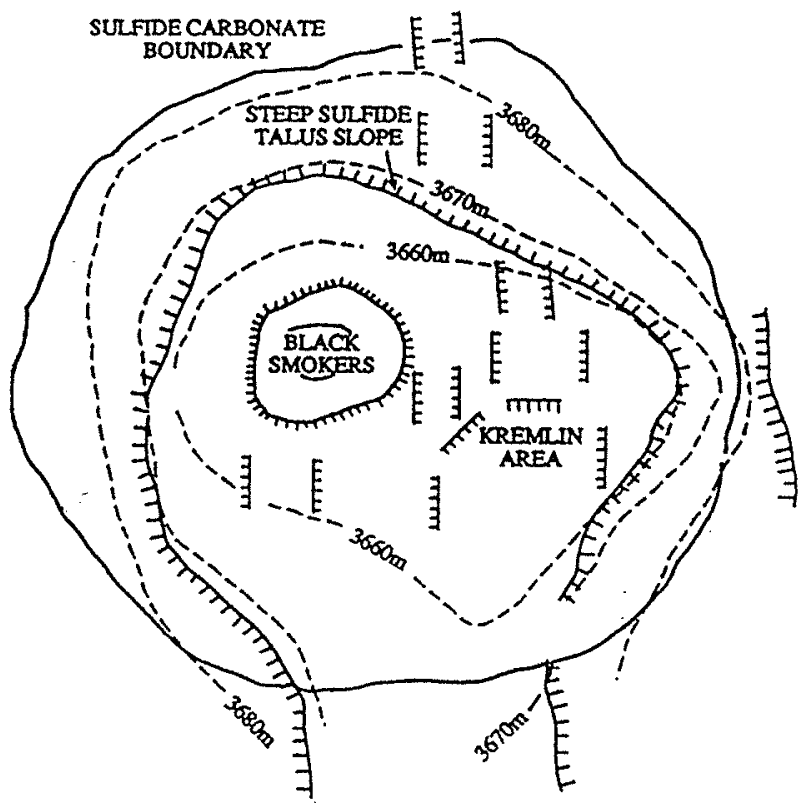

Figure 5. Plan view of the TAG active mound compiled from observations made during Alvin dives. Figure from Tivey et al. (1995). 


\begin{tabular}{|c|c|c|c|c|c|c|c|}
\hline & 1986 BS & $1990 \mathrm{BS}$ & 1993 BS & 1995 BS & 1995 ODP 6 & $1990 \mathrm{WS}$ & 1994 WS \\
\hline Temp. $\left({ }^{\circ} \mathrm{C}\right)$ & $290-320$ & $360-366$ & $363-364$ & 369 & - & 273-301 & 270 \\
\hline $\mathrm{pH}\left(25^{\circ} \mathrm{C}\right)$ & - & 3.35 & - & 3.8 & 3 & 3 & $<3$ \\
\hline $\mathrm{Si}(\mathrm{OH})_{4}(\mathrm{mM})$ & 22 & 21 & - & 21 & 21 & 19 & 18 \\
\hline $\mathrm{H}_{2} \mathrm{~S}(\mathrm{mM})$ & - & $2.5-3.5$ & - & 3 & 3 & 0.5 & 3 \\
\hline $\mathrm{Cl}(\mathrm{mmol} / \mathrm{kg})$ & 659 & 636 & 633.5 & 645 & 643 & - & 636 \\
\hline $\mathrm{Na}^{*}(\mathrm{mmol} / \mathrm{kg})$ & 584 & 557 & 543 & 553 & 549 & - & 549 \\
\hline $\mathrm{Li}(\mu \mathrm{mol} / \mathrm{kg})$ & 411 & - & 368 & 370 & 367 & - & 352 \\
\hline $\mathrm{K}(\mathrm{mmol} / \mathrm{kg})$ & 17 & 17 & 18 & 20 & 20 & 17 & 20 \\
\hline $\mathrm{Ca}(\mathrm{mmol} / \mathrm{kg})$ & 26 & 31 & 30 & 31 & 30 & 27 & 27 \\
\hline $\mathrm{Sr}(\mu \mathrm{mol} / \mathrm{kg})$ & 99 & 103 & 99 & 99 & 100 & 91 & 95 \\
\hline $\mathrm{Fe}(u \mathrm{~mol} / \mathrm{kg})$ & 1640 & 5590 & 5180 & 5040 & 5450 & 3830 & 3840 \\
\hline $\mathrm{Mn}(\mu \mathrm{mol} / \mathrm{kg})$ & 1000 & 680 & 689 & 677 & 666 & 750 & 762 \\
\hline $\mathrm{Zn}(\mu \mathrm{mol} / \mathrm{kg})$ & - & 46 & - & $>36$ & $>36$ & $300-400$ & - \\
\hline $\mathrm{Cu}(\mu \mathrm{mol} / \mathrm{kg})$ & - & $120-150$ & - & $>83$ & $>91$ & 3 & - \\
\hline
\end{tabular}

Table 1. Time series study of TAG active mound fluid samples. BS = samples from black smoker complex; ODP 6 = black smoker samples from ODP Marker 6 ; WS = white smokers. $\mathrm{Na}^{*}$ is sodium concentration calculated from charge balance. Data for 1986 and 1990 from Edmond et al. (1995). Table from Edmonds et al. (1996) 
Figure 6. Location of Samples on TAG active mound. , Plan view compiled from observations made during Alvin dives.

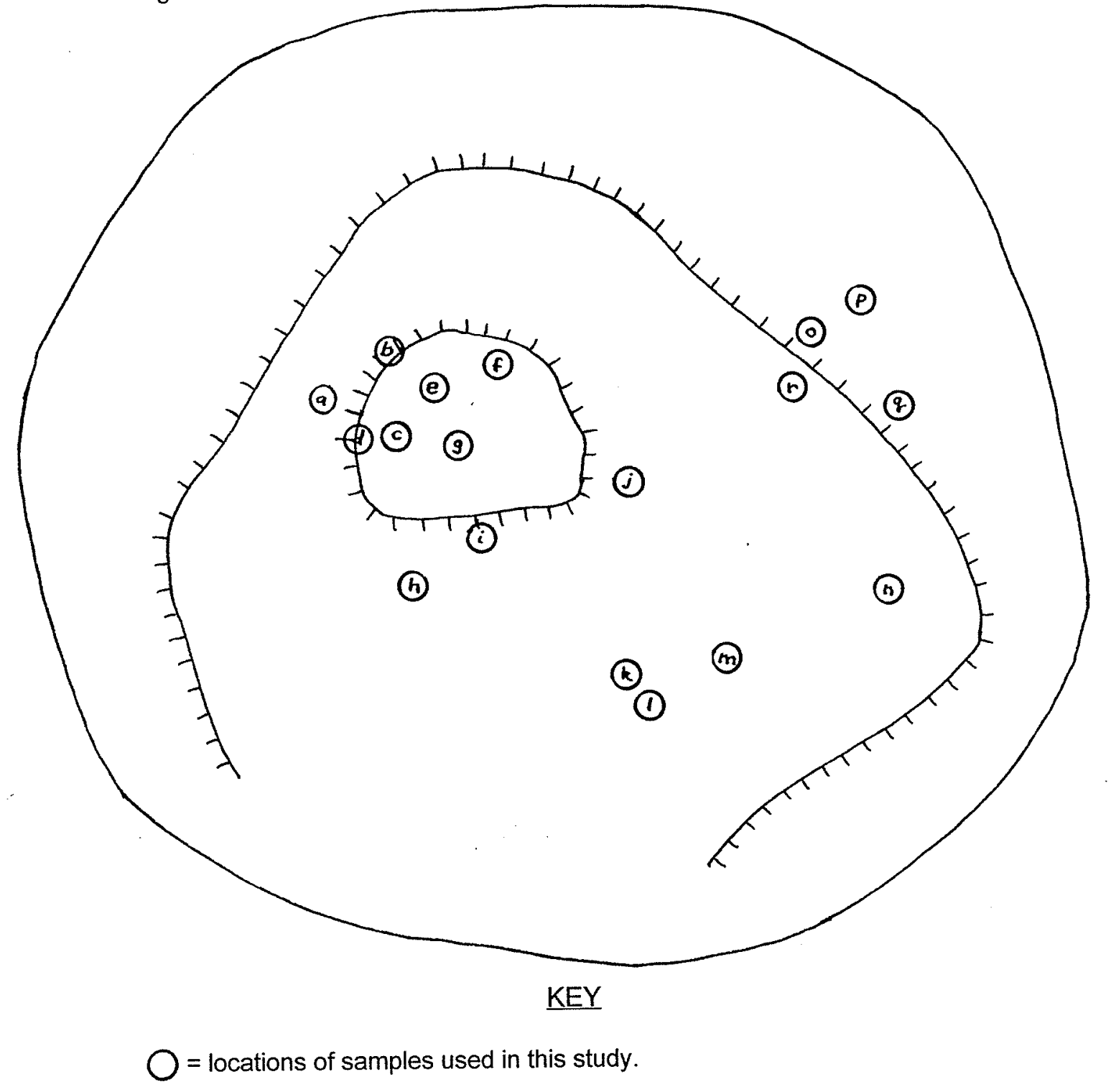

Letters identify individual samples:

$\begin{array}{llll}\text { a } & \text { MIR2-75-5A } & \text { j } & 2178-3 \\ \text { b } 2190-13 & \text { k } & 2190-14 \\ \text { c } 2180-3 & \text { l } & 2187-1 \\ \text { d } 2180-1 & \text { m } & 2183-4 \\ \text { e } 2179-1 & \text { n } & \text { ODP-6-2894 } \\ \text { f } 2190-8 & \text { o } & 2189-5 \\ \text { g } 2178-5 & \text { p } & 2190-6 \\ \text { h } 2186-1 & \text { q } & 2183-6 \\ \text { i } 2183-9 & \text { r } & 2190-7\end{array}$


TABLE 2. List of TAG Samples Used for $\delta^{34} \mathrm{~S}$ and Trace Element Analyses

\begin{tabular}{|c|c|c|}
\hline Sample \# & Sample Type & Description of Sub-sample \\
\hline $2178-5-1$ & $\begin{array}{l}\text { Black } \\
\text { Smoker }\end{array}$ & Solid base of black smoker chimney. \\
\hline $2178-5-2$ & $\begin{array}{l}\text { Black } \\
\text { Smoker }\end{array}$ & $\begin{array}{l}\text { Chimney wall. Displays two independent, sub-parallel } \\
\text { channels marked by chalcopyrite crystals }\end{array}$ \\
\hline $2181-1-1$ & $\begin{array}{l}\text { Black } \\
\text { Smoker }\end{array}$ & $\begin{array}{l}\text { Cross-section of chimney lined with fine grained } \\
\text { sulfide minerals and marked by veins of anhydrite. }\end{array}$ \\
\hline ODP-6-2894 & $\begin{array}{l}\text { Black } \\
\text { Smoker }\end{array}$ & $\begin{array}{l}\text { Cylindrical cross-section of chimney. Chalcopyrite } \\
\text { crystals mark the channel at either end. }\end{array}$ \\
\hline $2179-1-1$ & Crust & $\begin{array}{l}\text { Cross-section of plate-like sample. Euhedral } \\
\text { chalcopyrite with minor amount of pyrite and trace } \\
\text { anhydrite. Few mm-sized pockets of cubic pyrite. }\end{array}$ \\
\hline $2180-1$ & Crust & $\begin{array}{l}\text { Cross-section of plate-like sample. Few mm-sized } \\
\text { pockets of cubic and massive pyrite. }\end{array}$ \\
\hline $2180-3$ & Crust & $\begin{array}{l}\text { Cross-section of plate-like sample Fine grained } \\
\text { chalcopyrite and pyrite with trace anhydrite. }\end{array}$ \\
\hline MIR2-75-5A & Crust & $\begin{array}{l}\text { Thick plate with small, convoluted channels. } \\
\text { Pyrite/marcasite with } 10 \% \text { sphalerite, }<1 \% \\
\text { chalcopyrite, and trace silica. }\end{array}$ \\
\hline $2178-3-1$ & $\begin{array}{l}\text { Massive } \\
\text { Anhydrite }\end{array}$ & $\begin{array}{l}\text { Anhydrite matrix with } \mathrm{mm} \text { to } \mathrm{cm} \text { sized pyrite grains. } \\
\text { Some euhedral, cubic pyrite. }\end{array}$ \\
\hline $2183-7 \varnothing$ & $\begin{array}{l}\text { Massive } \\
\text { Anhydrite }\end{array}$ & $>95 \%$ pure anhydrite, contains little sulfide. \\
\hline $2190-8-1$ & $\begin{array}{l}\text { Massive } \\
\text { Anhydrite }\end{array}$ & $\begin{array}{l}\text { Primarily pyrite with }<10 \% \text { intergrown chalcopyrite } \\
\text { and traces of silica and anhydrite. Includes } 1 \mathrm{~cm} \text { sized } \\
\text { pyrite clast. }\end{array}$ \\
\hline $2187-1-2$ & $\begin{array}{l}\text { White } \\
\text { Smoker }\end{array}$ & $\begin{array}{l}\text { Anhydrite-rich area of sample with regions of }<5 \% \\
\text { sulfide. }\end{array}$ \\
\hline $2187-1-4$ & $\begin{array}{l}\text { White } \\
\text { Smoker }\end{array}$ & $\begin{array}{l}\text { Light gray, porous, friable chimney cross sections. } \\
\text { Sphalerite with } 5 \% \text { fine grained chalcopyrite, } 1 \% \\
\text { disseminated pyrite. }\end{array}$ \\
\hline $2187-1-7$ & $\begin{array}{l}\text { White } \\
\text { Smoker }\end{array}$ & $\begin{array}{l}\text { Cylindrical cross section of chimney. Both light and } \\
\text { dark (lower and higher iron) sphalerite with trace pyrite } \\
\text { and silica, and variable amounts of chalcopyrite. } \\
\text { Includes well-formed channel lined with chalcopyrite. }\end{array}$ \\
\hline $2190-14-1$ & $\begin{array}{l}\text { White } \\
\text { Smoker }\end{array}$ & $\begin{array}{l}\text { Light gray, porous, friable chimney cross sections. } \\
\text { Sphalerite with trace silica, } 1 \% \text { chalcopyrite, }<5 \% \\
\text { pyrite. }\end{array}$ \\
\hline $2183-4-1$ & Mound & Friable, gray, porous sample. Sphalerite with trace \\
\hline
\end{tabular}




\begin{tabular}{|l|l|l|}
\hline & & $\begin{array}{l}\text { chalcopyrite. Few regions of dark sphalerite and few } \\
\text { regions of fine grained chalcopyrite. }\end{array}$ \\
\hline $2183-9-1$ & Mound & $\begin{array}{l}\text { Large bulbous sample with red oxidized exterior, dark } \\
\text { gray sulfide interior, and patches of white salt. Fine } \\
\text { grained mix of sulfides with some regions of euhedral } \\
\text { chalcopyrite. }\end{array}$ \\
\hline $2186-1$ & Mound & $\begin{array}{l}\text { Large bulbous sample with red oxidized exterior, dark } \\
\text { gray sulfide interior, and patches of white salt. Mix of } \\
\text { sphalerite, chalcopyrite, pyrite, and silica with few } \\
\text { small strips of massive pyrite. }\end{array}$ \\
\hline $2190-7-1$ & Mound & $\begin{array}{l}\text { Small chunk of red oxidized exterior. Sphalerite with } \\
\text { fine grained chalcopyrite. }\end{array}$ \\
\hline $2190-13-1$ & Mound & $\begin{array}{l}\text { Large bulbous sample with red oxidized exterior and } \\
\text { dark gray sulfide interior. Sphalerite and trace pyrite } \\
\text { with few small semi-circular patches of euhedral cubic } \\
\text { pyrite that may mark a former channel. }\end{array}$ \\
\hline $2183-6-1$ & $\begin{array}{l}\text { Massive } \\
\text { Sulfide }\end{array}$ & $\begin{array}{l}\text { Dense, massive pyrite with trace chalcopyrite and } \\
\text { sphalerite. }\end{array}$ \\
\hline $2189-5-1$ & $\begin{array}{l}\text { Massive } \\
\text { Sulfide }\end{array}$ & $\begin{array}{l}\text { Dense, massive pyrite with some euhedral cubic } \\
\text { crystals. Trace chalcopyrite. }\end{array}$ \\
\hline $2190-6-1$ & $\begin{array}{l}\text { Massive } \\
\text { Sulfide }\end{array}$ & \begin{tabular}{l} 
Dense. Fine grained pyrite with minor chalcopyrite. \\
\hline
\end{tabular} \\
\hline
\end{tabular}




\section{Chapter 2. STABLE SULFUR ISOTOPES STUDY}

\section{Section 1. SULFUR ISOTOPE ANALYSIS OF SURFICIAL SAMPLES FROM THE TAG MOUND}

\section{Introduction and Background}

In volcanic-associated massive sulfide (VMS) deposits as old as the Precambrian, $\delta^{34} \mathrm{~S}$ analyses of sulfides have been used to infer the source of sulfur, the mechanisms of mineralization, and the temperature, oxidation state, and $\mathrm{pH}$ of ore-forming fluids (Franklin et al., 1981; Ohmoto and Rye, 1979). With the recognition of the genetic relationship between seafloor hydrothermal systems and certain VMS deposits, $\delta^{34} \mathrm{~S}$ analyses of sulfides have become a powerful tool for understanding reactions and the sources of sulfur which form sulfides at seafloor hydrothermal vents.

$\delta^{34} \mathrm{~S}$ values in seafloor vent deposits depend on the relative contributions of sulfur from isotopically "heavy" seawater with $\delta^{34} \mathrm{~S}$ of $+21 \pm 0.2 \%$ (Rees et al., 1978) and isotopically "light" basalt with $\delta^{34} \mathrm{~S}$ of $+0.3 \pm 0.5 \%$ (Sakai et al., 1984; Figure 7). In organic- and sulfide-rich sedimented hydrothermal environments, sulfate-reducing bacteria can constitute an additional source of sulfur with low $\delta^{34} \mathrm{~S}$ values. For example, bacteriogenic pyrite in carbonate-cemented worm burrows at Middle Valley, Northern Juan de Fuca Ridge, yields highly negative $\delta^{34} \mathrm{~S}$ values of $-19.4 \%$ to $-39.7 \%$ (Goodfellow et al., 1993). Non-biogenic, cubic pyrite from the same site yields the positive range of $+0.1 \%$ to $+7.5 \%$ (Goodfellow et al., 1993), which falls within the limits set by the basalt and seawater end-members. Previous $\delta^{34} \mathrm{~S}$ analyses of seafloor hydrothermal sulfides and fluids (Table 3) show that $\delta^{34} \mathrm{~S}$ values of non-biogenic hydrothermal vent sulfides and fluids range generally from +1 to $+8 \%$ (Shanks et al., 1995), which indicates an origin from isotopically light basalt with a lesser component derived from isotopically heavy seawater.

The $\delta^{34} \mathrm{~S}$ values of seafloor deposits are hypothesized to be the result of a series of reactions between seawater and basalt. Beginning in the recharge zone at temperatures 
$<150^{\circ} \mathrm{C}$, basalt contributes light sulfur into evolving seawater (Alt, 1995), decreasing the $\delta^{34} \mathrm{~S}$ value of the fluid. Once $150^{\circ} \mathrm{C}$ is reached, isotopically heavy anhydrite $\left(\delta^{34} \mathrm{~S} \sim\right.$ 21\%) precipitates from the circulating fluid (McDuff and Edmond, 1982), further decreasing the $\delta^{34} \mathrm{~S}$ value of the fluid. In the reaction zone, most of the remaining seawater sulfate is reduced by the oxidation of basaltic pyrrhotite (FeS) to pyrite:

$$
8 \mathrm{FeS}+10 \mathrm{H}^{+}+\mathrm{SO}_{4}{ }^{2-}=4 \mathrm{FeS}_{2}+\mathrm{H}_{2} \mathrm{~S}+4 \mathrm{H}_{2} \mathrm{O}+4 \mathrm{Fe}^{2+}
$$

which produces $\mathrm{H}_{2} \mathrm{~S}$ with $\delta^{34} \mathrm{~S}$ values of +1 to $+1.5 \%$ (Shanks and Seyfried, 1987; Shanks et al., 1995). Evolved fluid leaving the reaction zone and ascending through the discharge zone is hypothesized to have $\delta^{34} \mathrm{~S}$ values close to $1 \%$ (Shanks and Seyfried, 1987; Janecky and Shanks, 1988). As shown in Table $3, \delta^{34} \mathrm{~S}$ values of both fluids and precipitates are generally $>1 \%$, which suggests that the fluid receives some additional input of heavy seawater sulfur while in the discharge zone.

Possible discharge zone processes which may contribute additional heavy sulfur have been modeled by Janecky and Shanks (1988). Based on the results of Shanks and Seyfried (1987) and others, the model assumes ascending hydrothermal fluid has a uniform $\delta^{34} \mathrm{~S}$ of $1 \%$ as it enters the shallow subsurface $(<500 \mathrm{~m}$ depth) of the system. Using adiabatic mixing reactions between hydrothermal fluid $\left(\delta^{34} \mathrm{~S}=1 \% 0\right)$ and seawater $\left(\delta^{34} \mathrm{~S}=21 \%\right.$ ) in both equilibrium and disequilibrium paths, the model produces fluids with $\delta^{34}$ S only as heavy as $4.5 \%$ (Janecky and Shanks, 1988). Janecky and Shanks (1988) find that neither adiabatically mixing hydrothermal fluids nor hydrothermal fluids reacting with chimney minerals during mixing have the capacity to reduce enough sulfate in the chimney environment to produce $\delta^{34} \mathrm{~S}$ values heavier than $4.5 \%$. They conclude that fluid $\delta^{34} \mathrm{~S}$ values $>4.5 \%$ require reaction in the shallow subsurface between $\mathrm{Fe}^{2+}$ minerals in basalt and sulfate derived from seawater (Janecky and Shanks, 1988). These results indicate that a localized entrainment of seawater into the shallow subsurface of a vent is necessary to produce the observed range of $\delta^{34} \mathrm{~S}$ values of seafloor hydrothermal sulfides.

Seawater sulfate in the shallow subsurface of a vent can come from two sources: (1) direct mixing of vent fluid with entrained seawater, and (2) dissolution of anhydrite 
that previously precipitated from entrained seawater. Using mineralogical and geochemical data and geochemical modeling, Tivey et al. (1995) discuss the internal circulation of entrained seawater and hydrothermal fluid in the TAG hydrothermal mound, and suggest that both sources of seawater sulfate are available in the shallow subsurface. In this study, the results from $\delta^{34} \mathrm{~S}$ analyses of TAG active mound fluid and mineral samples are used to constrain the seawater entrainment and shallow subsurface processes described by Tivey et al. (1995).

\section{Methods}

Minerals were carefully excavated from distinct zones in a suite of sulfide samples (see Table 2) and crushed to expose maximum surface area. Because of their fine grained, intergrown texture, samples were matched to polished thin sections whenever possible. Specimens removed from isomineralic zones or zones shown in thin section to contain only very minor $(<5 \%)$ amounts of other intergrown minerals were hand picked under a binocular microscope. After hand picking, samples containing trace amounts of anhydrite were soaked for approximately 24 hours at room temperature in 6 $\mathrm{M} \mathrm{HCl}$ to dissolve anhydrite.

Specimens containing a mixture of sphalerite and other minerals were hand picked only to remove obvious contaminants such as flakes of oxidized iron or fragments of amorphous silica. The remainder was then subjected to chemical extraction under the guidance of W. C. (Pat) Shanks III at the U.S. Geological Survey (USGS) in Denver. Sphalerite was dissolved in $6 \mathrm{~N} \mathrm{HCl}$ at $60^{\circ} \mathrm{C}$ in a $\mathrm{N}_{2}$ flushed system. Resulting $\mathrm{H}_{2} \mathrm{~S}$ was passed through a $0.1 \mathrm{M} \mathrm{AgNO}_{3}$ trap, where it precipitated as $\mathrm{Ag}_{2} \mathrm{~S}$. Undissolved residues containing pure pyrite or chalcopyrite were hand picked. Residues containing impure or insufficient quantities of pyrite or chalcopyrite were not analyzed.

Both precipitated $\mathrm{Ag}_{2} \mathrm{~S}$ and hand picked minerals were combusted with $\mathrm{Cu}_{2} \mathrm{O}$ at $1050^{\circ} \mathrm{C}$. Resulting $\mathrm{SO}_{2}$ was purified by vacuum distillation which removed $\mathrm{H}_{2} \mathrm{O}, \mathrm{CO}_{2}$,

and non-condensable gases. ${ }^{34} \mathrm{~S}{ }^{32} \mathrm{~S}$ ratios were measured on a Nuclide Corporation mass spectrometer at the USGS Stable Isotope Laboratory in Denver. The results are 
standardized relative to the Canyon Diablo troilite (CDT) and given in units of permil (\%o) in conventional $\delta^{34} \mathrm{~S}$ notation:

$$
\delta^{34} \mathrm{~S}=\left[\left[\left(^{34} \mathrm{~S} /^{32} \mathrm{~S}\right)_{\text {sample }}-\left({ }^{34} \mathrm{~S} /{ }^{32} \mathrm{~S}\right)_{\text {standard }}\right] /\left({ }^{34} \mathrm{~S} /{ }^{32} \mathrm{~S}\right)_{\text {standard }}\right] * 1000
$$

Analytical uncertainty is $\pm 0.2 \%$ o $(1 \sigma)$, based on replicated preparation of duplicate samples (W. C. (Pat) Shanks, pers. comm.).

\section{Results}

Table 4 gives the results of $\delta^{34} \mathrm{~S}$ analyses for anhydrite from TAG vent deposits. The overall range is 20.0 to $20.9 \%$ with a mean value and standard deviation of 20.6 $\pm 0.4 \%$, indicative of precipitation from seawater.

$\delta^{34} \mathrm{~S}$ values in sulfide samples range from 2.7 to $7.6 \%$ (Table 5). The overall mean and standard deviation are $6.0 \pm 0.9 \%$. With the exception of the single low analysis of $2.7 \%$, the range of $\delta^{34} \mathrm{~S}$ values (4.5 to $7.6 \%$ ) in sulfides from the TAG active mound is higher than the range reported for sulfide minerals from any other seafloor hydrothermal site. The $\delta^{34} \mathrm{~S}$ values from black smoker samples include only one mineral type and are remarkably consistent (Figure 8). White smoker and massive sulfides tend to have higher $\delta^{34} \mathrm{~S}$ values that range 6.1 to $7.6 \%$, excluding one unusual low $\delta^{34} \mathrm{~S}$ value of $5.2 \%$ (Figure 8 ). The four other sample types all show scatter between 2.7 and $7.1 \%$ (Figure 8).

Examination of the data by mineral type indicates that pyrite $\delta^{34} \mathrm{~S}$ values are highly variable, and span the entire range of 2.7 to $7.6 \%$ with a mean and standard deviation of $5.7 \pm 1.2 \%$. Chalcopyrite $\delta^{34} \mathrm{~S}$ values are much less variable and show a more limited range of 5.2 to $7.3 \%$, only a few high values, and an overall mean and standard deviation of $5.5 \pm 0.6 \%$. Sphalerite $\delta^{34} \mathrm{~S}$ values are also less variable and show a limited range of generally high $\delta^{34} \mathrm{~S}$ values of 5.2 to $7.8 \%$ and a mean and standard deviation of $6.4 \pm 0.7 \%$.

$\delta^{34} \mathrm{~S}$ values tend to cluster by sample type. For pyrite, crust samples yield a mean $\delta^{34} \mathrm{~S}$ value and standard deviation of $5.2 \pm 0.8 \%$, massive anhydrite samples yield 6.2 $\pm 0.6 \%$, mound samples yield $4.9 \pm 1.2 \%$, and massive sulfide samples yield $7.2 \pm 0.4 \%$ o (Figure 9). For chalcopyrite, black smoker samples exhibit a mean $\delta^{34} \mathrm{~S}$ value and 
standard deviation of $5.6 \pm 0.04 \%$, crust samples exhibit $5.4 \pm 0.2 \%$, white smoker samples exhibit $7.0 \pm 0.3 \%$, and mound samples exhibit $5.5 \pm 0.4 \%$ (Figure 10). The black smoker, crust, and mound samples show consistent chalcopyrite data, but the white smoker data are noticeably high. For sphalerite, white smoker samples have a mean $\delta^{34} \mathrm{~S}$ value and standard deviation of $6.7 \pm 0.6 \%$, and mound samples have $5.9 \pm 0.5 \%$ (Figure 11 ), although the ranges of values overlap. 
Figure 7: Schematic drawing of sources of sulfur for a hydrothermal vent unaffected by biogenic processes. Isotopically heavy seawater and isotopically light basalt react to produce hydrothermal fluid with a sulfur isotopic signature reflecting input from basalt with a small component of seawater.

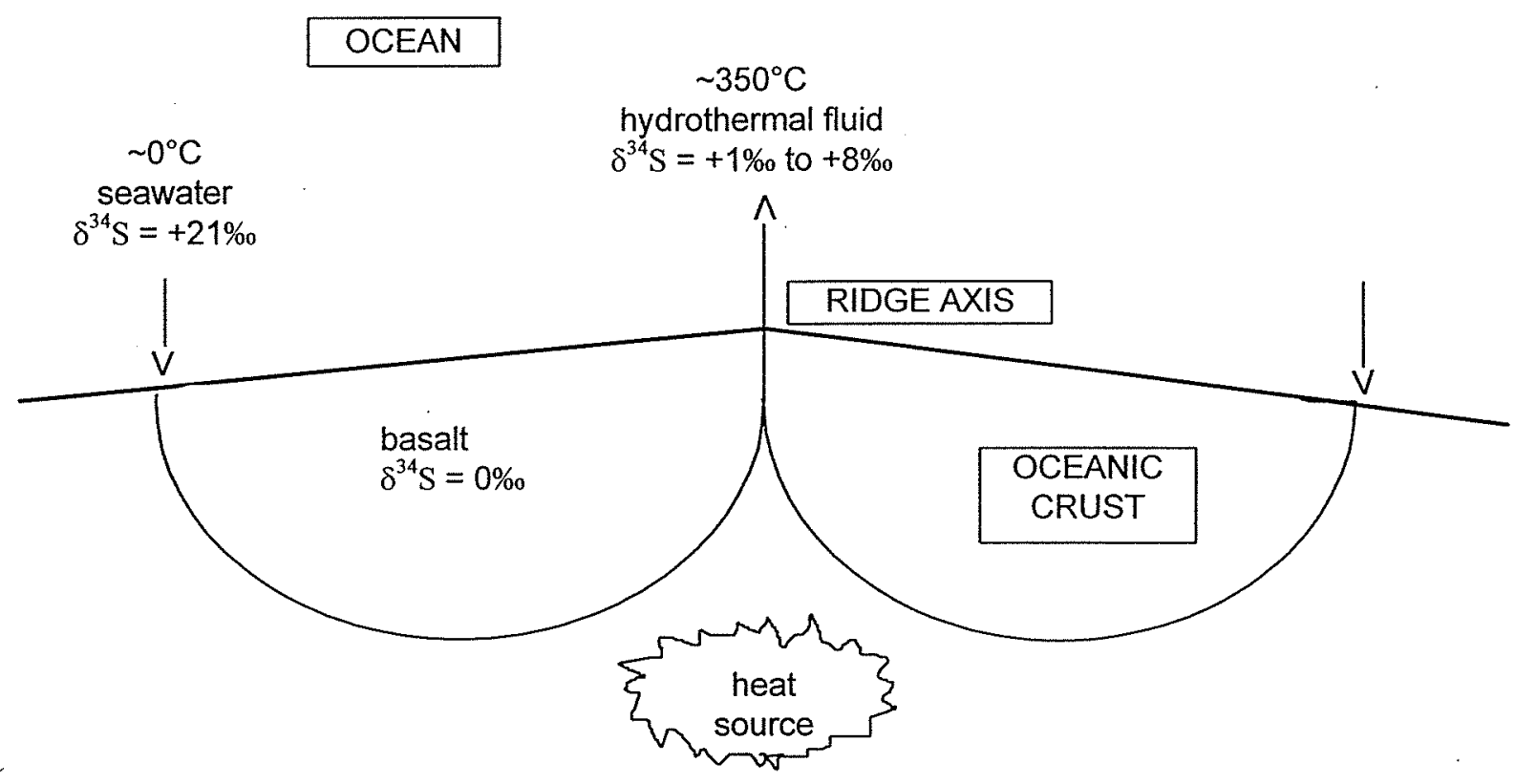


TABLE 3. Previous Studies of $\delta^{34} \mathrm{~S}$ in Non-Biogenic Sulfides and Fluids at Hydrothermal Vents

\begin{tabular}{|c|c|c|}
\hline Location & $\delta^{34} \mathrm{~S}$ & Reference \\
\hline $\begin{array}{c}9^{\circ} \mathrm{N}, \\
\text { East Pacific Rise }\end{array}$ & +3.2 to $7.8 \%$, chimney fluids & Shanks et al., 1995 \\
\hline $\begin{array}{l}11^{\circ} \text { and } 13^{\circ} \mathrm{N} \\
\text { East Pacific Rise }\end{array}$ & $\begin{array}{l}+2.3 \text { to } 5.2 \% \text {, chimney fluids } \\
+1.7 \text { to } 5.0 \% \text {, chimney sulfides }\end{array}$ & Bluth and Ohmoto, 1988 \\
\hline $\begin{array}{c}21^{\circ} \mathrm{N} \\
\text { East Pacific Rise }\end{array}$ & $\begin{array}{l}+1.3 \text { to } 5.5 \% \text {, chimney fluids } \\
+1.5 \text { to } 4 \% \text {,chimney sulfides }\end{array}$ & $\begin{array}{l}\text { Woodruff and Shanks, } 1988 \\
\text { Zierenberg et al., } 1984\end{array}$ \\
\hline $\begin{array}{c}\text { Southern } \\
\text { Juan de Fuca Ridge }\end{array}$ & $\begin{array}{l}+4.0 \text { to } 7.4 \% \text {, chimney fluids } \\
+1.6 \text { to } 5.7 \% \text {, chimney sulfides }\end{array}$ & $\begin{array}{c}\text { Shanks and Seyfried, } 1987 \\
\text { Woodruff and Shanks, } 1988 \\
\text { Zierenberg et al., } 1984\end{array}$ \\
\hline $\begin{array}{l}\text { Axial Seamount, } \\
\text { Juan de Fuca Ridge }\end{array}$ & +6.1 to $7.3 \%$, chimney fluids & Shanks et al., 1995 \\
\hline $\begin{array}{l}\text { Endeavour Segment, } \\
\text { Juan de Fuca Ridge }\end{array}$ & +3.8 to $6.6 \%$, chimney fluids & Shanks et al., 1995 \\
\hline $\begin{array}{c}85^{\circ} 55^{\prime} \mathrm{W} \\
\text { Galapagos Rift }\end{array}$ & $\begin{array}{l}+2.7 \text { to } 5.5 \% \text {, core from a } \\
\text { sulfide boulder }\end{array}$ & Knott et al., 1995 \\
\hline $\begin{array}{c}\text { MARK, } 23^{\circ} \mathrm{N}, \\
\text { Mid-Atlantic Ridge }\end{array}$ & +4.9 to $5.0 \%$, chimney fluids & Campbell et al., 1988 \\
\hline $\begin{array}{c}29^{\circ} \mathrm{N} \\
\text { Mid-Atlantic Ridge }\end{array}$ & -0.8 to $+2.4 \%$, all sulfides & Duckworth et al., 1995 \\
\hline
\end{tabular}

TABLE 4. $\delta^{34} \mathrm{~S}$ Data in Anhydrite from TAG Vent Deposits

\begin{tabular}{llc}
\hline \multicolumn{1}{c}{ Sample \# } & \multicolumn{1}{c}{ Sample Type } & $\delta^{34} \mathrm{~S}(\%)^{2}$ \\
\hline $2181-1-\mathrm{A} \gamma$ & Black Smoker & 20.0 \\
$2178-3-1 \beta$ & Massive Anhydrite & 20.6 \\
$2183-7 \varnothing-\mathrm{B}$ & Massive Anhydrite & 20.7 \\
$2187-1-2$ & White Smoker & 20.9 \\
\hline
\end{tabular}

${ }^{1}$ Capital letters refer to pieces of a main sample; Greek letters refer to subsamples collected for sulfur isotope analysis.

${ }^{2}$ Note error on $\delta^{34} \mathrm{~S}$ values is $\pm 0.2 \%$. 
TABLE 5. $\delta^{34} \mathrm{~S}$ Data in Sulfides from TAG Vent Deposits

\begin{tabular}{|c|c|c|c|}
\hline Sample \# & Sample Type & Mineral & $\delta^{34} \mathrm{~S}(\% 0)^{2}$ \\
\hline $2178-5-1 \alpha$ & Black Smoker & Chalcopyrite & 5.6 \\
\hline $2178-5-1 \beta$ & Black Smoker & Chalcopyrite & 5.6 \\
\hline $2178-5-2 \mathrm{G} \alpha$ & Black Smoker & Chalcopyrite & 5.6 \\
\hline $2178-5-2 G \beta$ & Black Smoker & Chalcopyrite & 5.6 \\
\hline 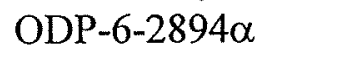 & Black Smoker & Chalcopyrite & 5.6 \\
\hline ODP-6-2894 $\beta$ & Black Smoker & Chalcopyrite & 5.5 \\
\hline $2179-1-1 \alpha$ & Crust & Chalcopyrite & 5.6 \\
\hline $2179-1-1 \beta$ & Crust & Chalcopyrite & 5.3 \\
\hline 2179-1-1 $\beta$, dup. & Crust & Chalcopyrite & 5.2 \\
\hline $2179-1-1 \gamma$ & Crust & Chalcopyrite & 5.3 \\
\hline $2179-1-1 \delta$ & Crust & Pyrite & 5.7 \\
\hline $2180-1 \alpha$ & Crust & Pyrite & 6.4 \\
\hline 2180-1 $\alpha$, dup. & Crust & Pyrite & 6.2 \\
\hline $2180-3$ & Crust & Chalcopyrite & 5.4 \\
\hline MIR2-75-5A3 & Crust & Pyrite & 4.6 \\
\hline MIR2-75-5A3, dup. & Crust & Pyrite & 4.5 \\
\hline MIR2-75-5A6 & Crust & Pyrite & 4.6 \\
\hline MIR2-75-5A7 & Crust & Pyrite & 4.7 \\
\hline $2178-3-1 \alpha$ & Massive Anhydrite & Pyrite & 6.4 \\
\hline $2178-3-1 \gamma$ & Massive Anhydrite & Pyrite & 5.9 \\
\hline $2190-8-1 \mathrm{~B} \alpha$ & Massive Anhydrite & Pyrite & 5.4 \\
\hline $2190-8-1 \mathrm{~B} \beta$ & Massive Anhydrite & Pyrite & 6.4 \\
\hline $2190-8-1 \mathrm{~B} \gamma$ & Massive Anhydrite & Pyrite & 7.1 \\
\hline $2187-1-4 B$ & White Smoker & Sphalerite & 6.7 \\
\hline $2187-1-4 C$ & White Smoker & Sphalerite & 6.7 \\
\hline 2187-1-4C, dup. & White Smoker & Sphalerite & 6.4 \\
\hline $2187-1-7 \mathrm{E}$ & White Smoker & Chalcopyrite & 6.7 \\
\hline $2187-1-7 F \alpha$ & White Smoker & Sphalerite & 5.2 \\
\hline $2187-1-7 \mathrm{~F} \alpha$ & White Smoker & Chalcopyrite & 6.9 \\
\hline 2187-1-7F $\alpha$, dup. & White Smoker & Chalcopyrite & 6.9 \\
\hline $2187-1-7 F \beta$ & White Smoker & Sphalerite & 6.8 \\
\hline 2187-1-7F $\beta$, dup. & White Smoker & Sphalerite & 6.8 \\
\hline $2187-1-7 \mathrm{~F} \gamma$ & White Smoker & Sphalerite & 7.5 \\
\hline 2187-1-7YZ & White Smoker & Sphalerite & 7.0 \\
\hline 2187-1-7YZ, dup. & White Smoker & Sphalerite & 7.4 \\
\hline 2187-1-7YZ & White Smoker & Chalcopyrite & 7.3 \\
\hline 2190-14-1H & White Smoker & Sphalerite & 6.5 \\
\hline 2190-14-1I & White Smoker & Sphalerite & 6.7 \\
\hline
\end{tabular}




\begin{tabular}{|c|c|c|c|}
\hline $2190-14-1 \mathrm{~J} \alpha$ & White Smoker & Sphalerite & 6.4 \\
\hline $2190-14-1 \mathrm{~J} \beta$ & White Smoker & Sphalerite & 6.7 \\
\hline $2190-14-1 K \alpha$ & White Smoker & Sphalerite & 6.1 \\
\hline $2190-14-1 \mathrm{~K} \beta$ & White Smoker & Sphalerite & 6.4 \\
\hline 2183-4-1B & Mound & Chalcopyrite & 5.2 \\
\hline 2183-4-1B & Mound & Sphalerite & 5.5 \\
\hline 2183-4-1B, dup. & Mound & Sphalerite & 5.9 \\
\hline $2183-9-1$ & Mound & Chalcopyrite & 6.0 \\
\hline $2186-1 \mathrm{~A} \alpha$ & Mound & Pyrite & 2.7 \\
\hline $2186-1 \mathrm{~A} \gamma$ & Mound & Sphalerite & 5.8 \\
\hline 2186-1A $\delta$ & Mound & Pyrite & 5.7 \\
\hline 2186-1A & Mound & Sphalerite & 6.0 \\
\hline $2190-7-1 \mathrm{~A}$ & Mound & Chalcopyrite & 5.4 \\
\hline 2190-7-1A, dup. & Mound & Chalcopyrite & 5.2 \\
\hline $2190-13-1 \alpha$ & Mound & Pyrite & 4.6 \\
\hline $2190-13-1 \beta$ & Mound & Pyrite & 5.4 \\
\hline $2190-13-1 \gamma$ & Mound & Pyrite & 5.4 \\
\hline $2190-13-1 \gamma$ & Mound & Sphalerite & 5.0 \\
\hline $2190-13-1 \delta$ & Mound & Pyrite & 5.5 \\
\hline 2190-13-18, dup. & Mound & Pyrite & 5.8 \\
\hline $2190-13-1 \delta$ & Mound & Sphalerite & 6.7 \\
\hline $2183-6-1 \alpha$ & Massive Sulfide & Pyrite & 7.0 \\
\hline 2189-5-1D $\alpha$ & Massive Sulfide & Pyrite & 7.0 \\
\hline 2189-5-1D $\alpha$, dup. & Massive Sulfide & Pyrite & 6.7 \\
\hline $2190-6-1 \alpha$ & Massive Sulfide & Pyrite & 7.6 \\
\hline
\end{tabular}

'Capital letters refer to pieces of a main sample; Greek letters refer to subsamples collected for sulfur isotope analysis.

${ }^{2}$ Note error on $\delta^{34} \mathrm{~S}$ values is $\pm 0.2 \%$. 
Figure 8: Symbols indicate different sample types, as shown in legend. Note that BS = black smoker, $M A=$ massive anhydrite, $W S=$ white smoker, $M S=$ massive sulfide.

Figure 8. 8345 Data for All Sulfides

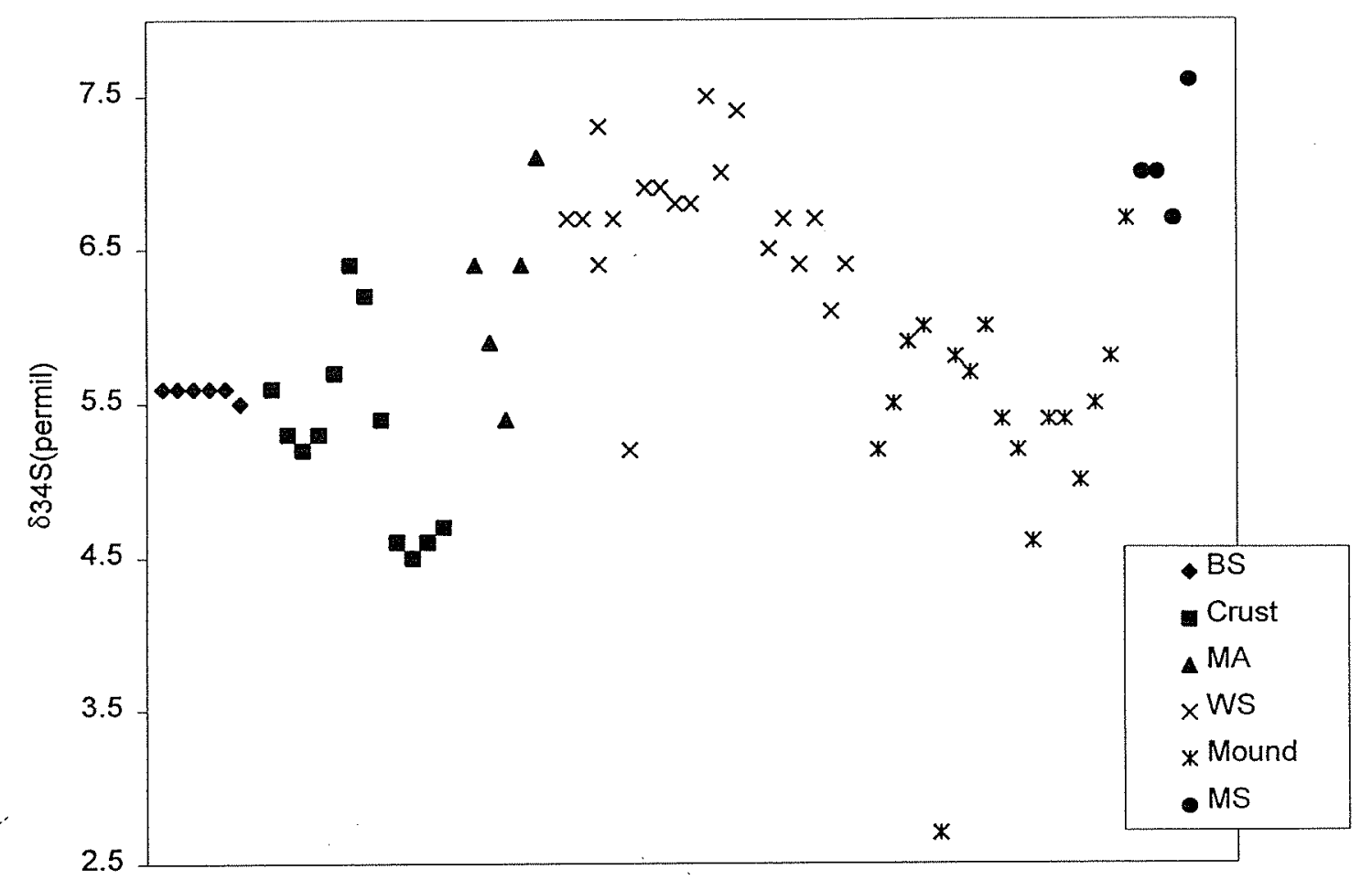


In figures 9, 10, and 11: Squares plotted are the mean $8^{34} \mathrm{~S}$ value for the particular sample type. Bars show the range of values.

Figure $9 . \delta 345$ in Pyrite by Sample Type

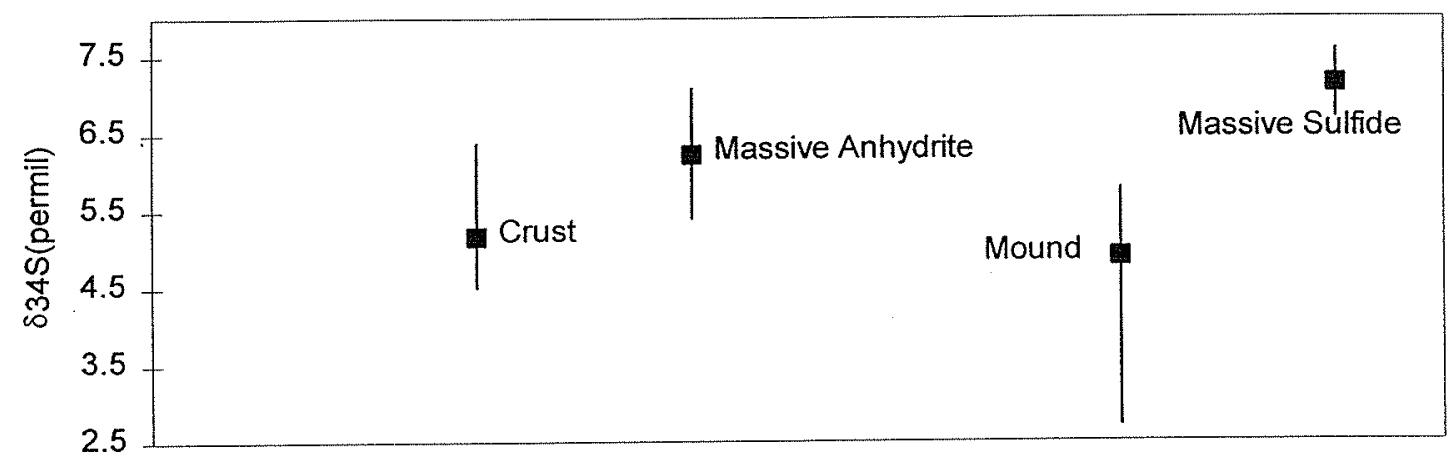

Figure $10.834 \mathrm{~S}$ in Chalcopyrite by Sample Type

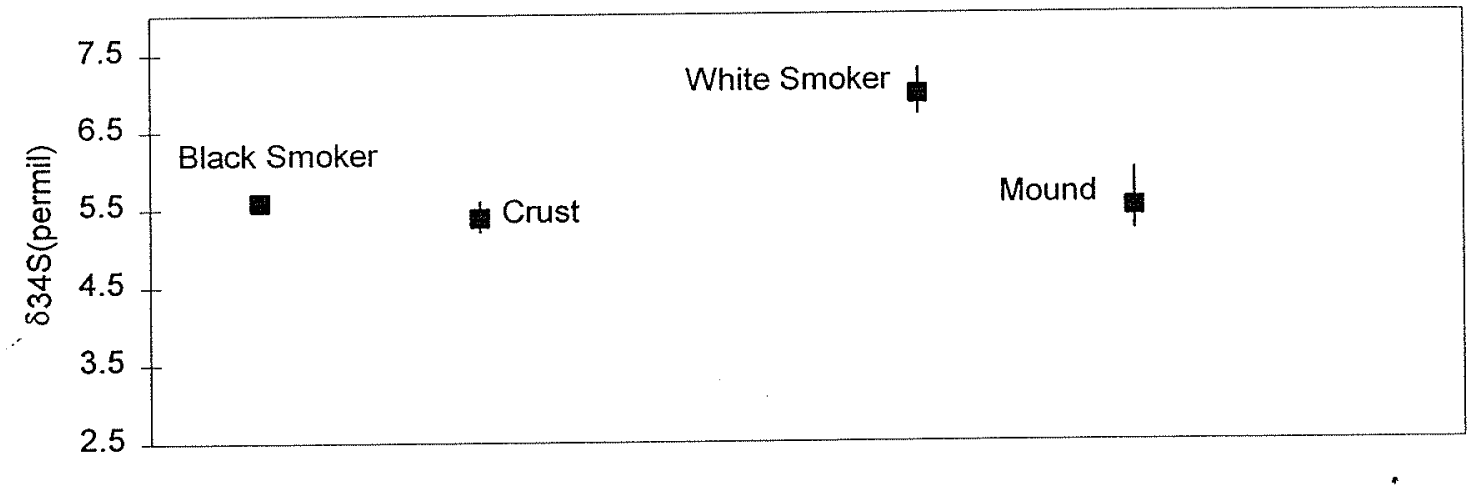

Figure 11. $\delta 34 \mathrm{~S}$ in Sphalerite by Sample Type

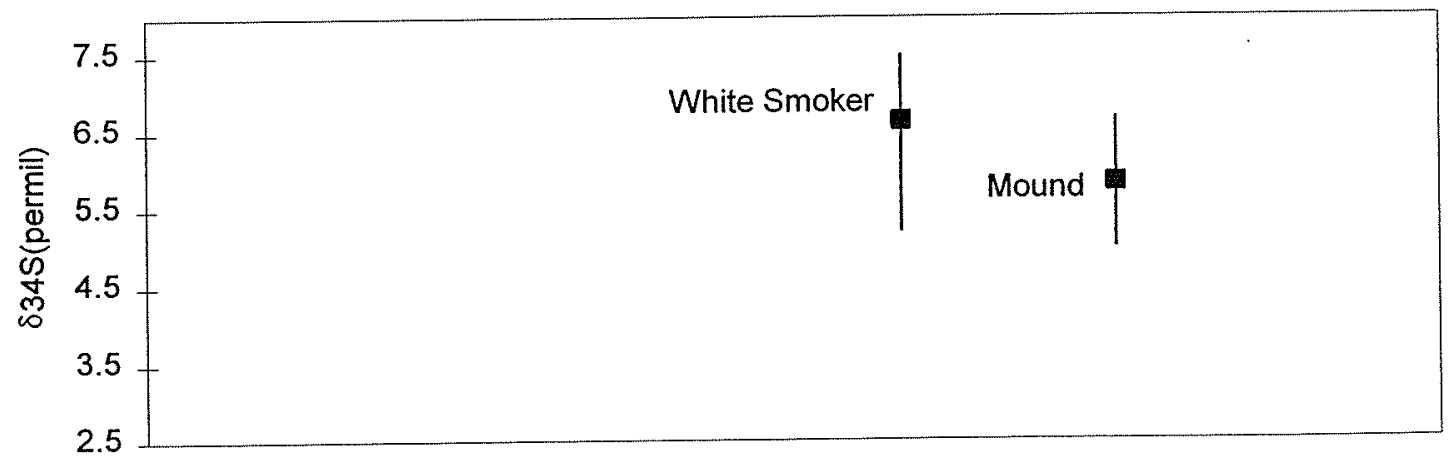




\section{Section 2. FACTORS AFFECTING $\delta^{34}$ S VALUES}

The primary influence on the $\delta^{34} \mathrm{~S}$ values of sulfides from the TAG active mound is the source of sulfur. The sulfur isotope ratios for TAG sulfides depend on the relative inputs of sulfur derived from seawater sulfate reduction $(\sim 21 \% 0)$ and from basalt $(\sim 0 \% 0)$. Because TAG samples do not show biogenic textures and yield $\delta^{34} \mathrm{~S}$ values which fall into the range between basalt and seawater, bacterial reduction of sulfate does not appear to be a factor in TAG sulfides.

Approximately $1 / 3$ seawater sulfur and $2 / 3$ basaltic sulfur combine to produce black smoker hydrothermal fluid with $\delta^{34} \mathrm{~S} \sim 7 \%$ (Table 6 ). The temperatures of hydrothermal fluids from the TAG active mound were measured by Edmond et al. (1995), and the sulfur isotope ratios of these fluids were analyzed by W. C. (Pat) Shanks III (unpublished data). $\delta^{34} \mathrm{~S}$ values in $\mathrm{H}_{2} \mathrm{~S}$ from 3 low $\mathrm{Mg}$, black smoker fluid samples range from 6.6 to $7.5 \%$ (Table 6 ), with a mean $\delta^{34} \mathrm{~S}$ value and standard deviation of 7.2 $\pm 0.5 \%$. All of the fluid samples are isotopically heavier than any of the sulfides from black smoker chimney samples and most of the sulfides from other TAG mound sample types.

The isotopic signature of the sulfides reflects the integrated effects of the isotopic composition of the source and the physical and chemical processes that can fractionate the isotopes. Isotopic fractionation depends on: (1) whether a sample attained equilibrium with its parent fluid, (2) the mineralogy of a sample, (3) the temperature at which a mineral precipitates, and (4) post-depositional reworking with hydrothermal fluid. To understand the relationships among samples and to identify the processes that produce their $\delta^{34} \mathrm{~S}$ values, it is necessary to determine the proportions of sulfur from the two sources and the relative importance of the processes which can fractionate sulfur isotopes.

\section{Variations in the $\delta^{34} \mathrm{~S}$ Value of End-Member Hydrothermal Fluid}

Variability in end-member fluid $\delta^{34} \mathrm{~S}$ has been used to explain the range of $\delta^{34} \mathrm{~S}$ 
values in samples from $11^{\circ}$ and $13^{\circ} \mathrm{N}$, East Pacific Rise. Bluth and Ohmoto (1988) argue for a gradual increase in the $\delta^{34} \mathrm{~S}$ value of end-member fluid due to increased inputs of heavy seawater sulfate deep in the hydrothermal systems. Time series studies at TAG indicate that the major element chemistry and $\mathrm{pH}$ of TAG black smoker fluids have been invariant over a time scale of a decade (Table 1; Edmonds et al., 1996; Gamo et al., 1996). Although a time series study of sulfur isotope ratios has not been conducted, invariability in the $\delta^{34} \mathrm{~S}$ values of end-member fluid over the time scale of about a decade is suggested by the $\delta^{34} \mathrm{~S}$ data from chalcopyrite which lines the inner walls of black smoker chimneys. The $\delta^{34} \mathrm{~S}$ values are remarkably constant, even though the black smoker samples are from different parts of the mound and were collected during different years (Table 5 and Figure 6). Given the fact that the chalcopyrite which lines black smoker chimneys is believed to precipitate directly from end-member fluids, the invariability of the chalcopyrite $\delta^{34} \mathrm{~S}$ data implies invariability in the $\delta^{34} \mathrm{~S}$ values of endmember fluids over the time scale of the deposition of the black smokers.

Although the uniform $\delta^{34} \mathrm{~S}$ values in chalcopyrite from black smoker chimney walls implies uniformity in the mineralizing fluid, the $\delta^{34} \mathrm{~S}$ values measured in TAG black smoker fluids are variable (Table 6). This discrepancy cannot be resolved based on the data collected in this study. To investigate the problem, transects could be analyzed for $\delta^{34} \mathrm{~S}$ values in chalcopyrite from TAG black smoker chimney walls using a microanalytical technique such as an ion microprobe. The transects would yield $\delta^{34} \mathrm{~S}$ values as a function of distance and time, providing information regarding the temporal variability of $\delta^{34} \mathrm{~S}$ in black smoker chimneys and end-member fluids. Hydrothermal fluids exhibiting invariable chemistry yet variable $\delta^{34} \mathrm{~S}$ values have also been found at $21^{\circ} \mathrm{N}$, East Pacific Rise (Table 3; Woodruff and Shanks, 1988).

Although the fluid chemistry and black smoker chalcopyrite $\delta^{34} \mathrm{~S}$ data support short-term invariability of end-member fluids, it cannot be established whether there has been variability over the entire 18,000 year history of the mound. Geochronological studies suggest hydrothermal activity has been episodic (Lalou et al., 1990; 1993), and changes in the composition of fluids are possible with each new episode. The $\delta^{34} \mathrm{~S}$ of 
end-member fluids currently exiting the TAG active mound may only represent fluid which has been precipitating surface sulfides during the current episode of activity which commenced 50 years ago (Lalou et al., 1990; 1993). The fact that sulfides from other hydrothermal sites yield slightly different $\delta^{34} \mathrm{~S}$ ranges (Table 3 ) suggests that endmember hydrothermal fluid can have different isotopic signatures while still remaining "end-member fluids."

A likely source for variability in $\delta^{34} \mathrm{~S}$ values of end-member fluids over long time scales is altered basalt. Basalt $\delta^{34} \mathrm{~S}$ is believed to be constant, as observed early on by Shima et al. (1963) and Smitheringale and Jensen (1963). However, B isotope data and $\mathrm{Cs}$ to $\mathrm{Rb}$ ratios suggest that in the modern TAG hydrothermal system, seawater is reacting with previously altered basalt to produce end-member fluids (Edmond et al., 1995; Palmer and Edmond, 1989). Because basalt is altered by reaction with isotopically heavy seawater, alteration can result in basalt with elevated $\delta^{34} \mathrm{~S}$ values (Alt et al., 1995), and this may explain why TAG fluids have higher $\delta^{34} \mathrm{~S}$ values than fluids from other vent sites (Table 3).

In summary, variability in the $\delta^{34} \mathrm{~S}$ of end-member fluids does not appear to explain variability in the $\delta^{34} \mathrm{~S}$ of sulfides over the short time scale of the deposition of surface samples. It is possible, however, that variability in the $\delta^{34} \mathrm{~S}$ of end-member fluids has caused variability in the $\delta^{34} \mathrm{~S}$ of sulfides over the entire life span of the TAG active mound deposit. A change in TAG end-member fluids over a long time scale has the greatest implication for sample types which show evidence of reworking, like massive sulfide samples.

\section{Seawater Entrainment}

The compositions of TAG active mound black smoker and white smoker fluids (Edmond et al., 1995) and the results of chemical modeling by Tivey et al. (1995) provide evidence for seawater entrainment into the mound. This is further substantiated by drilling, which has revealed the presence of anhydrite within the mound (Humphris et al., 1995). 
Evidence from other hydrothermal sites bolster the theory that seawater can be locally entrained at a hydrothermal vent. In a study of the Southern Juan de Fuca Ridge, Shanks and Seyfried (1987) concluded that seawater is entrained through the porous chimney walls of sulfide samples formed from lower velocity hydrothermal fluids. In a study of $21^{\circ} \mathrm{N}$, East Pacific Rise, Woodruff and Shanks (1988) provided evidence that seawater-derived sulfate is reduced in chimneys and in the hydrothermal mound. Also, since heavy seawater sulfate can be derived either directly from locally entrained seawater or indirectly from previously deposited anhydrite, Woodruff and Shanks (1988) concluded that previously deposited anhydrite reduced in the "near surface feeder zone" constitutes an additional source of heavy sulfur isotopes. Shanks et al. (1995) reviewed $\delta^{34} \mathrm{~S}$ data from many hydrothermal sites and reaffirmed the conclusion that seawaterderived sulfate can be reduced and added to ascending fluids in the discharge zone or in the chimneys. Knott et al. (1995) used a slightly different theory to explain the role of seawater sulfur in causing variability in samples from $85^{\circ} 55^{\prime} \mathrm{W}$, Galapagos Rift. In addition to sulfate reduction within the deposit, Knott et al. (1995) suggested that variability in sulfide precipitates is produced by mixing of rising hydrothermal fluid in the shallow subsurface with a heavier seawater-influenced fluid of $\delta^{34} \mathrm{~S}=7.7 \%$. Finally, chemical modeling by Bowers (1989) showed that isotopically heavy fluids required an addition of reduced sulfate close to the exit point of the fluid, as in the shallow subsurface environment of a hydrothermal mound.

\section{Isotopic Equilibrium}

The isotopic signature imparted by end-member fluid and variable amounts of entrained seawater is modified by processes which fractionate the isotopes. One such cause of fractionation is variability in the equilibrium state of a sample relative to its parent fluid. To assess whether or not a sample is in equilibrium, $\delta^{34} \mathrm{~S}$ values from at least two related minerals or fluids must be compared. "Related minerals" are precipitates which formed from the same fluid. A "related fluid" is the parent solution from which a mineral precipitated or was post-depositionally reworked. 
The $\delta^{34} \mathrm{~S}$ values of equilibrium related minerals and fluids differ as a function of temperature, as shown in Figure 12. For any mineral (i) and any parent fluid $\left(\mathrm{H}_{2} \mathrm{~S}\right)$, the isotopic fractionation factor $(\alpha)$ is defined as:

$$
\alpha_{\mathrm{i}-\mathrm{H} 2 \mathrm{~S}}=\left({ }^{34} \mathrm{~S} /{ }^{32} \mathrm{~S}\right)_{\mathrm{i}} /\left({ }^{34} \mathrm{~S}{ }^{32} \mathrm{~S}\right)_{\mathrm{H} 2 \mathrm{~S}}
$$

(Ohmoto and Rye, 1979). Using the fractionation factor, the following relationship can be solved:

$$
\delta^{34} \mathrm{~S}_{\mathrm{i}}-\delta^{34} \mathrm{~S}_{\mathrm{H} 2 \mathrm{~S}}=1000\left(\alpha_{\mathrm{i}-\mathrm{H} 2 \mathrm{~S}}-1\right) *\left[1+\left(\delta^{34} \mathrm{~S}_{\mathrm{H} 2 \mathrm{~S}} / 1000\right)\right]
$$

(see Appendix 1) which can be approximated as:

$$
\delta^{34} S_{\mathrm{i}}-\delta^{34} \mathrm{~S}_{\mathrm{H} 2 \mathrm{~S}} \sim 1000 \ln \alpha_{\mathrm{i}-\mathrm{H} 2 \mathrm{~S}}
$$

(Ohmoto and Rye, 1979).

At very high temperatures, equilibrium isotopic fractionation of pyrite, chalcopyrite, and sphalerite is insignificant both relative to parent fluids and relative to each other. At the $<367^{\circ} \mathrm{C}$ temperatures measured for exiting fluids at the TAG active mound, however, isotopic fractionation between sulfides may be large enough to be significant (Figure 12). For precipitates at or approaching equilibrium, the difference in $\delta^{34} \mathrm{~S}$ values between minerals and fluids increases with decreasing temperature, and the rate and direction of change depends on the mineral (Figure 12).

At a given temperature, a quantitative estimate of equilibrium isotopic fractionation between related minerals can be calculated using the equations in Table 7 . In the first column of Table 7, for any two minerals, $i$ and $j$, "mineral $i$ - mineral $j$ " refers to their difference. In the second column of Table 7 , for the same minerals, $i$ and $j, \Delta$ is defined as $\Delta=\delta^{34} S_{\mathrm{i}}-\delta^{34} \mathrm{~S}_{\mathrm{j}}$.

If $\delta^{34} \mathrm{~S}$ analyses of related minerals are unavailable, $\delta^{34} \mathrm{~S}$ analyses of a related fluid and mineral can be used to calculate the state of equilibrium as:

$$
\left.1000 \ln \alpha_{\mathrm{i}-\mathrm{H} 2 \mathrm{~S}}=\left(\mathrm{A} / \mathrm{T}^{2}\right) \times 10^{6}+\mathrm{B} \quad \text { (Equation } 1\right)
$$

where A and B are constants listed in Table 8 for each mineral (Ohmoto and Rye, 1979). $1000 \ln \alpha_{\mathrm{i}-\mathrm{H} 2 \mathrm{~S}}$ approximates $\Delta_{\mathrm{i}-\mathrm{H} 2 \mathrm{~S}}$, which equals $\delta^{34} \mathrm{~S}_{\mathrm{i}}-\delta^{34} \mathrm{~S}_{\mathrm{H} 2 \mathrm{~S}}$. Given the $\delta^{34} \mathrm{~S}$ value of any mineral, Eq. 1 can be used with the constants in Table 8 to calculate the $\delta^{34} \mathrm{~S}$ value of an equilibrium parent fluid. Alternatively, Eq. 1 can be used to write separate equations for each of two minerals in a related pair. The two equations may then be subtracted to 
cancel out the variable for $\mathrm{H}_{2} \mathrm{~S}$. Subtraction leaves only $1000 \ln \alpha_{\mathrm{i}-\mathrm{j}}$, which approximates $\delta^{34} \mathrm{~S}_{\mathrm{i}}-\delta^{34} \mathrm{~S}_{\mathrm{j}}$

\section{Isotopic Relationships of Coexisting Minerals}

The methods for investigating isotopic equilibrium can be applied to the $\delta^{34} \mathrm{~S}$ values of related minerals from TAG active mound samples. A qualitative comparison between Figure 12 and any pair of related $\delta^{34} \mathrm{~S}$ values can readily identify whether the pair is in disequilibrium. At any temperature in Figure 12, the order of enrichment with heavy isotopes is anhydrite $>$ pyrite $>$ sphalerite $>$ fluid $\mathrm{H}_{2} \mathrm{~S}>$ chalcopyrite. This experimentally determined order corresponds with decreasing bond strengths and has generally been confirmed by analytical data. TAG mound sulfides qualitatively show this equilibrium order of $\delta^{34} \mathrm{~S}$ values within analytical uncertainty, with the exception of a sphalerite-chalcopyrite pair from white smoker sample 2187-1-7F, and a sphalerite-pyrite pair from mound sample $2190-13-1 \delta$. For example, $\delta^{34} \mathrm{~S}$ analysis of the $2187-1-7 \mathrm{~F}$ mineral pair yields chalcopyrite $(6.9 \pm 0.2 \%)$ isotopically heavier than related sphalerite $(5.2 \pm 0.2 \%$ ) , giving a reversed order of enrichment where sphalerite < chalcopyrite.

Mineral pairs which qualitatively mimic the isotopic enrichment order of Figure 12 may be in isotopic equilibrium. The equations in Tables 7 and 8 can be used to investigate the equilibrium status of such minerals with better precision. For example, the sulfide-sulfide mineral pair in mound sample $2190-13-1 \gamma$ and the sulfide-sulfate mineral pair of pyrite and anhydrite in massive anhydrite sample 2178-3-1 both agree with the equilibrium isotopic enrichment order.

Analysis of mound sample $2190-13-1 \gamma$ yields a pyrite $\delta^{34} \mathrm{~S}$ value of $5.4 \pm 0.2 \%$ and a sphalerite value of $5.0 \pm 0.2 \%$. (Note that the fact that these two samples yield identical $\delta^{34} \mathrm{~S}$ values within analytical error does not imply that they are in equilibriumsee Figure 12). The difference in measured $\delta^{34} \mathrm{~S}$ values between the two minerals is $\Delta_{\text {py-sp }}$ $=0.4 \pm 0.3 \%$ o (where $0.3 \% \mathrm{o}=\sigma_{\mathrm{tot}}=\operatorname{sqrt}\left[\sigma_{\mathrm{py}}{ }^{2}+\sigma_{\mathrm{sp}}{ }^{2}\right]$ ). Pyrite and sphalerite in $2190-13-1 \gamma$ were chemically separated from each other in the original sample prior to analysis, and are thought to be "related" minerals. 
The temperature at which the mound sample precipitated is not known. Applying $150^{\circ} \mathrm{C}$ as a reasonable lower limit, the equations in Table 7 can be used to calculate an equilibrium $\Delta_{\text {py-sp }}=1.7 \pm 0.2 \%$ :

$$
\Delta_{\text {py-sp }}=\left[\left((0.55 \pm 0.04) * 10^{3}\right) /(150+273)\right]^{2}=1.7 \pm 0.2 \%
$$

This calculated equilibrium difference is around $1.3 \%$ greater than the analyzed difference. $1.3 \%$ is much larger than the analytical uncertainty of $0.3 \%$, indicating isotopic disequilibrium in sample $2190-13-1 \gamma$ at the temperature of $150^{\circ} \mathrm{C}$.

Calculations of pyrite and sphalerite from 2190-13-1 $\gamma$ fail to demonstrate equilibrium at $150^{\circ} \mathrm{C}$. Because the temperature at which the samples precipitate is not well-constrained, it is possible that the apparent disequilibrium is an artifact from using an incorrect equilibrium temperature. As derived in Appendix 2, it is possible to determine the temperature of a parent fluid from which a sample would precipitate minerals with certain $\delta^{34} \mathrm{~S}$ values. The temperature at which minerals from sample 219013-1 $\gamma$ would precipitate the observed minerals in equilibrium can be calculated using the measured value $\Delta_{\mathrm{py}-\mathrm{sp}}=0.4 \pm 0.3 \%$ :

$$
\mathrm{T}=\left[(0.55 \pm 0.04)^{*} 10^{3}\right] /\left(\Delta_{\text {py-sp }}\right)^{1 / 2}=870 \pm 63^{\circ} \mathrm{K}=597 \pm 63^{\circ} \mathrm{C}
$$

Even considering the uncertainty, a temperature of $597 \pm 63^{\circ} \mathrm{C}$ is unrealistically high.

The sulfide pair in 2190-13-1 $\gamma$ demonstrates isotopic disequilibrium at all temperatures observed at TAG. This may be due to the fact that pyrite precipitates over a longer period of the paragenesis than sphalerite, allowing pyrite to experience depositional conditions which are not necessarily identical to those which precipitated sphalerite (Ohmoto and Rye, 1979). Abnormal equilibrium temperatures for pyritesphalerite pairs are common (Ohmoto and Rye, 1979), and disequilibrium among coexisting sulfides has also been reported from $11^{\circ} \mathrm{N}$ and $13^{\circ} \mathrm{N}$ East Pacific Rise (Bluth and Ohmoto, 1988).

Given that the sulfide-sulfide mineral pair was calculated to be in disequilibrium, do sulfate-sulfide minerals also show disequilibrium? Analysis of massive anhydrite sample 2178-3-1 yields a mean pyrite $\delta^{34} \mathrm{~S}=6.2 \pm 0.2 \%$ and an anhydrite $\delta^{34} \mathrm{~S}=20.6$ $\pm 0.2 \%$, giving $\Delta_{\text {anh-py }}=14.4 \pm 0.3 \%$. Anhydrite in 2178-3-1 is from the sub-sample $\beta$, which was collected from two areas located within $2 \mathrm{~cm}$ of each other on a broken face of 
a $<5 \mathrm{~cm}$ square sample piece. Related pyrite is from sub-samples $\alpha$ and $\gamma$. Sub-sample $\alpha$ was collected on the same broken face as sub-sample $\beta$. Sub-sample $\gamma$ was collected on a different face on the opposite side of the sample from which $\alpha$ and $\beta$ were collected. Even though $\gamma$ was collected on a different face, it is included in determining the mean pyrite $\delta^{34} \mathrm{~S}$ value because it was more carefully cleaned of trace anhydrite than was subsample $\alpha$.

Fluid inclusion data in a surficial massive anhydrite sample from the TAG active mound indicate that the sample precipitated from a fluid at 338 to $353^{\circ} \mathrm{C}$ (Tivey et al., in press). Considering this range of temperatures and the provisions of Table 7, a temperature of $349^{\circ} \mathrm{C}\left(622^{\circ} \mathrm{K}\right)$ is used to calculate $\Delta_{\text {anh-py }}=18.1 \pm 0.5 \%$. This calculated equilibrium $\Delta_{\text {anh-py }}$ is $3.6 \%$ greater than the measured values and is much greater than the analytical uncertainty of $0.3 \%$. The minerals in sample $2178-3-1$ are in disequilibrium, and isotopic disequilibrium between sulfate and sulfide has also been found at the southern Juan de Fuca Ridge (Shanks and Seyfried, 1987) and at $21^{\circ} \mathrm{N}$ East Pacific Rise (Woodruff and Shanks, 1988).

At what temperature would the $\delta^{34} \mathrm{~S}$ values for the mineral pair appear to be in equilibrium? From Appendix 2 and using the measured $\Delta_{\text {anh-py }}=14.4 \pm 0.3 \%$, the equilibrium temperature is calculated to be $483 \pm 32^{\circ} \mathrm{C}$. As was the case with sample 2190-13-1 $\gamma$, calculated temperatures for equilibrium given measured $\delta^{34} \mathrm{~S}$ values are higher than those observed at the TAG active mound.

\section{Isotopic Relationship of Black Smoker Fluids and Sulfides}

Since pairs of minerals show disequilibrium, paired minerals and fluids may also demonstrate disequilibrium. Because only end-member, black smoker fluids have been analyzed for $\delta^{34} \mathrm{~S}$ and because chalcopyrite crystals line the passages through which black smoker fluids flow, the only related TAG minerals and fluids which can be investigated are black smoker chalcopyrite and black smoker fluids.

Black smoker fluid $\delta^{34} \mathrm{~S}$ values range 6.5 to $7.5 \pm 0.2 \%$ at the invariant temperature of $362^{\circ} \mathrm{C}$ (Table 5), and black smoker chalcopyrite from 6 analyses yields a 
mean $\delta^{34} \mathrm{~S}$ value and standard deviation of $5.6 \pm 0.04 \%$. Fluid $\delta^{34} \mathrm{~S}$ values are heavier than sulfide $\delta^{34} \mathrm{~S}$ values, as has also been found at the Southern Juan de Fuca Ridge (Shanks and Seyfried, 1987), at $21^{\circ} \mathrm{N}$ East Pacific Rise (Woodruff and Shanks, 1988), and in 4 out of 6 vents at $11^{\circ} \mathrm{N}$ and $13^{\circ} \mathrm{N}$ East Pacific Rise (Bluth and Ohmoto, 1988). As discussed previously, the $\delta^{34} \mathrm{~S}$ values of black smoker chalcopyrite are invariant while the $\delta^{34} \mathrm{~S}$ values of black smoker fluids vary. This discrepancy can be further illustrated by calculating the isotopic relationship of the fluid and precipitate at equilibrium.

Measured $\Delta_{\mathrm{cp}-\mathrm{H} 2 \mathrm{~S}}=-0.9$ to $-1.9 \pm 0.3 \%$, while calculated equilibrium $\Delta_{\mathrm{cp}-\mathrm{H} 2 \mathrm{~S}}=-$ $0.12 \pm 0.2 \%$ at $366^{\circ} \mathrm{C}$ using Table 8 . The $\delta^{34} \mathrm{~S}$ value of fluid $\mathrm{H}_{2} \mathrm{~S}$ calculated to be in equilibrium with the black smoker chalcopyrite can be found:

$$
\begin{gathered}
\Delta_{\mathrm{cp}-\mathrm{H} 2 \mathrm{~S} \text {, calculated }}=\delta^{34} \mathrm{~S}_{\mathrm{cp}}-\delta^{34} \mathrm{~S}_{\mathrm{H} 2 \mathrm{~S} \text {, calculated }} \\
\delta^{34} \mathrm{~S}_{\mathrm{H} 2 \mathrm{~S} \text {, calculated }}=\delta^{34} \mathrm{~S}_{\mathrm{cp}}-\Delta_{\mathrm{cp}-\mathrm{H} 2 \mathrm{~S}, \text { calculated }}=5.6 \pm 0.04 \% 0-(-0.12 \pm 0.20 \%)=5.7 \pm 0.2 \% 0
\end{gathered}
$$

The calculated equilibrium fluid value of $5.7 \pm 0.2 \%$ is 1 to $2 \%$ lighter than the measured fluid values of 6.5 to $7.2 \pm 0.2 \%$. The difference is significant relative to the analytical uncertainty of $0.3 \%$ and indicates disequilibrium.

\section{Post-Depositional Reworking}

Post-depositional reworking can modify the original $\delta^{34} \mathrm{~S}$ values of a sulfide. Evidence for post-depositional reworking includes the alteration, veining, and brecciation found in drill cores, indicative that the TAG active mound has evolved through multiple stages of growth (Humphris et al., 1995). Additional evidence comes from TAG mound massive sulfide samples. Because the massive sulfide samples are believed to have originated in the interior of the mound (Tivey et al., 1995), the large grain size and replacement textures exhibited by the samples demonstrate that post-depositional processes modify sulfides inside the TAG active mound (Tivey et al., 1995). 
TABLE 6. Temperatures and $\delta^{34} \mathrm{~S}$ Values for $\mathrm{H}_{2} \mathrm{~S}$ from TAG Black Smoker Fluid Samples

\begin{tabular}{ccc}
\hline Sample \# & $\mathrm{T}\left({ }^{\circ} \mathrm{C}\right)^{1}$ & $\delta^{34} \mathrm{~S}(\% \mathrm{o})^{2}$ \\
\hline $2179-1 \mathrm{c}$ & 362 & 7.4 \\
$2179-7 \mathrm{c}$ & 362 & 7.5 \\
$2179-9 \mathrm{c}$ & 362 & 6.6 \\
\hline
\end{tabular}

Note error on $\delta^{34} \mathrm{~S}$ values is $\pm 0.2 \%$.

${ }^{1}$ From Edmond et al. (1995).

${ }^{2}$ From W. C. (Pat) Shanks III, unpublished data.

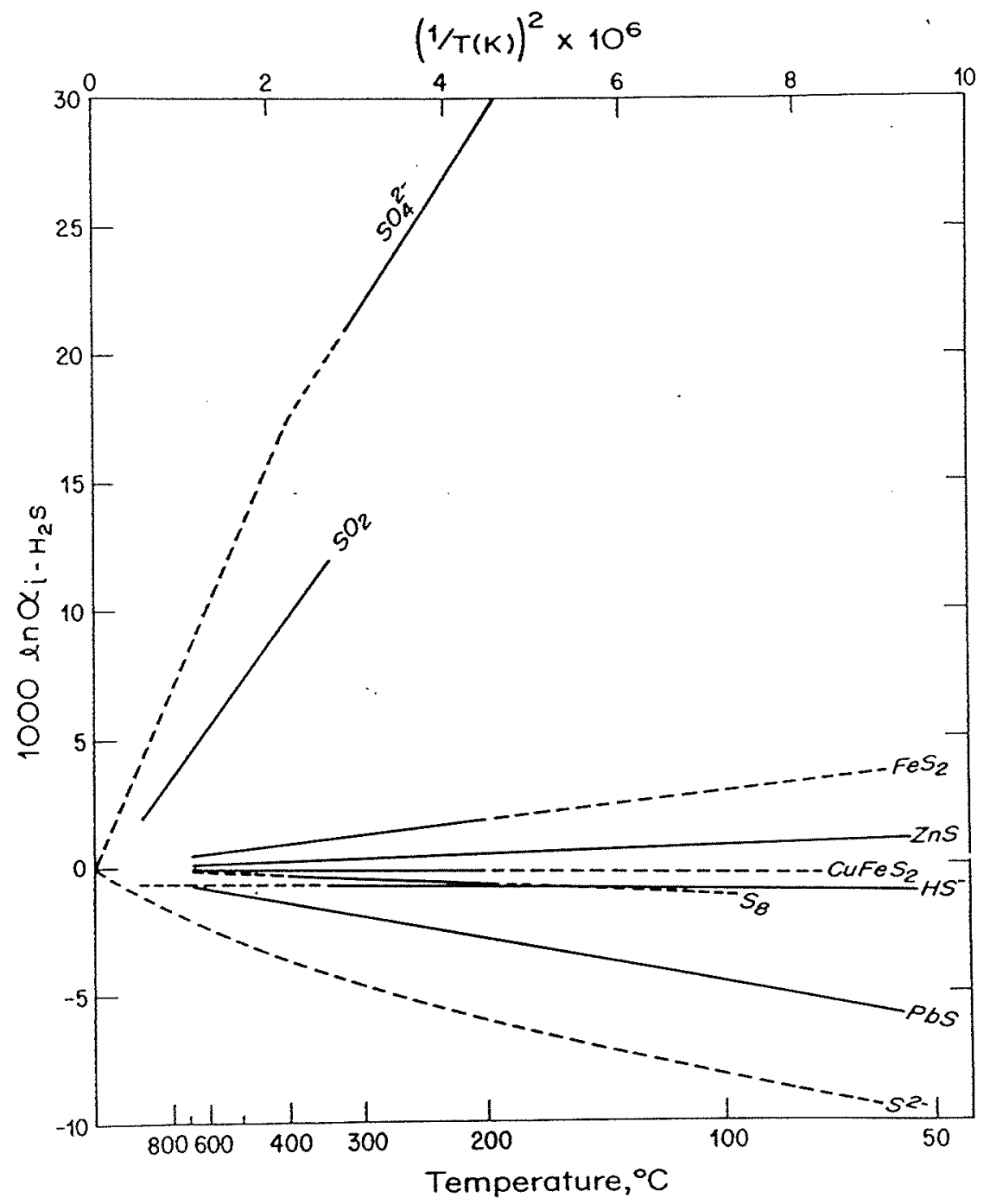

Figure 12. $\delta^{34} \mathrm{~S}$ values of minerals (i) relative to parent fluid $\left(\mathrm{H}_{2} \mathrm{~S}\right)$ at equilibrium. Reported in terms of fractionation factors $(\alpha) . \quad 1000 \ln \alpha_{i-H 2 S}$ is approximately equal to $\delta^{34} S_{i}-\delta^{34} S_{H 2 S}$, as discussed in text. Solid lines experimentally determined. Dashed lines extrapolated or theoretically calculated. Figure from Ohmoto and Rye (1979). 
TABLE 7. Difference in $\delta^{34} \mathrm{~S}$ Values Between Two Minerals in Equilibrium

\begin{tabular}{cc}
\hline Mineral Pair & Equation* $^{*}$ \\
\hline Anhydrite - chalcopyrite & $\Delta=\left[\left(2.85 \times 10^{3}\right) / \mathrm{T}\right]^{2} \pm 1$, for $\mathrm{T}>673^{\circ} \mathrm{K}$ \\
& $\Delta=\left[\left(2.30 \times 10^{3}\right) / \mathrm{T}\right]^{2}+6 \pm 0.5$, for $\mathrm{T}<623^{\circ} \mathrm{K}$ \\
\hline Anhydrite - pyrite & $\Delta=\left[\left(2.76 \times 10^{3}\right) / \mathrm{T}\right]^{2} \pm 1$, for $\mathrm{T}>673^{\circ} \mathrm{K}$ \\
& $\Delta=\left[\left(2.16 \times 10^{3}\right) / \mathrm{T}\right]^{2}+6 \pm 0.5$, for $\mathrm{T}<623^{\circ} \mathrm{K}$ \\
\hline Pyrite - chalcopyrite & $\Delta=\left[\left[(0.67 \pm 0.04) \times 10^{3}\right] / \mathrm{T}\right]^{2}$ \\
\hline Pyrite - sphalerite & $\Delta=\left[\left[(0.55 \pm 0.04) \times 10^{3}\right] / \mathrm{T}\right]^{2}$ \\
\hline
\end{tabular}

*Temperature is in degrees Kelvin.

Based on Ohmoto and Rye (1979), Table 10-2. See Appendix 2 for derivation.

TABLE 8. Equilibrium Isotopic Fractionation Factors

\begin{tabular}{l|ccc}
\hline Mineral & A & B & Temp. Range $\left({ }^{\circ} \mathrm{C}\right)$ \\
\hline Anhydrite & 5.26 & $6.0 \pm 0.5$ & $200-350$ \\
Pyrite & $0.40 \pm 0.08$ & -- & $200-700$ \\
Sphalerite & $0.10 \pm 0.05$ & --- & $50-705$ \\
Chalcopyrite & $-0.05 \pm 0.08$ & --- & $200-600$ \\
\hline
\end{tabular}

Based on Ohmoto and Rye (1979), Table 10-1. 


\section{Section 3. INTERPRETATION OF $\delta^{34}$ S DATA}

\section{Black Smoker, Crust, and Massive Anhydrite Samples}

$\delta^{34} \mathrm{~S}$ data for chalcopyrite in black smoker samples is very uniform and yields a mean of $5.6 \%$ with a standard deviation of $0.04 \%$ (Figure 10). The lack of variation is notable considering the fact that the analyses include inactive sample 2178-5-1 collected from the main black smoker complex and actively venting sample ODP-6-2894 collected from the mound surface (Figure 6). The uniformity in the data implies deposition with a constant temperature and disequilibrium status from a parent fluid with a constant $\delta^{34} \mathrm{~S}$ value. This result confirms Tivey et al.'s (1995) findings that black smoker linings precipitate directly from chemically and thermally invariant end-member fluids. Also, the similarity between the active and inactive samples indicates that the black smoker samples have been neither significantly reworked by fluids with differing $\delta^{34} \mathrm{~S}$ signatures, nor significantly affected by any short-term variability in the $\delta^{34} \mathrm{~S}$ values of parent fluids.

$\delta^{34} \mathrm{~S}$ values in chalcopyrite from crust samples are also fairly uniform (mean $=5.4$ $\pm 0.2 \%$ ). Within error, the mean chalcopyrite in crust samples is isotopically identical to the mean chalcopyrite in black smoker samples, which suggests that crust and black smoker samples precipitate from the same fluid. Although it cannot be related to the black smoker data, pyrite from crust samples was also analyzed for $\delta^{34} \mathrm{~S}$ values. As shown in Figure 13, crust pyrite $\delta^{34} \mathrm{~S}$ values cluster in two groups, the first with a mean of $6.0 \pm 0.4 \%$ (Group $\mathrm{H}$ ) and the second with a mean of $4.6 \pm 0.1 \%$ (Group L). Both groups of samples were collected on the west side of the black smoker complex, but the isotopically heavier Group $\mathrm{H}$ was collected closer to the active black smokers than the isotopically light Group L (Figure 6). All of the chalcopyrite analyzed from crust samples comes from Group H. Group L samples do not contain sufficient quantities of chalcopyrite to permit $\delta^{34} \mathrm{~S}$ analyses by the bulk analytical technique used in this study.

Group L pyrite/marcasite minerals were deposited in situ, as indicated by the microscopic texture of radial bands of pyrite crystals. The sampled areas in MIR2-75$5 A 3$ and $-5 A 6$ are channel linings, and the sampled area in MIR2-75-5A7 is a massive 
pyrite region close to a minor channel. End-member fluids with $\delta^{34} \mathrm{~S}$ values of 6.6 to $7.5 \%$ are reversed with respect to equilibrium with Group $L$ pyrite values of 4.6 to $4.7 \%$ o (Figure 12). The light Group L pyrite $\delta^{34} \mathrm{~S}$ values cannot be explained by deposition from a conductively cooled end-member fluid, a fluid contaminated with seawater sulfur, or a fluid from which chalcopyrite had already been precipitated because all of these processes would drive pyrite values heavier. However, deposition from a fluid which had cooled extensively to the point that it precipitated significant amounts of pyrite could ultimately result in an isotopically light sample. This hypothesis requires that the decrease in fluid $\delta^{34} \mathrm{~S}$ from pyrite precipitation outweighs the increase in fluid $\delta^{34} \mathrm{~S}$ from chalcopyrite precipitation and cooling. Because $\mathrm{Fe}$ is much more abundant than $\mathrm{Cu}$ in end-member fluid (Table 1), and because the $\delta^{34} S_{\mathrm{i}}-\delta^{34} \mathrm{~S}_{\mathrm{H} 2 \mathrm{~S}}$ gradient is steeper for pyrite than for chalcopyrite (Figure 12), it is likely that pyrite precipitation could affect greater change in the fluid $\delta^{34} \mathrm{~S}$ than chalcopyrite precipitation. Whether pyrite deposition could override the isotopic increase in the fluid due to cooling and what quantity of sulfur would have to be removed as pyrite are not known because the $\delta^{34} S$ values of pyrite which would precipitate prior to depositing Group L crust samples are not known. While cooling and pyrite precipitation may be factors in producing the low $\delta^{34} \mathrm{~S}$ values in Group $\mathrm{L}$ crust samples, it is not possible to determine the origin for Group $\mathrm{L}$ with certainty based solely on the sulfur isotope data.

Group $H$ consists of two samples, 2179-1-1 $\delta$ and 2180-1 $\alpha$. Pyrite analyzed for sample 2179-1-1 $\delta$ came from a single $5 \mathrm{~mm}$ clast which was removed from a finergrained matrix. Pyrite analyzed from 2180-1 $\alpha$ came from a group of fewer than 10 small grains sitting in a very fine-grained matrix. The size and shape of the pyrite and the finergrained texture of the matrix indicate that the pyrite in both samples are isolated debris later cemented into a matrix. Sulfide debris in TAG active mound crust samples has also been mentioned by Tivey et al. (1995). The pyrite debris is not in isotopic equilibrium with chalcopyrite from the matrix. For example, analysis of sample 2179-1-1 yields a pyrite $\delta^{34} \mathrm{~S}$ value of $5.7 \pm 0.2 \%$ and a chalcopyrite value of $5.3 \pm 0.2 \%$. The temperature at which the minerals would display equilibrium can be calculated using the measured 
difference of $\Delta_{\mathrm{py}-\mathrm{cp}}=0.4 \pm 0.3 \%$ :

$$
\mathrm{T}=\left[(0.67 \pm 0.04) \times 10^{3}\right] /\left(\Delta_{\mathrm{py}-\mathrm{cp}}\right)^{1 / 2}=1059 \pm 63^{\circ} \mathrm{K}=786 \pm 63^{\circ} \mathrm{C}
$$

(see Appendix 2). Even considering the uncertainty, this is an unrealistically high temperature.

Because the pyrite debris is precipitated neither in situ in the crust samples nor in equilibrium with the surrounding matrix, pyrite in Group $\mathrm{H}$ is not representative of the environment under which crust samples are deposited. The pyrite is not comparable to chalcopyrite from the surrounding matrix, nor to pyrite from Group L. However, Group $\mathrm{H}$ pyrite is isotopically identical to pyrite from massive anhydrite samples, within error. Pyrite from Group $H$ crust samples yields a mean $\delta^{34} \mathrm{~S}$ value of $6.0 \pm 0.4 \%$ (range 5.7 to $6.4 \% 0$ ), and pyrite from massive anhydrite samples yields a mean of $6.2 \pm 0.6 \%$ (range 5.4 to $7.1 \%$ ). The $\delta^{34} \mathrm{~S}$ data suggests that pyrite in Group $\mathrm{H}$ samples was originally deposited in massive anhydrite samples and later incorporated as debris cemented by endmember fluids.

The range of 5.4 to $7.1 \%$ in pyrite from massive anhydrite samples is wide, and the pyrite is not in equilibrium with coexisting anhydrite. Pyrite occurs as inclusions in and intergrown with anhydrite of $\delta^{34} \mathrm{~S}=20.6 \%$ and $20.7 \%$. The sulfate in anhydrite from massive anhydrite samples is isotopically identical to seawater sulfate ( $21 \pm 0.2 \%$; Rees et al., 1978), within analytical error. This indicates that the sulfate in massive anhydrite was derived from seawater, not from oxidized end-member fluid $\mathrm{H}_{2} \mathrm{~S}$, and that the seawater did not experience significant sulfate reduction. The presence of both sulfate and sulfide minerals deposited in situ in massive anhydrite samples shows that the minerals form from a mixture of seawater and hydrothermal fluid. The fact that anhydrite in massive anhydrite samples is in isotopic equilibrium with seawater sulfate and in isotopic disequilibrium with coexisting pyrite demonstrates that seawater-derived sulfate and hydrothermal fluid-derived $\mathrm{H}_{2} \mathrm{~S}$ do not equilibrate during mixing. Sulfate- $\mathrm{H}_{2} \mathrm{~S}$ disequilibrium requires that mixing between seawater and hydrothermal fluid be sufficiently rapid to prevent equilibration between the two fluids.

Rapid mixing is further supported by the fact that the pyrite $\delta^{34} \mathrm{~S}$ values in massive anhydrite samples are in disequilibrium with the $\mathrm{Mg}$-free, highest temperature 
end-member fluid. The pyrite $\delta^{34} \mathrm{~S}$ values are also in disequilibrium with any fluid that can be derived from end-member fluid by cooling, precipitation of chalcopyrite, or mixing with entrained seawater because fluids derived from any of these processes would be isotopically heavier than end-member fluid. Also, $\delta^{34} \mathrm{~S}$ values in pyrite from massive anhydrite samples are highly variable, providing additional evidence that pyrite is in isotopic disequilibrium with parent fluids and was rapidly precipitated.

To summarize, the uniform data for black smoker samples indicates that they precipitate directly from end-member fluids. Group $\mathrm{H}$ crust samples are composed of pyrite debris in a fine-grained matrix. Chalcopyrite in the matrix precipitated from endmember fluids, and the pyrite debris likely originated in a massive anhydrite sample. Group L crust samples yield pyrite $\delta^{34} \mathrm{~S}$ values which are too low to be explained by precipitation from end-member fluid, cooled fluid, fluid from which chalcopyrite has already precipitated, or fluid contaminated with seawater sulfate. However, precipitation of significant quantities of pyrite prior to the deposition of Group L pyrite may in part explain the low $\delta^{34} \mathrm{~S}$ values. Finally, disequilibrium between sulfate and sulfide minerals in massive anhydrite samples provides evidence that the samples form from rapid mixing between hydrothermal fluid and entrained seawater.

\section{White Smoker Samples}

$\delta^{34} \mathrm{~S}$ data from both chalcopyrite (mean $=7.0 \pm 0.3 \%$ ) and sphalerite (mean $=6.7$ $\pm 0.6 \%$ ) in white smoker samples are high relative to data from other TAG sample types. High values in white smoker minerals may indicate deposition from fluids contaminated with seawater-derived sulfur, from fluids out of which isotopically light minerals have previously been deposited, or from fluids into which isotopically heavy minerals have dissolved. A change in depositional temperature cannot account for the high $\delta^{34} \mathrm{~S}$ values because heating would be required to produce isotopically heavy chalcopyrite while cooling would be required to produce isotopically heavy sphalerite.

Geochemical modeling has indicated that TAG white smoker fluids can be reproduced as a mixture of black smoker fluids and 14-20\% entrained seawater, 
accompanied by precipitation of anhydrite, pyrite, and chalcopyrite, and by dissolution of sphalerite inside the TAG active mound (Edmond et al., 1995; Tivey et al., 1995).

Because the $\delta^{34} \mathrm{~S}$ values of the minerals which are modeled to precipitate and dissolve inside the mound are not known, it is not possible to quantify the relative contribution of each of these processes to the heavy $\delta^{34} \mathrm{~S}$ values of white smoker chalcopyrite and sphalerite. For this reason, it is not clear whether mineral precipitation and dissolution alone can account for the increase in white smoker $\delta^{34} \mathrm{~S}$ values.

Since the $\delta^{34} \mathrm{~S}$ value of seawater sulfate is known, the likelihood that the heavy $\delta^{34} \mathrm{~S}$ values of white smoker samples are solely the result of contamination of endmember fluids with reduced seawater sulfate can be examined. If the entire difference in $\delta^{34} \mathrm{~S}$ values between chalcopyrite from white smokers and chalcopyrite from black smokers and crusts is attributed to inputs of seawater sulfur, white smoker chalcopyrite can be calculated to precipitate from a fluid containing on the order of $7 \%$ sulfur from entrained seawater and 93\% sulfur from end-member fluid:

(mean white smoker chalcopyrite) - (mean black smoker and crust chalcopyrite) $=7.0 \%-5.5 \% 0=1.5 \%$ $1.5 \%=21 \% * \mathrm{P}_{\mathrm{sw}}$, where $\mathrm{P}_{\mathrm{sw}}=$ proportion of seawater sulfur added to white smoker samples

$$
\mathrm{P}_{\mathrm{sw}}=0.071=7.1 \%
$$

This calculation assumes that the minerals all precipitated at the same temperature, and that white smoker samples and white smoker fluids, and black smoker samples and black smoker fluids, are in equilibrium.

$\mathrm{P}_{\mathrm{sw}}$ refers to the proportion of seawater-derived sulfur, which is not equal to the proportion of actual seawater. Given the fact that the concentration of sulfur in seawater is $905 \mathrm{ppm}$ (Brown et al., 1995) and in end-member hydrothermal fluid is $3 \mathrm{mM}=102 \mathrm{mg}$ $1^{-1}=102 \mathrm{ppm}$ (Table 1), a $7 \%$ input of seawater-derived sulfur is equivalent to a $<1 \%$ input of actual seawater by volume:

vol. seawater $/$ vol. end-member fluid $=\left(\mathrm{P}_{\mathrm{sw}} /[\mathrm{S}]\right.$ in seawater $) /\left(\mathrm{P}_{\mathrm{emf}} /[\mathrm{S}]\right.$ in end-member fluid $)$

$$
=(7 / 905) /(93 / 102)=0.0085
$$

Let vol. end-member fluid $=1$, then vol. seawater $=0.0085$, and total vol. $=1.0085$, in which case $\%$ vol. seawater $=(0.0085 / 1.0085) * 100=0.84 \%$

where $\mathrm{P}_{\mathrm{emf}}$ is the proportion of sulfur from end-member fluid.

If $14-20 \%$ seawater is mixed into end-member fluid, as suggested by geochemical 
modeling (Edmond et al., 1995; Tivey et al., 1995), then $<1 \%$ of this mixed seawater sulfate would be reduced to $\mathrm{H}_{2} \mathrm{~S}$ to account for the white smoker chalcopyrite $\delta^{34} \mathrm{~S}$ values. This conclusion concurs with the results of modeling which suggest that approximately $80 \%$ of sulfate from entrained seawater is precipitated as anhydrite (Edmond et al., 1995), leaving 20\% of the sulfate from entrained seawater available for reduction and direct incorporation into the white smoker fluid. Since $<1 \%$ is less than $20 \%$, the unprecipitated sulfate in entrained seawater could explain the increase in the $\delta^{34} \mathrm{~S}$ values of white smoker chalcopyrite.

It is also possible that previously deposited anhydrite inside the mound serves as a source of seawater-derived sulfur. Anhydrite from TAG mound surface samples is isotopically indistinguishable from seawater sulfate (Table 4), and, assuming that the $\delta^{34} \mathrm{~S}$ data from the surficial anhydrite represents the $\delta^{34} \mathrm{~S}$ values of anhydrite inside the mound, an increase in $\delta^{34} \mathrm{~S}$ values resulting from the dissolution of anhydrite would be similar to the increase resulting from the entrainment of seawater. Thus the increase in $\delta^{34} \mathrm{~S}$ values of white smoker samples may result from the direct reduction of sulfate from up to $6 \%$ of the entrained seawater, with or without the dissolution of previously deposited anhydrite, pyrite, and sphalerite, or the precipitation of chalcopyrite inside the mound.

These experimental calculations employed chalcopyrite $\delta^{34} \mathrm{~S}$ values from white smoker samples, and it should be mentioned that the presence of chalcopyrite in white smoker samples is unusual and indicates precipitation from a hotter than normal fluid. This conclusion is supported by sample 2187-1-7F, an exceptional white smoker specimen in that it has a well-formed, chalcopyrite-lined channel similar to the channels in black smokers. $\delta^{34} \mathrm{~S}$ in the sphalerite from subsample $2187-1-7 \mathrm{~F} \alpha$ is unusually low (5.2\%o), compared to the overall mean $\delta^{34} \mathrm{~S}$ of white smoker sphalerite $(6.7 \pm 0.6 \%)$. The low sphalerite $\delta^{34} \mathrm{~S}$ value (Figure 12) and the mineralogy and texture of the channel suggest that this sample was in contact with a hotter fluid similar to the end-member fluids which precipitate black smokers.

Comparison with subsamples 2187-1-7F $\beta$ and 2187-1-7F $\gamma$ support the theory that sphalerite from $2187-1-7 \mathrm{~F} \alpha$ was precipitated from a hotter fluid. Subsamples 7F $\beta$ and 
$7 \mathrm{~F} \gamma$ were collected $<5 \mathrm{~cm}$ away from the chalcopyrite-rich zone from which $2187-1-7 \mathrm{~F} \alpha$ was collected, and they yield sphalerite $\delta^{34} \mathrm{~S}$ values of $6.8 \%$ and $7.5 \%$, respectively. These values are within the range of the sphalerite analyses from the other white smoker samples, and they represent regions on the sample which are not rich in chalcopyrite.

To summarize, white smoker sulfides are isotopically heavy, but sulfur isotope ratios alone do not provide enough information to quantify the relative influences of contamination with entrained seawater-derived sulfur, dissolution of isotopically heavy anhydrite, pyrite, and sphalerite, or deposition of isotopically light chalcopyrite. Because the $\delta^{34} \mathrm{~S}$ value of seawater sulfate is known, it is possible to approximate the proportions of seawater-derived sulfur that could account for the $\delta^{34} \mathrm{~S}$ values of white smoker minerals. The combined results of very rough calculations and of previous geochemical models demonstrate that the direct reduction of entrained seawater sulfate can contribute the necessary $7 \%$ of isotopically heavy sulfur to the fluid which precipitates white smoker samples. As the $\delta^{34} \mathrm{~S}$ values of the other minerals modeled to dissolve or precipitate inside the mound are not known, it is not clear what role, if any, they play in producing the heavy $\delta^{34} \mathrm{~S}$ values of white smoker precipitates.

\section{Mound Samples}

Sphalerite, chalcopyrite, and pyrite $\delta^{34} \mathrm{~S}$ data from mound samples are highly variable (Figures 9, 10, and 11), are generally lighter than white smoker sulfides, and are similar to $\delta^{34} \mathrm{~S}$ values from black smoker and crust sulfides. The mean chalcopyrite values for black smoker $(5.6 \pm 0.04 \%)$, crust $(5.4 \pm 0.2 \%$ ) , and mound $(5.5 \pm 0.4 \%$ ) samples are identical within analytical error, which suggests that mound samples precipitate from a fluid which is isotopically similar to the fluid from which black smoker and crust samples precipitate.

In contrast to the $\delta^{34} \mathrm{~S}$ data, mineralogy and geochemistry suggests that mound samples precipitate from a fluid which is chemically distinct from the fluid from which black smoker and crust samples precipitate. The presence of sphalerite and of high concentrations of $\mathrm{Au}, \mathrm{Cd}, \mathrm{Sb}, \mathrm{Pb}$, and $\mathrm{Ag}$ indicate that mound samples were deposited 
from a fluid which is more Zn-rich than end-member fluid (Tivey et al., 1995). Together, the mineralogical, geochemical, and $\delta^{34} \mathrm{~S}$ data suggest that mound samples may have precipitated from end-member fluid which was modified by some of the same processes, such as cooling, which can generate white smoker fluid from end-member fluid. Because the $\delta^{34} \mathrm{~S}$ value of white smoker fluid is not known, and because the $\delta^{34} \mathrm{~S}$ values of minerals which precipitate and dissolve inside the TAG mound to produce white smoker fluid are not known, it is not possible to quantify the extent of the modification of endmember fluids that is needed to produce the observed $\delta^{34} \mathrm{~S}$ values, mineralogy, and geochemistry of mound samples based on the sulfur isotope data. It is clear, however, that the fluid from which mound samples precipitate must be modified to exhibit trace element concentrations comparable to white smokers while maintaining the isotopic signature of the fluid which precipitates black smoker and crust samples.

In addition to enrichments in $\mathrm{Zn}, \mathrm{Cd}$, and other metals (Tivey et al., 1995), mound samples are distinct from black smoker and crust samples in that chalcopyrite and pyrite $\delta^{34} \mathrm{~S}$ data from mound samples are much more variable than the $\delta^{34} \mathrm{~S}$ data in black smoker and Group $L$ crust samples. The variability in the mound $\delta^{34} \mathrm{~S}$ values suggests that the samples precipitate under variable depositional conditions or in variable states of disequilibrium. The very light pyrite $\delta^{34} \mathrm{~S}$ value of 2.7\% from sample 2186-1A $\alpha$ may support this conclusion. Pyrite in this sample was collected from an isolated $\mathrm{cm}-$ long narrow strip of massive pyrite in a mineralogically and texturally heterogeneous mound sample. It is not clear why this value is so much lighter than all other pyrite $\delta^{34} \mathrm{~S}$ values from TAG active mound samples, but the heterogeneous mineralogy and texture of this and other mound samples supports the statement that mound samples precipitate under variable conditions and states of disequilibrium.

Tivey et al. (1995) discuss the mineralogical heterogeneity in mound samples from TAG, separating mound samples into $\mathrm{Cu}$ or Fe-rich types and $\mathrm{Zn}$-rich types. They find that $\mathrm{Cu}$ or Fe-rich types have lower $\mathrm{Pb}, \mathrm{Sb}, \mathrm{Ag}$, and $\mathrm{Au}$ and higher Co concentrations than white smokers, which suggests that the $\mathrm{Cu}$-rich type reflects deposition from a hotter fluid with a greater end-member component. Trace element concentrations in $\mathrm{Zn}$-rich 
types, on the other hand, are similar to the concentrations in white smoker samples, reflecting either deposition from fluid with a greater white smoker fluid component (Tivey et al., 1995) or with a greater extent of modification by the same processes which produce white smokers. The mound samples analyzed in this study include $\mathrm{Cu}$ or Fe-rich samples 2183-9-1, 2190-7-1A, and 2190-13-1A, and Zn-rich samples 2183-4-1B and 2186-1A. There does not appear to be a relationship between $\delta^{34} \mathrm{~S}$ values and whether the samples are $\mathrm{Cu}$ or Fe-rich or Zn-rich (Table 5). For instance, chalcopyrite $\delta^{34} \mathrm{~S}$ values from $\mathrm{Cu}$ and Fe-rich samples 2183-9-1 and 2190-7-1A are 6.0\% and 5.3*\%o (*the mean of the duplicate analyses), respectively, while the chalcopyrite $\delta^{34} \mathrm{~S}$ value from the $\mathrm{Zn}$ rich sample $2183-4-1 \mathrm{~B}$ is $5.2 \%$. If the $\mathrm{Cu}$ or Fe-rich sample types were deposited from fluid with a greater end-member fluid component (Tivey et al., 1995), it would be expected that the $\delta^{34} \mathrm{~S}$ values of the $\mathrm{Cu}$ or Fe-rich types would be lighter than the $\delta^{34} \mathrm{~S}$ values of the $\mathrm{Zn}$-rich types.

Overall, the $\delta^{34} \mathrm{~S}$ data in this study suggest that all mound samples precipitate from a fluid which is isotopically similar to end-member fluid, while studies of mineralogy and geochemistry indicate that mound samples form from fluids which are chemically similar to white smoker fluids (Tivey et al., 1995). It is possible that mound samples form from end-member fluid which has been modified by some of the same processes, including cooling, which produce white smoker fluids, but the discrepancy between the $\delta^{34} \mathrm{~S}$ data and the mineralogy and geochemistry cannot be explained based on the information in this study.

\section{Massive Sulfide Samples}

Pyrite is the only sulfide mineral analyzed in massive sulfide samples, and the $\delta^{34} \mathrm{~S}$ values are heavier (range $=6.7$ to $7.6 \%$ ) and less variable $($ standard deviation $=$ $\pm 0.4 \%$ ) than pyrite $\delta^{34} \mathrm{~S}$ values from any other TAG active mound sample type (Figure 9). Large grain size and recrystallized and replacement textures indicate that massive sulfide samples are the product of post-depositional reworking (Tivey et al., 1995). The fact that ${ }^{230} \mathrm{Th} /{ }^{234} \mathrm{U}$ dating on two TAG active mound massive sulfide samples yields old 
ages on the order of 10,000 years (Lalou et al., 1993) supports the idea that massive sulfide samples form through reworking of previously-deposited samples.

The compositions of the parent fluids which precipitated the original samples are not known and may be distinct from the fluids which currently precipitate TAG sulfides (Tivey et al., 1995). Assuming that the reworking fluid overprints or partially overprints the isotopic signature of the original fluid, heavy pyrite $\delta^{34} \mathrm{~S}$ values in massive sulfide samples indicate recrystallization with a fluid which is isotopically heavier than the fluid precipitating crust or massive anhydrite samples.

Pyrite precipitated in equilibrium with end-member fluids (mean $=7.2 \%$ ) at $350^{\circ} \mathrm{C}$ would have $\delta^{34} \mathrm{~S}$ values of $8.2 \%$. Measured $\delta^{34} \mathrm{~S}$ values in massive sulfide samples are lower than $8.2 \%$, indicating that massive sulfide precipitates are not in equilibrium with end-member fluids. This conclusion is not surprising given that none of the TAG sulfides are calculated to be in equilibrium with end-member fluids.

Pyrite from massive sulfide samples is also not explained by equilibrium reaction with a fluid calculated to be in equilibrium with chalcopyrite from black smoker linings. Pyrite in equilibrium with black smoker chalcopyrite would yield $\delta^{34} \mathrm{~S}=6.7 \%$, the low end of the range of observed $\delta^{34} \mathrm{~S}$ values for pyrite from massive sulfide samples (Table 5). $\delta^{34} \mathrm{~S}$ values greater than $6.7 \%$ likely reflect precipitation from a fluid contaminated with heavy sulfur isotopes. To illustrate, the mean pyrite $\delta^{34} \mathrm{~S}$ value from massive sulfide samples is about 1 to $2 \%$ higher than the mean pyrite value from the crust and massive anhydrite samples. A 1 to $2 \%$ difference is equivalent to roughly 5 to $10 \%$ contamination with seawater-derived sulfur, assuming no temperature change:

$$
\begin{aligned}
& 1 \%=21 \% * \mathrm{P} 1 \text {, where } \mathrm{P} 1=\text { minimum proportion of seawater sulfur added to fluid } \\
& \qquad \mathrm{P} 1=0.048=4.8 \% \\
& 2 \%=21 \% * \mathrm{P} 2 \text {, where } \mathrm{P} 2=\text { maximum proportion of seawater sulfur added to fluid } \\
& \mathrm{P} 2=0.095=9.5 \%
\end{aligned}
$$

It can be argued that cooling of hydrothermal fluid could also account for the increase in $\delta^{34} \mathrm{~S}$ values. However, cooling of over $350^{\circ} \mathrm{C}$ would be necessary to account for a 1 to $2 \%$ change, assuming no input of seawater derived sulfur and assuming equilibrium with parent fluids: 


$$
\begin{gathered}
\left(\delta^{34} \mathrm{~S}_{\text {massive sulfide }}-\delta^{34} \mathrm{~S}_{\mathrm{H} 2 \mathrm{~S}}\right)-\left(\delta^{34} \mathrm{~S}_{\text {other three sample types }}-\delta^{34} \mathrm{~S}_{\mathrm{H} 2 \mathrm{~S}}\right)=\left[0.40 / \mathrm{T}^{2}\right] * 10^{6}-\left[0.40 /(350+273)^{2}\right]^{*} 10^{6} \\
\delta^{34} \mathrm{~S}_{\text {massive sulfide }}-\delta^{34} \mathrm{~S}_{\text {other three sample types }}=\left[0.40 / \mathrm{T}^{2}\right]^{*} 10^{6}-\left[0.40 /(350+273)^{2}\right]^{*} 10^{6} \\
1 \text { to } 2=\left[400,000 / \mathrm{T}^{2}\right]-1.03 \\
2 \text { to } 3=400,000 / \mathrm{T}^{2} \\
\mathrm{~T}^{2}=400,000 /(2 \text { to } 3)=133,000 \text { to } 200,000 \\
\mathrm{~T}=365 \text { to } 447^{\circ} \mathrm{C}
\end{gathered}
$$

Cooling TAG hydrothermal fluids by this amount would produce $\mathrm{a} \sim 0^{\circ} \mathrm{C}$ fluid. Since temperatures this low do not precipitate TAG sulfides, conductive cooling is not the primary cause of the heavy $\delta^{34} \mathrm{~S}$ values in pyrite from massive sulfide samples.

The texture and mineralogy of massive sulfide samples suggests a relationship to the sulfides in drill cores studied by Knott et al. (in press). Both pyrite from massive sulfides in drill cores and pyrite from massive sulfides in this study have generally high $\delta^{34} \mathrm{~S}$ values, and the $\delta^{34} \mathrm{~S}$ values increase with increasing depth into the TAG active mound (Knott et al., in press). This provides evidence that the massive sulfide samples were originally formed inside the mound where the drill cores were taken, and were later exposed on the talus slopes. The drill cores contain anhydrite (Humphris et al., 1995), and this anhydrite could provide a source of seawater sulfate that could be reduced and added to end-member fluids to produce pyrite with heavy isotopic signatures. Thus, massive sulfide samples likely form inside the mound by reworking of previously precipitated sulfides with end-member fluid contaminated with on the order of 5 to $10 \%$ seawater sulfur, and the seawater sulfur was likely derived from previously precipitated anhydrite. 
Figure 13. Duality in Crust Pyrite $\delta 34 S$ Values

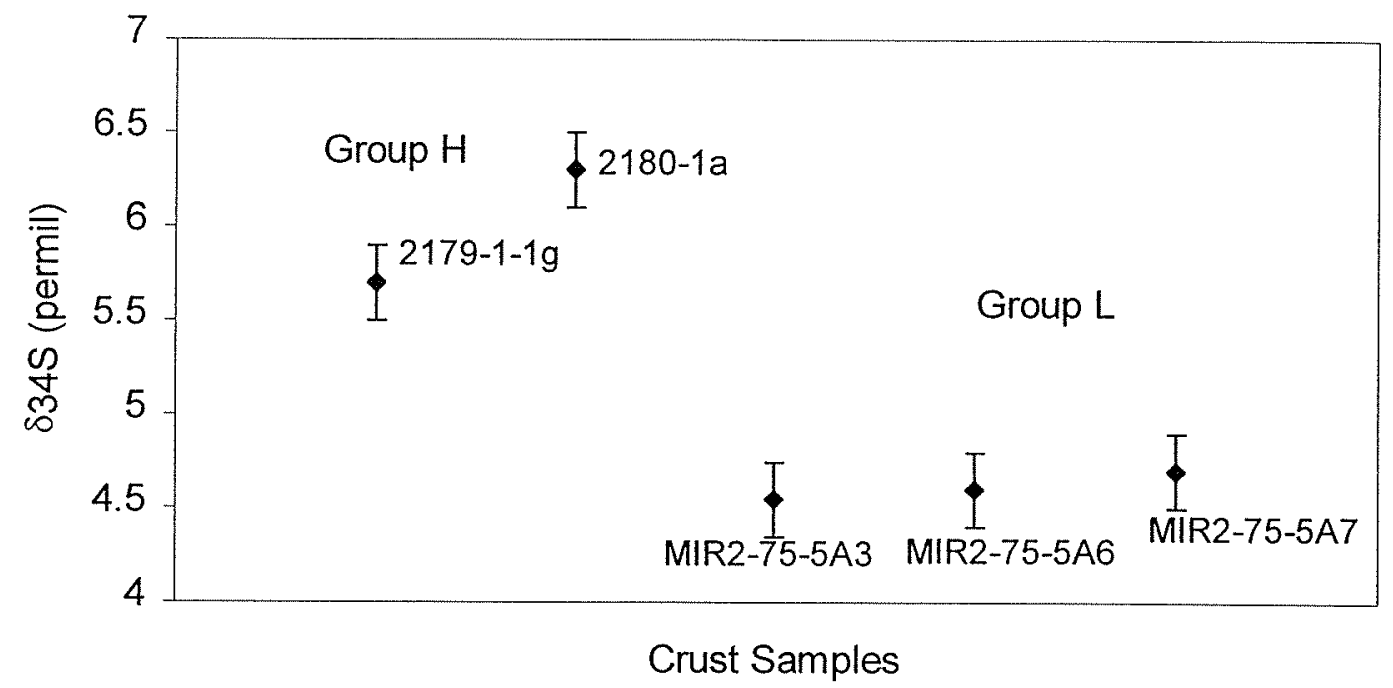

Data points represent individual $\delta^{34} \mathrm{~S}$ values, and error bars show analytical error of $\pm 0.2 \%$. Group $\mathrm{H}=$ isotopically heavy crust samples; Group $\mathrm{L}=$ isotopically light crust samples. 


\section{Section 4. SUMMARY}

$\delta^{34} \mathrm{~S}$ values in surficial samples from the TAG active mound help identify the processes which form the various sample types, indicate the genetic relationships among the sample types, and suggest a model for hydrothermal circulation within the mound. The range of $\delta^{34} \mathrm{~S}$ data indicates that the TAG hydrothermal mound samples are produced from a mixture of variable proportions of $21 \%$ sulfur from seawater and $\sim 0 \%$ sulfur from basalt. The range of $\delta^{34} \mathrm{~S}$ values from anhydrite is 20.0 to $20.9 \%$, with a mean of 20.6 $\pm 0.4 \%$. The range of $\delta^{34} \mathrm{~S}$ from all the sulfide minerals is 2.7 to $7.6 \%$, with an overall mean of $6.0 \pm 0.9 \%$.

The $\delta^{34} \mathrm{~S}$ data show that sulfides from black smoker, crust, and massive anhydrite samples all precipitate from the same end-member fluid. Chalcopyrite from black smoker and crust samples precipitate directly from end-member fluids, and massive anhydrite samples precipitate from rapid mixing between end-member fluids and entrained seawater. The $\delta^{34} \mathrm{~S}$ data for sulfides in white smoker samples demonstrate that these samples precipitate from a fluid which is isotopically heavier than end-member fluid. The isotopic enrichment likely results from entrainment and subsequent reduction of seawater sulfate, possibly with the added affects of mineral precipitation and dissolution inside the mound. Sulfur isotope ratios in sulfide minerals from mound samples indicate that mound samples form from fluid which is isotopically similar to end-member fluid, while mineralogical and geochemical studies (Tivey et al., 1995) suggest that mound samples form from fluid geochemically similar to white smoker fluid. Together, the data suggest that mound samples may have formed from end-member fluid which has undergone some of the same processes, such as cooling, that produce white smoker fluid. Finally, $\delta^{34} \mathrm{~S}$ values in massive sulfide samples demonstrate that they form by reworking of previously precipitated sulfides with a mixture of end-member fluid and seawater-derived sulfur. The conclusions based on the $\delta^{34} \mathrm{~S}$ analyses in this study substantiate a model for hydrothermal circulation in the TAG mound that was derived from mineralogical and chemical studies (Figure 14). 


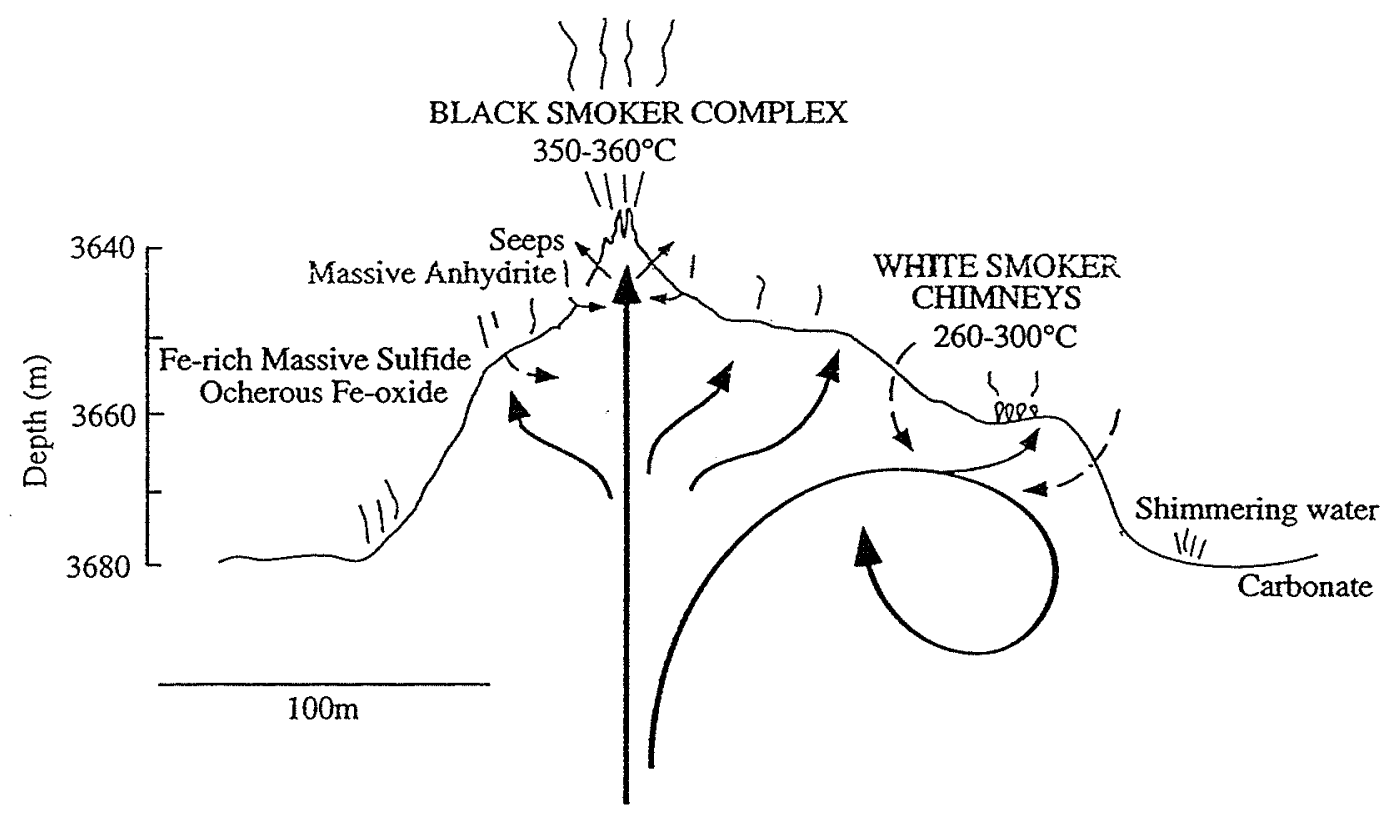

Figure 14. Illustration of hypothesized flow patterns of hydrothermal fluid exiting and seawater entering the TAG active mound. Dashed arrows indicate entrainment of seawater into the regions surrounding black smokers, white smokers, and other areas on the surface of the mound. Figure from Tivey (1995). 


\section{Chapter 3. TRACE COBALT STUDY}

\section{Section 1. ANALYSIS OF COBALT}

\section{Introduction and Background}

The concentrations of trace elements in massive sulfides can provide information on the composition of parent fluids, the conditions of primary precipitation, and the extent of post-depositional reworking. Cobalt (Co), in particular, can serve as an indicator of depositional temperatures. Studies of Co in pyrite have shown that Co is present in high concentrations in high temperature deposits, and Co has been used to infer the presence of high-temperature feeder zones in the volcanic-hosted massive sulfide (VMS) deposit at Rosebery, Tasmania (Green et al., 1981). Studies have also shown that Co concentrations are related to $\mathrm{Cu}$ concentrations, and $\mathrm{Co}$ is enriched in $\mathrm{Cu}$-rich portions of VMS deposits in Eastern Australia (Huston et al., 1995). Bulk chemical analyses indicate that Co concentrations are also enriched in higher temperature mineral assemblages from a host of seafloor hydrothermal sites, including the TAG active mound (Table 9). In general, Co concentrations are highest in black smoker, or " $\mathrm{Cu}$ " chimneys (Fouquet et al., 1993), in stockwork zones believed to be in direct contact with high temperature fluids (Fouquet et al., 1993; Green et al, 1981), and in high temperature pyrite-chalcopyrite mineral assemblages (Hannington et al., 1991).

While it can be shown that Co concentrations are high in seafloor deposits which precipitate at high temperature, inconsistent analytical techniques make it difficult to demonstrate that sampled hydrothermal fluids also show Co enrichments with increasing temperatures. Variations in how precipitates in sampling bottles were handled and the influences of $\mathrm{pH}$ and salinity complicate comparisons between fluid Co concentrations and temperature. As shown in Table 10, analyzed Co concentrations in fluid from the Cleft Segment on the Juan de Fuca Ridge (Trefry et al., 1994), from the Guaymas Basin (Von Damm, 1990), and from $21^{\circ} \mathrm{N}$ on the East Pacific Rise (Von Damm et al., 1985) 
can vary from $<5$ to 1430 nanomoles per kilogram $(\mathrm{nmol} / \mathrm{kg})$, but nevertheless the Co concentrations are generally 3 to 4 orders of magnitude higher than the seawater Co concentration of $0.03 \mathrm{nmol} / \mathrm{kg}$ (Von Damm et al., 1985).

Because pyrite deposition occurs over a wide range of temperatures, pyrite precipitates are potentially good indicators of the effect of temperature on Co concentrations in sulfides. Pyrite with high Co values tends to be associated with the highest temperature $\left(-350^{\circ} \mathrm{C}\right) \mathrm{Cu}$-mineral, chalcopyrite, rather than with the moderately high temperature $\left(250^{\circ} \mathrm{C}\right) \mathrm{Zn}$-mineral, sphalerite (Table 9). Also, Co solubility in pyrite is thought to increase with temperature (Huston et al., 1995). Thus, variability in Co concentrations in pyrite result from (1) differences in the hydrothermal fluid temperatures, and (2) increases in the solubility of $\mathrm{Co}$ in pyrite at high temperature.

In this study, cobalt concentrations are analyzed in pyrite from TAG active mound sulfides to help identify the relative temperatures at which the minerals precipitate, the relationships among sample types, and the processes which build and modify the mound. Tivey et al. (1995) previously studied Co concentrations in TAG mound samples, but the work relied on bulk analyses and electron microprobe analyses. In this study, the ion microprobe is used to measure Co in pyrite from the TAG mound because the instrument can provide very low detection limits and $\mu \mathrm{m}$-scale analyses within the textural framework of the sample. The techniques for analyzing trace elements in sulfides using an ion probe are still being developed. Because Co was relatively easy to detect, and because a potential pyrite standard was available, the preliminary work focused on analyzing only trace Co in pyrite. The results of this preliminary work are presented in this paper, and it is expected that this investigation will be expanded to include a range of trace elements and other sulfide minerals.

\section{Methods}

Pyrite in five samples from the TAG active mound were analyzed for Co concentrations using secondary ion mass spectrometry (SIMS), or an "ion probe." Bulk rock analytical methods adequately measure trace Co concentrations from 2 to $5 \mathrm{ppm}$ (Green et al., 1981; Hannington et al., 1991; Fouquet et al., 1993). However, a bulk rock 
approach requires a relatively large sample size which can be as great as $1 \mathrm{~kg}$ if the sample must be physically or chemically separated (Green et al., 1981). Hand picking a pure mineral separate from a hydrothermal sulfide can be impossible, and bulk separation techniques offer limited success: for instance, pyrite and chalcopyrite cannot be chemically separated. Furthermore, the sample preparation, and the processes used to analyze the bulk samples, homogenize what was likely a texturally and chemically heterogeneous sample.

To analyze small samples and intergrown minerals, and to study a sample in a textural framework, in situ microanalytical techniques are needed. Unfortunately, microanalytical techniques tend to have one major disadvantage compared to bulk analytical techniques: they generally have higher detection limits. While bulk analytical techniques can measure trace Co down to concentrations of 2 to $5 \mathrm{ppm}$, microanalytical techniques such as the electron microprobe cannot detect $\mathrm{Co}$ in pyrite in concentrations lower than several hundred ppm (Tivey et al., 1995). Previous analyses of Co in pyrite from the TAG active mound used both bulk and microanalytical techniques, and the bulk analyses detected Co in pyrite at concentrations that cannot be detected by electron microprobe (Table 11; Tivey et al., 1995). Other microanalytical techniques can yield lower detection limits than the electron probe. The proton microprobe, or "PIXE" probe, can detect $\mathrm{Co}$ in pyrite in concentrations as low as $\sim 50$ ppm (Huston et al., 1995).

However, as Table 12 shows, most Co concentrations in pyrite from three VMS deposits are still below the PIXE probe detection limit.

The Cameca IMS $3 \mathrm{f}$ is the SIMS instrument used in this study, and it is expected that the results of this work will be applied to the future development of analytical techniques on the high resolution Cameca IMS 1270. The Cameca IMS $3 f$ offers spatial resolution better than $10 \mu \mathrm{m}$ at minimum detection limits better than $1 \mathrm{ppm}$ for precious metals in a sulfide matrix (e.g. Cabri and Chryssoulis, 1990), and the Cameca IMS 1270 is anticipated to provide spatial resolution and detection limits superior to those of the $3 \mathrm{f}$. Previous work using ion probes to analyze trace elements in sulfides include studies of Ag (Larocque et al., 1995a), Au (Cook and Chryssoulis, 1990; Larocque et al., 1995b; Cabri and McMahon, 1995), and Pt (Cabri and McMahon, 1995). The techniques 
developed for Co analyses in pyrite on the Cameca IMS $3 \mathrm{f}$ ion probe are expected to be applied to future analysis of other trace elements and other sulfide minerals.

\section{General Parameters}

Rock chips were mounted in epoxy in $\mathrm{Al}$ rings and polished to minimize scratches. Polished samples were coated with a thin film of gold to prevent build-up of charge and were inserted directly into the instrument. Analyses were performed using the small format Cameca IMS $3 \mathrm{f}$ located at the Woods Hole Oceanographic Institution (WHOI) as part of the Northeast Regional Ion Microprobe Facility. To minimize interference from ions with the same mass to charge ratio as the ion of interest, energy filtering with an energy offset of $-90 \mathrm{~V}$ and an energy window of $\pm 10 \mathrm{~V}$ was used. For a thorough discussion of the problems with molecular ion interferences and of other issues associated with use of the Cameca IMS $3 f$ ion probe, see Shimizu and Hart (1982) and Cabri and Chryssoulis (1990).

\section{Development of Standards}

A portion of the effort in analyzing Co in pyrite was directed at developing a standard ultimately needed to translate the trace element ratios measured on the ion probe to absolute concentrations. Because of (1) potential matrix interferences, and (2) the matrix dependence of ionization efficiencies, an ion probe standard must be the same mineral species as the sample which is being analyzed. A standard must also be homogeneous to a sub- $\mu \mathrm{m}$ scale with respect to the trace elements of interest. Collected from a high grade metamorphic massive sulfide in Balmat, New York, UL-9B is a potential standard for analysis of Co in pyrite. Analysis of Grain A of UL-9B provided the most promising results.

\section{Development of Analytical Techniques}

Analyses of ${ }^{59} \mathrm{Co}$ initially were done relative to ${ }^{57} \mathrm{Fe}$ because ${ }^{57} \mathrm{Fe}$ is invariant in pyrite, and because ${ }^{57} \mathrm{Fe}$ is present in sufficiently low concentrations to be analyzed alongside $\mathrm{Co}$ at a statistically favorable instrumental setting (-60V energy offset). Data 
taken during several sessions indicated, however, that measuring ${ }^{59} \mathrm{Co} /{ }^{57} \mathrm{Fe}$ was problematic. In analysis of Grain A of the potential standard UL-9B, variability in a group of 4 analyses taken at the start of a single analytical session was as low as $7.8 \%$, while variability in all 9 analyses taken during the entire session was as high as $40.8 \%$ (see Table 13). Analysis of the TAG sample MIR2-75-5A3 mirrored the problem with UL-9B. Duplicate analyses of individual sites on MIR2-75-5A3 varied over $20 \%$, even for analyses taken during a single session (Table 13).

It was hypothesized that the high variability in the ratios was caused by mass interference with Fe-hydrides. ${ }^{58} \mathrm{Fe}+\mathrm{H}^{+}$yields a mass number of 59, and, on the Cameca IMS $3 f$ ion probe, Fe-hydride with a mass number of 59 is indistinguishable from Co with a mass number of 59. To test this theory, 59, 57, and 56 were all analyzed, which required that the energy offset be changed to $-90 \mathrm{~V}$. The ratios $59 / 56$ and $57 / 56$ were plotted against one another (Figure 15). The ratio " $57 / 56$ " of all ions yielding mass numbers 57 and 56 is variable, while the correct ratio ${ }^{657} \mathrm{Fe} /{ }^{56} \mathrm{Fe}$ " of only Fe ions should be invariant and determined by the natural abundances of the Fe isotopes. (Any deviation of the actual ${ }^{57} \mathrm{Fe} /{ }^{56} \mathrm{Fe}$ ratio from the ratio determined by natural abundances is insignificant in hydrothermal sulfides -Nobu Shimizu and Graham Layne, pers. comm.) There is a strong positive correlation between $59 / 56$ and $57 / 56\left(\mathrm{R}^{2}=0.989\right)$. Assuming that ${ }^{58} \mathrm{Fe}$-hydrides develop at the same rate as ${ }^{56} \mathrm{Fe}$-hydrides, Fe-hydride formation can explain the positive correlation between mass numbers 59 and 57 .

An equation describing the relationship between the measured Fe-hydrideaffected ratios and the "real" ratios can be written:

$$
\begin{aligned}
& (59 / 56)_{\text {measured }}={ }^{59} \mathrm{Co} /{ }^{56} \mathrm{Fe}+{ }^{58} \mathrm{FeH} /{ }^{56} \mathrm{Fe} \quad \text { (Eq. 2) } \\
& (57 / 56)_{\text {measured }}={ }^{57} \mathrm{Fe} /{ }^{56} \mathrm{Fe}+{ }^{56} \mathrm{FeH} /{ }^{56} \mathrm{Fe} \quad \text { (Eq. 3) }
\end{aligned}
$$

where ${ }^{59} \mathrm{Co} /{ }^{56} \mathrm{Fe}$ is the "real" $\mathrm{Co}$ ratio, and ${ }^{57} \mathrm{Fe} /{ }^{56} \mathrm{Fe}$ is determined by natural abundances.

Given the fact that:

$$
\begin{gathered}
{ }^{58} \mathrm{FeH} /{ }^{56} \mathrm{Fe}=\left({ }^{58} \mathrm{Fe} /{ }^{56} \mathrm{Fe}\right) *(\mathrm{FeH} / \mathrm{Fe}) \\
{ }^{56} \mathrm{FeH} /{ }^{56} \mathrm{Fe}=\left({ }^{56} \mathrm{Fe} /{ }^{56} \mathrm{Fe}\right) *(\mathrm{FeH} / \mathrm{Fe})=1 *(\mathrm{FeH} / \mathrm{Fe})=(\mathrm{FeH} / \mathrm{Fe})
\end{gathered}
$$

Equations 2 and 3 can be combined:

$$
\begin{gathered}
(59 / 56)_{\text {measured }}={ }^{59} \mathrm{Co} /{ }^{56} \mathrm{Fe}+\left({ }^{58} \mathrm{Fe} /{ }^{56} \mathrm{Fe}\right) *(\mathrm{FeH} / \mathrm{Fe}) \\
(59 / 56)_{\text {measured }}={ }^{59} \mathrm{Co} /{ }^{56} \mathrm{Fe}+\left({ }^{58} \mathrm{Fe} /{ }^{56} \mathrm{Fe}\right) *\left({ }^{56} \mathrm{FeH} /{ }^{56} \mathrm{Fe}\right)
\end{gathered}
$$




$$
(59 / 56)_{\text {measured }}={ }^{59} \mathrm{Co} /{ }^{56} \mathrm{Fe}+\left({ }^{58} \mathrm{Fe} /{ }^{56} \mathrm{Fe}\right) *\left[(57 / 56)_{\text {measured }}-\left({ }^{57} \mathrm{Fe} /{ }^{56} \mathrm{Fe}\right)\right]
$$

where $\left({ }^{58} \mathrm{Fe} /{ }^{56} \mathrm{Fe}\right)=0.00305$ and $\left({ }^{57} \mathrm{Fe} /{ }^{56} \mathrm{Fe}\right)=0.02398$, as determined by natural abundances. The equation can be rewritten as:

$$
\begin{gathered}
(59 / 56)_{\text {measured }}={ }^{59} \mathrm{Co} /{ }^{56} \mathrm{Fe}+0.00305 *\left[(57 / 56)_{\text {measured }}-0.02398\right] \\
(59 / 56)_{\text {measured }}={ }^{59} \mathrm{Co} /{ }^{56} \mathrm{Fe}+0.00305 *(57 / 56)_{\text {measured }}-0.00305 * 0.02398 \\
(59 / 56)_{\text {measured }}={ }^{59} \mathrm{Co} /{ }^{56} \mathrm{Fe}-7.3139 \mathrm{e}-5+0.00305 *(57 / 56)_{\text {measured }}
\end{gathered}
$$

The real ratio of ${ }^{59} \mathrm{Co} /{ }^{56} \mathrm{Fe}$ therefore can be found by measuring $59 / 56$ and $57 / 56$ ratios and accounting for Fe-hydride formation:

$$
{ }^{59} \mathrm{Co} /{ }^{56} \mathrm{Fe}=(59 / 56)_{\text {measured }}+7.3139 \mathrm{e} 5-0.00305 *(57 / 56)_{\text {measured }} \quad(E q .5)
$$

To test the validity of Equation 5, a line can be regressed to the data in Figure 15, yielding:

$$
(59 / 56)_{\text {measured }}=-7.2026 \mathrm{e}-5+0.00312 *(57 / 56)_{\text {measured }} \quad \text { (Eq. 6) }
$$

The slope of the experimentally-determined Equation 6 is 0.00305 , and the slope of the theoretically-determined Equation 5 is 0.00312 . These slopes differ by only $2 \%$, indicating that the interference from Fe-hydrides accounted for in Equation 5 accurately corrects data to yield real $\mathrm{Co} / \mathrm{Fe}$ ratios.

To view the magnitude of the correction made with Equation 5 , raw ${ }^{59} \mathrm{Co} /{ }^{56} \mathrm{Fe}$ data can be compared to the corrected values of the same data. Both the corrected and uncorrected ${ }^{59} \mathrm{Co} /{ }^{56} \mathrm{Fe}$ ratios are multiplied by the constant natural abundance of ${ }^{56} \mathrm{Fe} /{ }^{57} \mathrm{Fe}$ to get the data in terms of ${ }^{59} \mathrm{Co} /{ }^{57} \mathrm{Fe}$ ratios. The two sets of ${ }^{59} \mathrm{Co} /{ }^{57} \mathrm{Fe}$ ratios are plotted on Figure 16. As the figure illustrates, corrections made with Equation 5 account for the variability in Grain A of UL-9B.

Equation 5 was developed based on data from Grain A of UL-9B, but it is applicable to an analysis of Co in pyrite from any sample. Uncorrected 59/56 and 57/56 ratios from a single analysis can be entered into Equation 5 to yield a correct value for ${ }^{59} \mathrm{Co} /{ }^{56} \mathrm{Fe}$, and this correction was applied to all the data reported below. All of the following results and interpretations employ the corrected ratios, and uncorrected ratios are not discussed further in this paper. 


\section{Results}

Co analyses in Grain A of UL-9B are uniform after being corrected for Fehydrides, except for a minor drift to lower ${ }^{59} \mathrm{Co} /{ }^{56} \mathrm{Fe}$ over time (Figure 16 ) $.{ }^{59} \mathrm{Co} /{ }^{56} \mathrm{Fe}$ ratios in Grain A range from $7.11 \times 10^{-5}$ to $8.90 \times 10^{-5}$, based on 29 analyses. The mean value and standard deviation are $7.89 \times 10^{-5} \pm 5.53 \times 10^{-6}$, and the standard deviation is $7 \%$ of the mean.

The ratios measured on Grain $\mathrm{A}$ are at the low end of the range of Co values measured in the TAG sulfide samples. As shown in Figure 17, both the concentrations of $\mathrm{Co}$ and the degree of variability in the Co analyses differ greatly among the TAG sulfide samples.

Crust sample MIR2-75-5A3 is primarily composed of pyrite interspersed with minor bands of sphalerite (Figure 18). Pyrite is present in bands of radial crystals growing towards a channel, large euhedral grains, smaller shiny grains, and a matrix of very small grains. All of the analyses were taken in the interior of the sample on the smaller grains and the matrix. ${ }^{59} \mathrm{Co} /{ }^{56} \mathrm{Fe}$ ratios are moderately high relative to the standard and range from $6.49 \times 10^{-5}$ to $2.43 \times 10^{-4}$ (Table 14). With the exception of $53 \mathrm{f}$ and $23 \mathrm{~b}$-e, the analyses were collected on September 23, 1997. Analyses $53 \mathrm{f}$ and $23 \mathrm{~b}$-e were collected on September 24, 1997, and are noticeably lower than all other analyses. It is not clear why these analyses are low. The mean value and standard deviation for all the analyses in this sample are $1.13 \times 10^{-4} \pm 4.72 \times 10^{-5}$, and the standard deviation is $42 \%$ of the mean. The standard deviation is included for this and all of the following samples because it is a way to describe variability among analyses. The samples are not assumed to be homogeneous, and the standard deviation will not be used in a strict statistical sense to interpret the data.

${ }^{59} \mathrm{Co} /{ }^{56} \mathrm{Fe}$ ratios for pyrite massive anhydrite sample $2190-8-1 \mathrm{~B}$ are moderately high and range widely from $1.14 \times 10^{-4}$ to $1.18 \times 10^{-3}$ (Table 15). The mean value and standard deviation are $4.11 \times 10^{-4} \pm 3.08 \times 10^{-4}$, and the standard deviation is $75 \%$ of the mean. All of the analyses were collected on October 21, 1997. Sites 6 and 7 listed in Table 15 are on one grain, and all other sites are on a second grain (Figure 19). Within each grain, all sites are within $100 \mu \mathrm{m}$ of each other. The sample is comprised of grains 
of anhydrite and of aggregates of grains containing mixtures of pyrite and chalcopyrite. Pyrite is present as anhedral grains, and also as a rim around pyrite or chalcopyrite grains. Both types of pyrite were analyzed.

${ }^{59} \mathrm{Co} /{ }^{56} \mathrm{Fe}$ ratios for pyrite in white smoker sample $2187-1-7 \mathrm{E}$ are invariant, low relative to the crust and massive anhydrite samples, and the same order of magnitude as the standard UL-9B. The ratios range from $7.71 \times 10^{-5}$ to $7.96 \times 10^{-5}$ (Table 16), and were collected on October 21,1997 . The mean value and standard deviation are $7.82 \times 10^{-5}$ $\pm 1.02 \times 10^{-6}$, and the standard deviation is $1 \%$ of the mean. Pyrite in this sample is present as anhedral grains alongside chalcopyrite grains in a sphalerite matrix (Figure 20).

${ }^{59} \mathrm{Co} /{ }^{56} \mathrm{Fe}$ ratios in pyrite from mound sample $2186-1 \mathrm{~A}$ are also low and invariant, ranging from $8.18 \times 10^{-5}$ to $8.89 \times 10^{-5}$ (Table 17). All of the analyses were collected on October 21,1997 . The mean value and standard deviation are $8.39 \times 10^{-5} \pm 2.62 \times 10^{-6}$, and the standard deviation is $3 \%$ of the mean. Pyrite in this sample is present as radial bands of varying thickness alternating with bands of sphalerite (Figure 21).

${ }^{59} \mathrm{Co} /{ }^{56} \mathrm{Fe}$ ratios for pyrite in massive sulfide sample $2183-6-1$ are very high relative to the standard and to the other samples, and range from $1.82 \times 10^{-3}$ to $6.28 \times 10^{-2}$ (Table 18). All of the analyses were collected on September 24, 1997. The mean value and standard deviation are $2.97 \times 10^{-2} \pm 1.91 \times 10^{-3}$, and the standard deviation is $64 \%$ of the mean. This sample is composed dominantly of pyrite with minor chalcopyrite (Figure 22). Pyrite is not in distinct grains or bands, but outlines of former grain boundaries can be distinguished in some massive clusters of pyrite. 
TABLE 9. Bulk Analyses of Cobalt in Different Mineral Assemblages and Sample Types from Hydrothermal Vent Sulfides

\begin{tabular}{|c|c|c|}
\hline Site & $\begin{array}{c}\text { Mineral Assemblage } \\
\text { or Sample Type }\end{array}$ & Co (ppm) \\
\hline Explorer Ridge $^{T}$ & $\begin{array}{l}\text { pyrite-chalcopyrite } \\
\text { pyrite-marcasite } \\
\text { marcasite-sphalerite } \\
\text { sphalerite-marcasite }\end{array}$ & $\begin{array}{c}957 \\
788 \\
102 \\
84\end{array}$ \\
\hline TAG hydrothermal field ${ }^{1}$ & $\begin{array}{l}\text { black smoker } \\
\text { white smoker } \\
\text { pyrite-chalcopyrite } \\
\text { marcasite-sphalerite } \\
\text { sphalerite-marcasite }\end{array}$ & $\begin{array}{c}531 \\
83 \\
75 \\
14 \\
19\end{array}$ \\
\hline TAG hydrothermal field ${ }^{2}$ & $\begin{array}{l}\text { mound sample } \\
\text { massive sulfide }\end{array}$ & $\begin{array}{c}20,154 \\
41,89\end{array}$ \\
\hline Snake Pit vent field ${ }^{1}$ & $\begin{array}{l}\text { black smoker } \\
335^{\circ} \mathrm{C} \text { chimney } \\
227^{\circ} \mathrm{C} \text { pyrite-sphalerite } \\
\text { pyrite-pyrrhotite } \\
\text { pyrite-marcasite } \\
\text { sphalerite-marcasite }\end{array}$ & $\begin{array}{c}108 \\
8 \\
51 \\
100 \\
20 \\
6\end{array}$ \\
\hline Snake Pit vent field ${ }^{3}$ & $\begin{array}{l}\text { Cu chimneys } \\
\text { Zn chimneys } \\
\text { active diffusers } \\
\text { inactive diffusers } \\
\text { Zn massive sulfide } \\
\text { Fe massive sulfide } \\
\text { Cu massive sulfide } \\
\text { stockwork } \\
\text { altered chimney }\end{array}$ & $\begin{array}{c}155,248 \\
21 \\
400 \\
13,122,22,30,46,17,283 \\
13 \\
155,7 \\
30,28 \\
945,1250 \\
50\end{array}$ \\
\hline Galapagos Rift ${ }^{1}$ & $\begin{array}{l}\text { pyrite-marcasite } \\
\text { pyrite-sphalerite }\end{array}$ & $\begin{array}{c}360 \\
24\end{array}$ \\
\hline $13^{\circ} \mathrm{N}$, East Pacific Rise ${ }^{1}$ & $\begin{array}{l}284-335^{\circ} \mathrm{C} \text { chimneys } \\
245-284^{\circ} \mathrm{C} \text { chimneys } \\
\text { pyrite-chalcopyrite } \\
\text { sphalerite-pyrite }\end{array}$ & $\begin{array}{c}174 \\
190 \\
3500 \\
38\end{array}$ \\
\hline $21^{\circ} \mathrm{N}$, East Pacific Rise ${ }^{1}$ & $\begin{array}{l}\text { black smoker } \\
\text { sphalerite-pyrite }\end{array}$ & $\begin{array}{c}29 \\
4\end{array}$ \\
\hline $11^{\circ} \mathrm{N}$, East Pacific Rise ${ }^{1}$ & sphalerite-pyrite & 16 \\
\hline Southern Juan de Fuca Ridge ${ }^{1}$ & sphalerite-pyrite & 11 \\
\hline
\end{tabular}

Only data that was above detection limits is reported.

${ }^{1}$ Data from Hannington et al. (1991), Tables 5 and 6, and references therein. Co concentrations are averages of a number of samples.

${ }^{2}$ Data from Tivey et al. (1995). Co concentrations are individual analyses.

${ }^{3}$ Data from Fouquet et al. (1993), Table 2. Co concentrations are individual analyses. 
TABLE 10. Cobalt Concentrations, Exit Temperatures, and pH in End-Member Hydrothermal Fluid

\begin{tabular}{|c|c|c|c|}
\hline Location & $\begin{array}{c}\text { Exit } \\
\text { Temperature }\left({ }^{\circ} \mathrm{C}\right)\end{array}$ & $\begin{array}{c}\mathrm{pH} \\
\left(25^{\circ} \mathrm{C}\right)\end{array}$ & $\begin{array}{c}\mathrm{Co} \\
(\mathrm{nmol} / \mathrm{kg})\end{array}$ \\
\hline Guaymas Basin ${ }^{1}$ & 100 to 300 & 5.9 & $<5$ \\
\hline Plume, 1990; Cleft, S. Juan de Fuca Ridge ${ }^{2}$ & 246 & 2.7 & 200 \\
\hline $\begin{array}{l}\text { Pipe Organ, 1991; Cleft, S. Juan de Fuca } \\
\text { Ridge }^{2}\end{array}$ & $262(310)$ & 2.8 & 1430 \\
\hline NGS, $21^{\circ} \mathrm{N}$, East Pacific Rise ${ }^{3}$ & 273 & 3.8 & 22 \\
\hline Table, 1990; Cleft, S. Juan de Fuca Ridge 2 & 276 & 3.1 & 72 \\
\hline $\begin{array}{l}\text { Brigadoon, 1990; Cleft, S. Juan de Fuca } \\
\text { Ridge }^{2}\end{array}$ & 296 & 3.1 & 35 \\
\hline $\begin{array}{l}\text { Monolith, 1990; Cleft, S. Juan de Fuca } \\
\text { Ridge }^{2}\end{array}$ & $298 ; 325$ & 2.8 & $47 ; 57$ \\
\hline $\begin{array}{l}\text { Monolith, 1991; Cleft, S. Juan de Fuca } \\
\text { Ridge }^{2}\end{array}$ & 327 & 3.0 & 67 \\
\hline Vent 1, 1990; Cleft, S. Juan de Fuca Ridge ${ }^{2}$ & 332 & -- & 450 \\
\hline Vent 1, 1991; Cleft, S. Juan de Fuca Ridge ${ }^{2}$ & 332 & 3.0 & 780 \\
\hline OBS, $21^{\circ} \mathrm{N}$, East Pacific Rise ${ }^{3}$ & 350 & 3.4 & 213 \\
\hline $\mathrm{HG}, 21^{\circ} \mathrm{N}$, East Pacific Rise ${ }^{3}$ & 351. & 3.3 & 227 \\
\hline $\mathrm{SW}, 21^{\circ} \mathrm{N}$, East Pacific Rise ${ }^{3}$ & 355 & 3.6 & 66 \\
\hline
\end{tabular}

${ }^{\mathrm{T}}$ Data from Von Damm (1990).

${ }^{2}$ Data from Trefry et al. (1994).

${ }^{3}$ Data from Von Damm et al. (1985).

Note that Co concentrations are determined by extrapolation to zero $\mathrm{Mg}$. 
TABLE 11. Comparison of Bulk Analytical and Electron Microprobe Analyses of Maximum Concentrations Measured in TAG Samples

\begin{tabular}{lll}
\hline Sample type & Analytical Technique & Co $(\mathrm{ppm})$ \\
\hline Black smoker & Bulk analysis & 910 \\
& Electron microprobe & $6800(\mathrm{Py}), 400(\mathrm{Cp})$ \\
White smoker & Bulk analysis & 10 \\
& Electron microprobe & bdl (Py), bdl (Cp) \\
Massive sulfide & Bulk analysis & 89 \\
& Electron microprobe & $900(\mathrm{Py}), 400(\mathrm{Cp})$ \\
\hline
\end{tabular}

Data from Tivey et al. (1995).

Note: bdl = below detection limit

Mineral abbreviations are as follows: $\mathrm{Py}=$ pyrite, $\mathrm{Cp}=$ chalcopyrite, $\mathrm{Sp}=$ sphalerite.

TABLE 12. Percent of PIXE Probe Analyses of Cobalt in Pyrite Below Minimum Detection Limits (MDL)

\begin{tabular}{lll}
\hline VMS deposit & Rock Type & $\%$ Below MDL \\
\hline Mount Chalmers & Footwall alteration-stinger zone & 68 \\
& Cu-rich massive sulfide & 83 \\
& Baritic Zn-rich massive sulfide & 89 \\
Rosebery & Footwall alteration zone & 57 \\
& Massive sulfide & 93 \\
& Massive barite & 100 \\
Dry River South & Footwall alteration-stinger zone & 78 \\
& Massive sulfide & 100 \\
\hline
\end{tabular}

Data from Huston et al. (1995), Table 3. 
TABLE 13. Examples of Variability in ${ }^{59} \mathrm{Co} /{ }^{57} \mathrm{Fe}$ Analyses

\begin{tabular}{|llcl|}
\hline Sulfide Sample & Type of Comparison & Group of Analyses & Variability \\
\hline UL-9B, Grain A & Start of session & $\# 15-18$ & $7.8 \%$ \\
& Entire session & $\# 15-23$ & $40.8 \%$ \\
MIR2-75-5A3 & Duplicate, different sessions & $\# 36$ and \#45 & $29.4 \%$ \\
& Duplicate, same session & $\# 15$ and 16 & $20.2 \%$ \\
\hline
\end{tabular}

${ }^{\mathrm{T}}$ Variability is calculated as [(standard deviation* $2 /$ mean) $\left.{ }^{*} 100\right]$, where the standard deviation is calculated assuming the group of analyses are the entire population. 


\section{Figure 15. Correcting for Fe-hydrides}

in Pyrite Standard UL-9B, Grain A

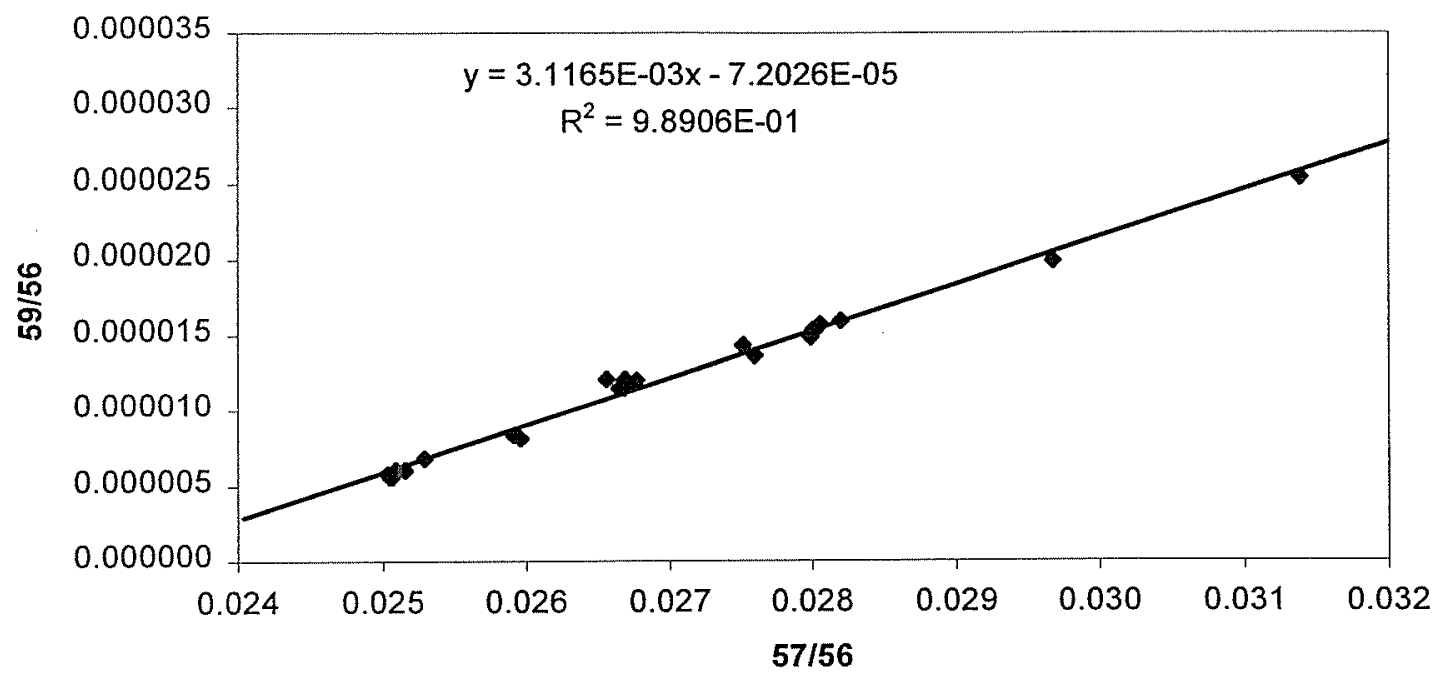

Plot shows strong positive correlation between $59 / 56$ and $57 / 56$, suggesting that formation of Fehydrides likely affect the analyzed ratios. Line regressed to data yields Equation 6 , which is compared to the theoretically-derived Equation 5 (see text). 
Figure 16. Comparison of Order of Magnitudes of Corrected and Uncorrected 59Co/57Fe Ratios

in Grain A of UL-9B

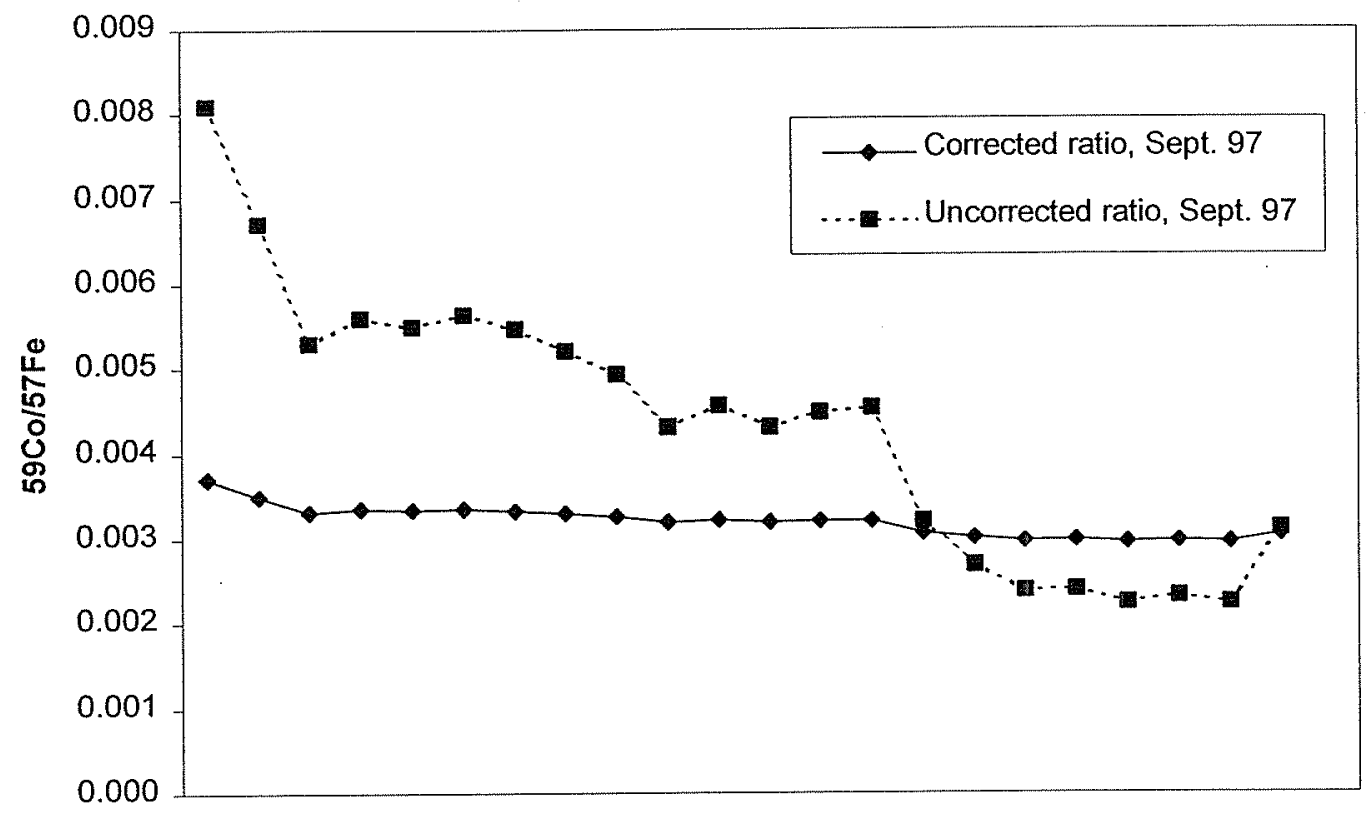

Analyses Ordered by Time

Dotted line shows variability in data when not corrected for Fe-hydride formation. Solid line demonstrates elimination of almost all variability after correction for hydride formation. Downward trend in solid line likely caused by drift in ion probe over the course of the analyses. 
Figure 17. Ranges of $59 \mathrm{Co} / 56 \mathrm{Fe}$

in Pyrite by Sample Type

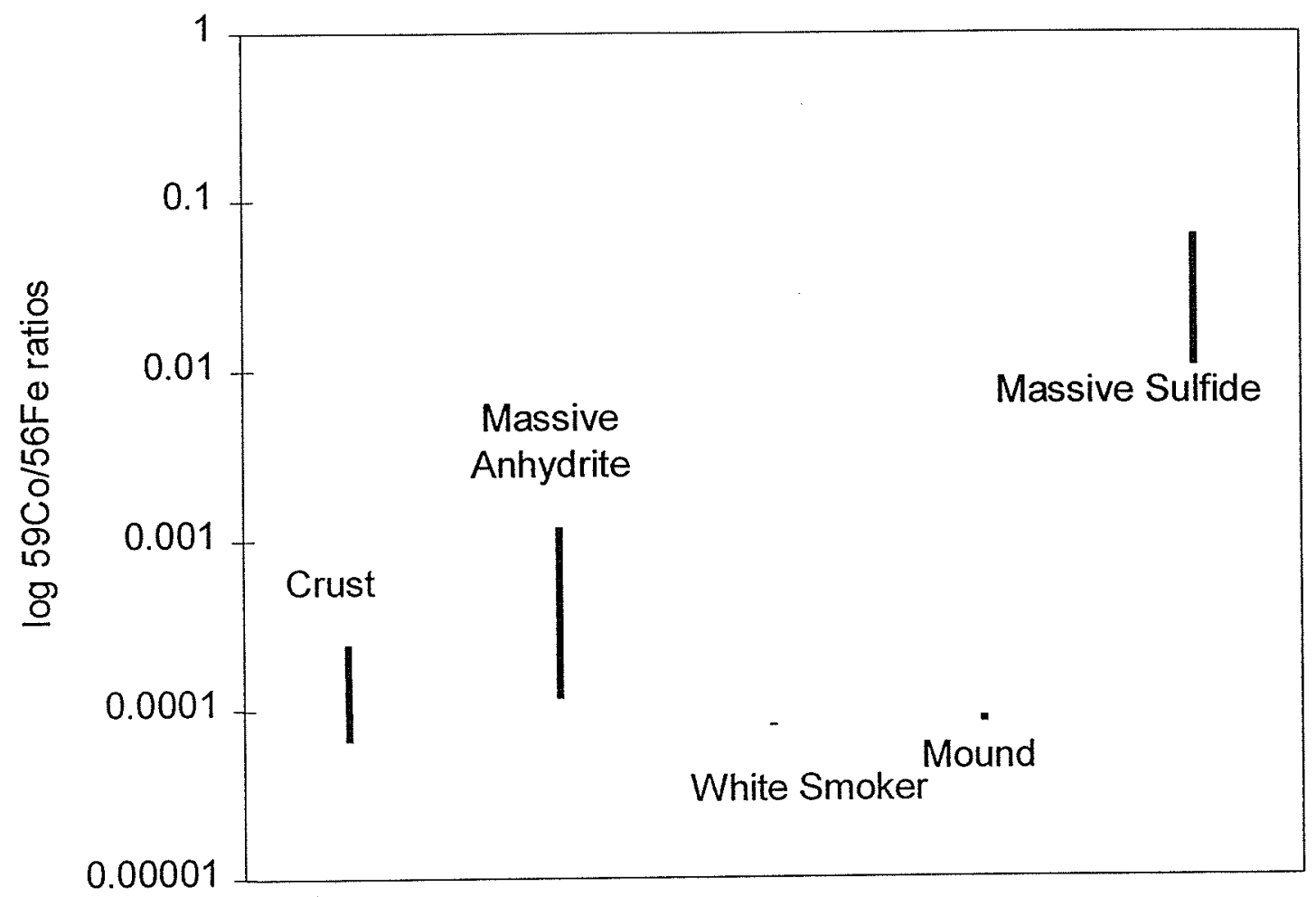

Lines show range of values. Crust and massive anhydrite samples yield moderately high Co concentrations and high variability; white smoker and mound samples demonstrate low Co concentrations and very little variability; the massive sulfide sample exhibits very high Co concentrations and very high variability.

The analyses were conducted on the following days:

September 23, 1997: crust sample

September 24, 1997: crust and massive sulfide samples

October 21, 1997: massive anhydrite, white smoker, and mound samples 
Figure 18: Drawing of crust sample MIR2-75-5A3 showing location of each analysis. Numbered black dots correspond to analysis \#'s listed in Table 14. Analyses on massive pyrite layer bordered by sphalerite layer ( $x$ region).

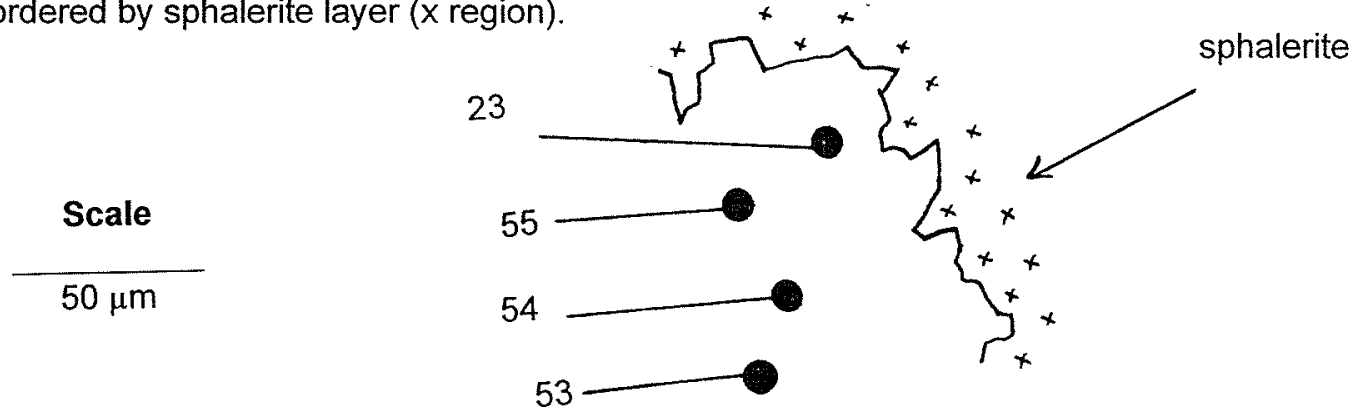

TABLE 14. ${ }^{59} \mathrm{Co} /{ }^{56} \mathrm{Fe}$ Ratios in Pyrite in Crust Sample MIR2-75-5A3

\begin{tabular}{|c|c|c|}
\hline Description of Site of Analysis & Analysis \#* & ${ }^{59} \mathrm{Co} /{ }^{56}$ Fe Ratios \\
\hline \multirow{6}{*}{$\begin{array}{l}\text { Site 53: Borders shiny grain. Analysis } 53 \text { f was } \\
\text { taken on the same spot, but on a different day. }\end{array}$} & $53 \mathrm{a}$ & 0.000243 \\
\hline & $53 b$ & 0.000212 \\
\hline & $53 \mathrm{c}$ & 0.000146 \\
\hline & $53 \mathrm{~d}$ & 0.000154 \\
\hline & $53 \mathrm{e}$ & 0.000156 \\
\hline & $53 f$ & 0.000065 \\
\hline \multirow[t]{4}{*}{ Site $54:<100 \mu \mathrm{m}$ from spot 53 ; rough texture. } & $54 a$ & 0.000136 \\
\hline & $54 \mathrm{~b}$ & 0.000128 \\
\hline & $54 \mathrm{c}$ & 0.000126 \\
\hline & $54 \mathrm{~d}$ & 0.000133 \\
\hline \multirow[t]{8}{*}{ Site $55:<100 \mu \mathrm{m}$ from spot 54 ; rough texture. } & $55 a$ & 0.000108 \\
\hline & $55 b$ & 0.000117 \\
\hline & $55 \mathrm{c}$ & 0.000114 \\
\hline & $55 \mathrm{~d}$ & 0.000110 \\
\hline & $55 \mathrm{e}$ & 0.000107 \\
\hline & $55 f$ & 0.000107 \\
\hline & $55 \mathrm{~g}$ & 0.000117 \\
\hline & $55 \mathrm{~h}$ & 0.000124 \\
\hline \multirow{4}{*}{$\begin{array}{l}\text { Site } 23:<100 \mu \mathrm{m} \text { from spot } 55 \text {; rough texture. } \\
\text { These analyses were taken on the same day as } \\
\text { analysis } 53 \mathrm{f} \text {. }\end{array}$} & $23 b$ & 0.000078 \\
\hline & $23 c$ & 0.000076 \\
\hline & $23 d$ & 0.000076 \\
\hline & $23 \mathrm{e}$ & 0.000077 \\
\hline
\end{tabular}

Data collected September 23 and 24, 1997.

*Numbers indicate a new site of analysis. Lower case letters indicate analysis at increasing depths at a single site. 
Figure 19: Drawing of massive anhydrite sample 2190-8-1B showing location of each analysis. Numbered black dots correspond to analysis \#'s listed in Table 15. Analyses on 2 pyrite grains. Dashed line on eastern grain indicates possible location of a pyrite rim. Chalcopyrite indicated by cross-hatched regions.

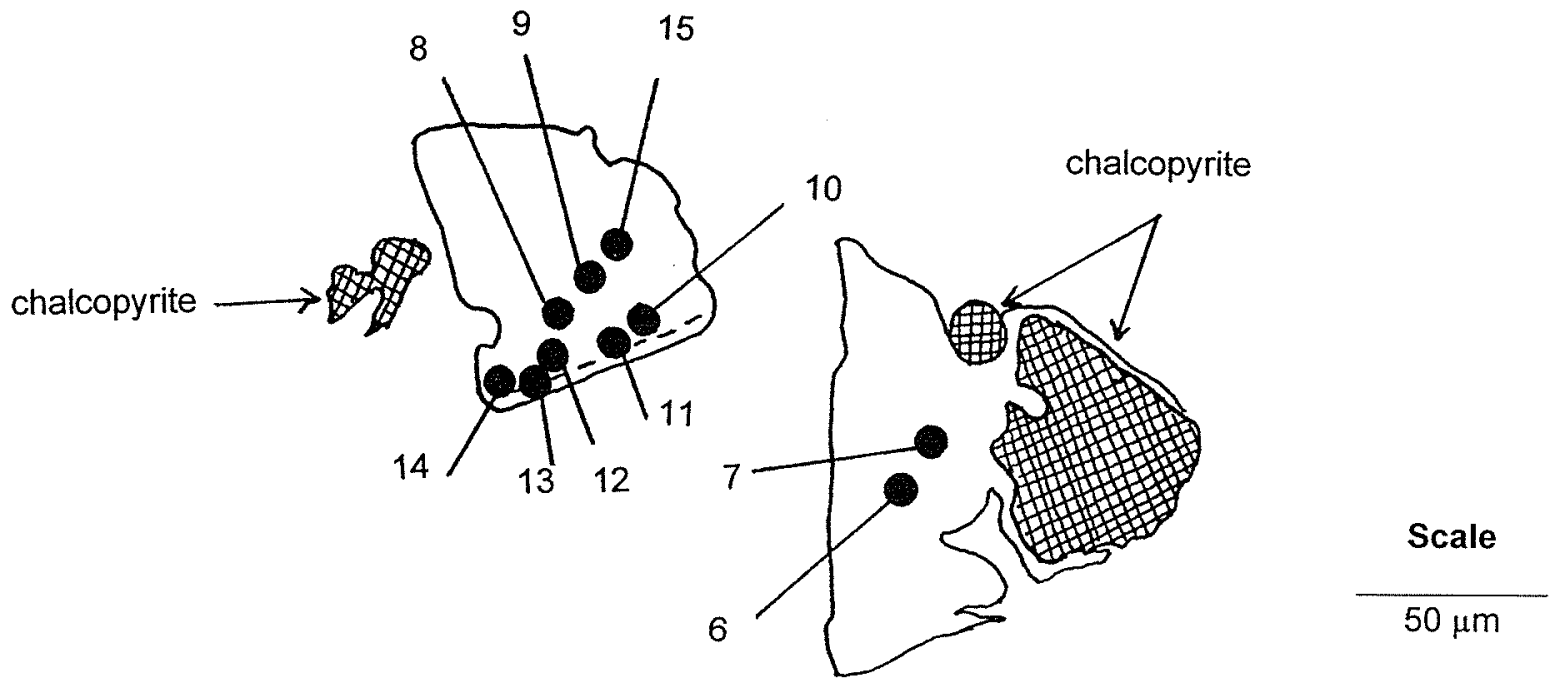

TABLE $15 .{ }^{59} \mathrm{Co} /{ }^{56} \mathrm{Fe}$ Ratios in Pyrite in Massive Anhydrite Sample 2190-8-1B

\begin{tabular}{|l|c|c|}
\hline \multicolumn{1}{|c|}{ Description of Site of Analysis } & Analysis \#* & ${ }^{59} \mathbf{C o}^{36} \mathbf{F e}$ Ratios \\
\hline In interior of grain. & 6 & 0.001176 \\
In interior of same grain. & 7 & 0.000345 \\
In interior of another grain. & 8 & 0.000179 \\
In interior of same grain. & 9 & 0.000347 \\
On border between rim and interior grain. & 10 & 0.000267 \\
On border, but closer to rim. & 11 & 0.000321 \\
In interior, but close to border with rim. & 12 & 0.000308 \\
On rim. & 14 & 0.000689 \\
In corner, on border with rim. & 15 & 0.000362 \\
In interior, far from border. & & 0.000114 \\
\hline
\end{tabular}

Data collected October 21, 1997.

*Numbers indicate a new site of analysis. 
Figure 20: Drawing of white smoker sample 2187-1-7E showing location of each analysis. Numbered black dots correspond to analysis \#'s listed in Table 16. Analyses on 3 anhedral grains of pyrite surrounded by sphalerite ( $x$ region) and minor chalcopyrite (cross-hatched region).

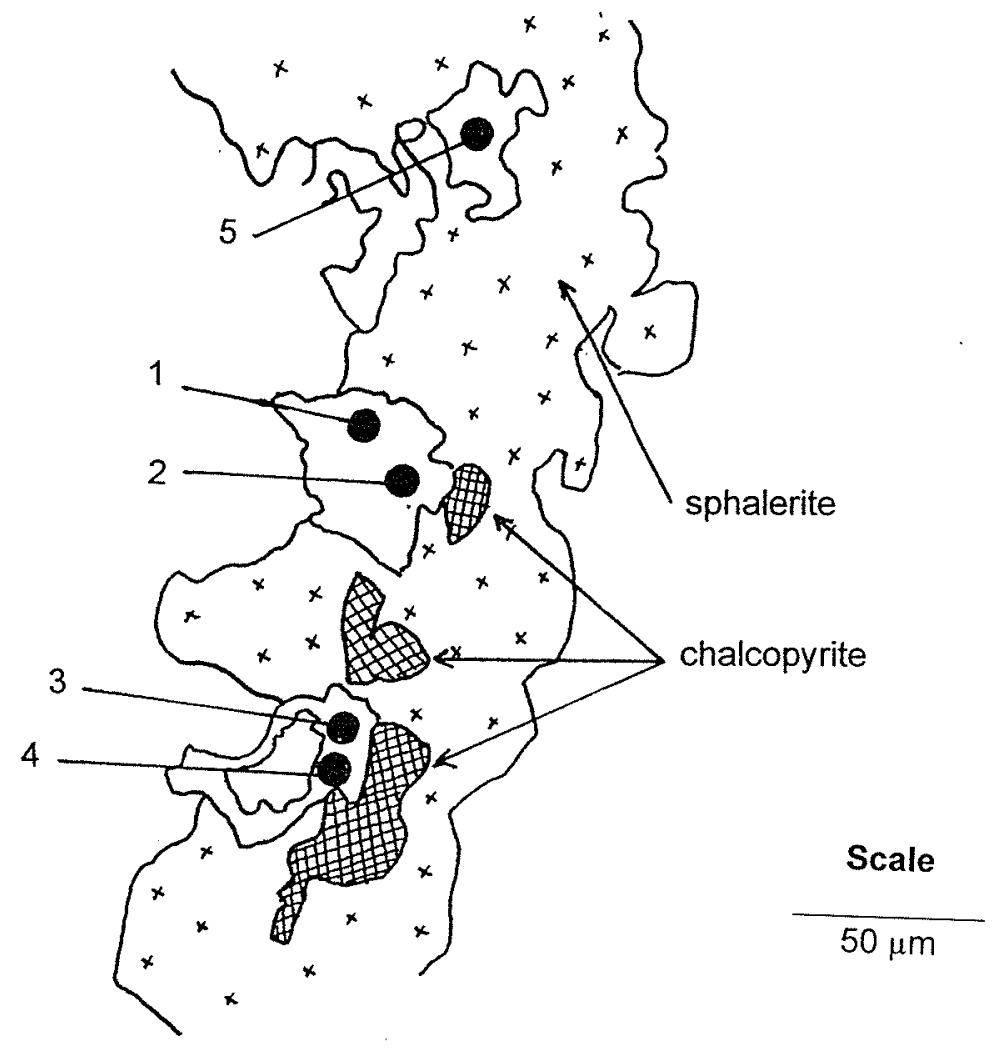

TABLE $16 .{ }^{59} \mathrm{Co} /{ }^{56} \mathrm{Fe}$ Ratios in Pyrite in White Smoker Sample 2187-1-7E

\begin{tabular}{|l|c|c|}
\hline \multicolumn{1}{|c|}{ Description of Site of Analysis } & Analysis $\#^{*}$ & ${ }^{59} \mathbf{C o} /{ }^{56} \mathbf{F e}$ Ratios \\
\hline On same grain as site 1. & 1 & 0.0000796 \\
On another grain. & 2 & 0.0000786 \\
On same grain as site 2. & 3 & 0.0000787 \\
On another grain. & 4 & 0.0000773 \\
\hline
\end{tabular}

Data collected October 21, 1997.

* Numbers indicate a new site of analysis. 
Figure 21: Drawing of mound sample 2186-1A showing location of each analysis. Numbered black dots correspond to analysis \#'s listed in Table 17. Analyses on concentric pyrite layers. Stipled regions indicate void spaces.

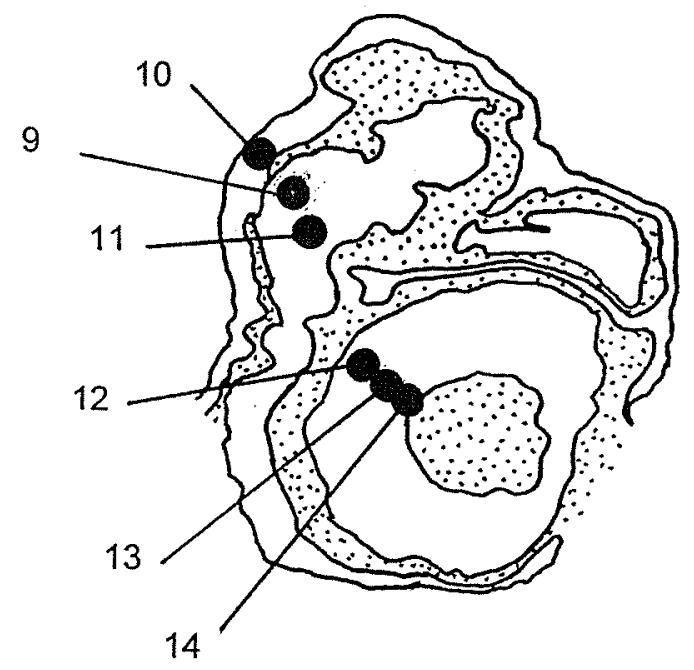

Scale

$50 \mu \mathrm{m}$

TABLE 17. ${ }^{59} \mathrm{Co} /{ }^{56} \mathrm{Fe}$ Ratios in Pyrite in Mound Sample 2186-1A

\begin{tabular}{|l|c|c|}
\hline \multicolumn{1}{|c|}{ Description of Site of Analysis } & Analysis $\#^{*}$ & ${ }^{59} \mathbf{C o} /{ }^{56} \mathbf{F e}$ Ratios \\
\hline On second layer in towards center. & 9 & 0.0000889 \\
On outermost thin layer. & 10 & 0.0000838 \\
On same layer as burn 9, but in towards center. & 11 & 0.0000842 \\
On innermost thick layer. & 12 & 0.0000824 \\
On same thick layer, closer to center. & 13 & 0.0000818 \\
On same thick layer, at center. & 14 & 0.0000823 \\
\hline
\end{tabular}

Data collected October 21, 1997.

* Numbers indicate a new site of analysis. 
Figure 22: Drawing of massive sulfide sample 2183-6-1 showing location of each analysis. Numbered black dots correspond to analysis \#'s listed in Table 18. Analyses on a section of massive pyrite. Dashed line indicates possible outline of an original pyrite grain. Small chalcopyrite grain also shown (cross-hatched region).

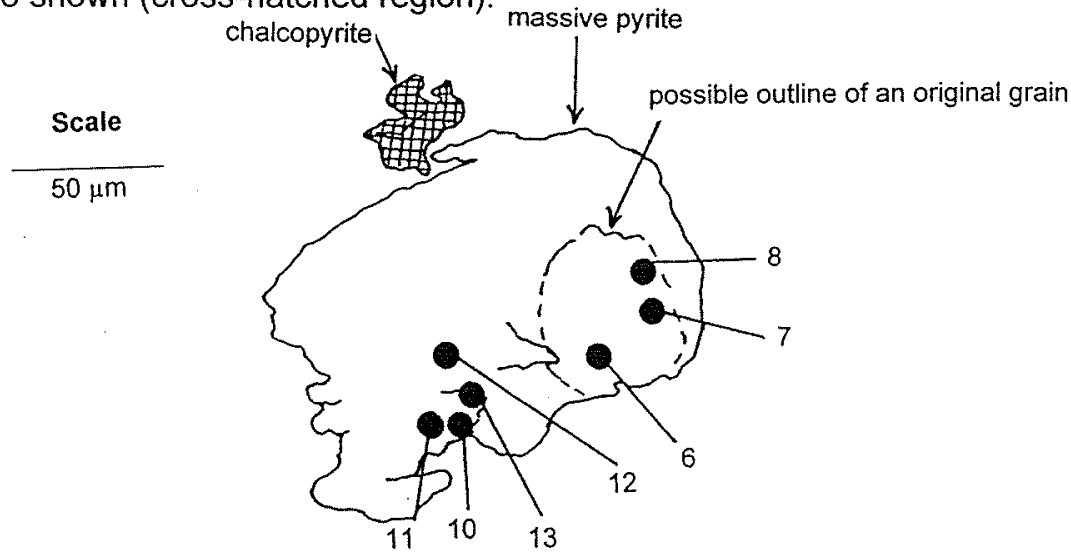

TABLE 18. ${ }^{59} \mathrm{Co} /{ }^{56} \mathrm{Fe}$ Ratios in Massive Sulfide Sample 2183-6-1

\begin{tabular}{|c|c|c|}
\hline Description of Site of Analysis & Analysis \#* & ${ }^{59} \mathrm{Co} /{ }^{36}$ Fe Ratios \\
\hline \multirow[t]{3}{*}{ Relict grain I. } & $6 \mathrm{a}$ & 0.014951 \\
\hline & $6 b$ & 0.014214 \\
\hline & $6 \mathrm{c}$ & 0.013145 \\
\hline \multirow[t]{2}{*}{ Also on relict grain $\mathrm{I}$. } & $7 a$ & 0.010396 \\
\hline & $7 b$ & 0.010413 \\
\hline Also on relict grain $\mathrm{I}$. & 8 & 0.001821 \\
\hline \multirow[t]{3}{*}{ Relict grain II. } & $10 \mathrm{~d}$ & 0.028619 \\
\hline & $10 \mathrm{e}$ & 0.030583 \\
\hline & $10 f$ & 0.028010 \\
\hline \multirow[t]{3}{*}{ Also on relict grain II. } & $11 \mathrm{~d}$ & 0.062801 \\
\hline & $11 \mathrm{e}$ & 0.060517 \\
\hline & $11 f$ & 0.058746 \\
\hline \multirow{3}{*}{$\begin{array}{l}\text { Possibly on another relict grain very close to } \\
\text { relict grain II. Still in same massive cluster } \\
\text { of pyrite. }\end{array}$} & $12 \mathrm{~d}$ & 0.021628 \\
\hline & $12 \mathrm{e}$ & 0.020904 \\
\hline & $12 f$ & 0.020617 \\
\hline \multirow[t]{3}{*}{ On relict grain II. } & $13 \mathrm{~d}$ & 0.043272 \\
\hline & $13 \mathrm{e}$ & 0.043373 \\
\hline & $13 \mathrm{f}$ & 0.042844 \\
\hline
\end{tabular}

Data collected September 24, 1997.

*Numbers indicate a new site of analysis. Lower case letters indicate analysis at increasing depths at a single site. 


\section{Section 2. INTERPRETATION OF COBALT DATA}

One of the main issues concerning use of the ion probe to analyze Co concentrations is the need for an acceptable standard. A standard serves as a reference for translating $\mathrm{Co} / \mathrm{Fe}$ ratios into actual Co concentrations, and as a basis for comparing ion probe analyses that may vary among days or due to drift in the instrument over the course of a single day. Three grains of the pyrite sample UL-9B were examined in this study to determine if it is a suitable standard for Co analyses in pyrite. Grain A of UL-9B showed the greatest potential as a standard.

The ${ }^{59} \mathrm{Co} /{ }^{56} \mathrm{Fe}$ ratios in Grain A are generally low relative to the TAG active mound samples. Because a standard should be sufficiently sensitive to detect changes that can affect low Co samples, the fact that Grain A yields low ratios makes it a potentially good gauge of Co analyses on the full range of samples at the TAG mound. Variability in analyses from Grain A of UL-9B is also low, but the sample is not perfectly invariant. Two out of the 5 TAG samples exhibit similarly low variability in ${ }^{59} \mathrm{Co} /{ }^{56} \mathrm{Fe}$ ratios. The standard deviation accounts for $1 \%$ of the mean ${ }^{59} \mathrm{Co} /{ }^{56} \mathrm{Fe}$ ratio in white smoker sample $2187-1-7 \mathrm{E}, 3 \%$ of the mean in mound sample $2186-1 \mathrm{~A}$, but $7 \%$ of the mean in Grain A. The variability of Grain A relative to the white smoker and mound samples may suggest that UL-9B is not a completely homogeneous standard. However, the percent of the mean ${ }^{59} \mathrm{Co} /{ }^{56} \mathrm{Fe}$ ratio encompassed by the standard deviation may be a misleading indication of the true Co variability in the sample. The standard deviations calculated for both the white smoker and mound samples were based on 5 and 6 analyses, respectively, and both sets of analyses were collected over the course of a single day. On the other hand, the standard deviation for UL-9B was based on 29 analyses collected over the course of 3 days. Although a greater number of analyses typically improves statistics, the nature of ion probe work is such that an increased number of analyses collected on more than one day allows for more opportunity for drift or other subtle differences in the instrument. Instrumental changes can create artificial variability, as illustrated by the downward drift in data in Figure 16. When the influence of the optical mechanics of the instrument are considered, the data for Grain A of UL-9B suggest that it does in fact have 
promise as a standard for Co analyses in pyrite. Furthermore, variability of $7 \%$ is still small, and if the analyses are considered correct to $10 \%$, then the ratios in the standard can be considered invariant within error.

A second issue regarding the trace Co analyses is whether the ion probe provides accurate data. The data does appear to be reliable based on the fact that they generally agree with prior Co analyses in TAG pyrite samples (Table 19; Tivey et al., 1995). As can be seen in Table 19, surpassing minimum detection limits is a problem for electron microprobe analyses of trace elements. In 3 out of the 5 TAG samples, Tivey et al. (1995) found Co to be below detection limits, and in the remaining 2 samples, only a subset of the total analyses were above detection limits. In contrast, every ion probe Co analysis in this study was above detection limits, even using the Cameca IMS $3 \mathrm{f}$ instrument, and not the larger format Cameca IMS 1270. This fact illustrates one of the major benefits of using the SIMS technique to measure trace elements.

Once UL-9B or another standard is developed to permit calculation of absolute Co concentrations, the ion probe can be a powerful tool for trace element analyses in hydrothermal sulfides. The fact that 4 orders of magnitude and a wide range of variabilities in Co values are measured among the 5 samples indicates that the ion probe is sensitive to variations in Co (Figure 17). The overall and intra-sample variabilities show that Co differs sufficiently to potentially yield information about the formation of TAG sulfides and the relationships among the sample types.

\section{Crust and Massive Anhydrite Samples}

Pyrite from both the crust and massive anhydrite samples yields Co ratios which are moderately high and variable. The ranges overlap, but the Co values from the crust sample (range $6.49 \times 10^{-5}$ to $2.43 \times 10^{-4}$ ) tend to be lower than the values from the massive anhydrite sample (range $1.14 \times 10^{-4}$ to $1.18 \times 10^{-3}$ ). Previous work by Tivey et al. (1995) generally agrees with the data. As shown in Table 19, the electron probe data in pyrite from the crust and massive anhydrite samples are of similar magnitude, but only 1 out of 12 analyses on the crust sample was above detection limits while 8 out of 12 analyses on the massive anhydrite sample were above detection limits. Thus, the electron probe data 
also suggests that Co is generally lower in the crust sample. Slightly lower values imply deposition from slightly cooler fluids, as does the fact that the pyrite in the crust sample was precipitated with sphalerite (Figure 18), while the pyrite in the massive anhydrite sample was precipitated with chalcopyrite (Figure 19).

Deposition from cooler temperatures relates well with the fact that the crust sample analyzed for Co is a sample from the Group $\mathrm{L}$ discussed in Chapter $2 . \delta^{34} \mathrm{~S}$ data from pyrite in Group L samples suggests that the samples may have been deposited from a fluid which underwent cooling accompanied by precipitation of isotopically heavy pyrite. Perhaps future analyses on the more precise Cameca IMS 1270 instrument will yield improved statistics that can clarify whether or not there exists a real distinction between the Co ratios in pyrite from Group L crust samples versus pyrite from massive anhydrite and Group $\mathrm{H}$ crust samples. Based on the Cameca IMS $3 \mathrm{f}$ data presented in this study, the distinction cannot be made statistically.

The Co analyses of pyrite in the massive anhydrite sample incorporated two pyrite grains (Figure 19), and the pyrite grain on which analyses 8 through 15 were conducted appears to have a thin rim. Analyses 8, 9, and 15 were taken in the interior of the grain, and analysis 13 was taken on the thin rim (Table 15). (Analyses 10 through 14 are from regions which may include variable proportions of both the interior and rim.) The Co ratio from analysis $13(0.000689)$ is 2 to 7 times greater than the ratios measured in analyses $8(0.000179), 9(0.000347)$, and $15(0.000114)$. Assuming the analyses are correct to $\pm 10 \%$, the difference is significant. The Co-enriched rim suggests that the interior grain initially precipitated from a lower temperature fluid and was later exposed to a higher temperature fluid. Variability in fluid temperatures bolsters the interpretation made based on the $\delta^{34} \mathrm{~S}$ data which states that massive anhydrite samples precipitate from disequilibrium mixing between end-member fluid and seawater.

\section{White Smoker and Mound Samples}

Pyrite from white smoker and mound samples yields Co ratios which are an order of magnitude lower than the ratios measured in the crust and massive anhydrite samples. 
The white smoker data (range $7.71 \times 10^{-5}$ to $7.96 \times 10^{-5}$ ) are very similar to the mound data (range $8.18 \times 10^{-5}$ to $8.89 \times 10^{-5}$ ), and both samples exhibit very little variability. The low Co concentrations concur with previous analyses by Tivey et al. (1995). All of the Co analyses on the white smoker and mound samples presented in Table 19 were below the electron microprobe minimum detection limits (Margaret Tivey, pers. comm.), which demonstrates that TAG white smoker and mound samples contain low Co concentrations. The low Co values in both the white smoker and mound samples indicate that the samples precipitated from a fluid that (1) is colder such that it reduced the solubility of Co into precipitating pyrite, (2) already deposited Co which was previously carried in solution at higher temperatures, or (3) mixed with cold, low Co seawater. In any case, the lack of variability in the Co ratios implies deposition under relatively constant conditions.

The white smoker Co data are fairly straightforward, and agree very well with the white smoker $\delta^{34} \mathrm{~S}$ data and with the findings of Tivey et al. (1995). White smoker samples are thought to precipitate from a lower temperature, well-mixed solution of endmember fluid and seawater. The low and invariant Co ratios are consistent with this conclusion.

Interpreting the mound Co ratios is more complex. The $\delta^{34} \mathrm{~S}$ values demonstrate that mound samples precipitate from a fluid which is isotopically similar to end-member fluid, yet the ion probe Co analyses and the geochemical and mineralogical studies by Tivey et al. (1995) suggest that the samples precipitate from fluids geochemically similar to white smoker fluids. The interpretation of the origin of mound samples presented in Chapter 2 states that mound samples may form from end-member fluid which had undergone some of the same processes, such as cooling, that white smoker fluids are thought to experience. Although deposition from cooled parent fluids increases the $\delta^{34} \mathrm{~S}$ value of pyrite (Figure 12), the effect is thought to be minor relative to the effect of cooling on Co concentrations. Based on a study by Trefry et al. (1994) of the concentrations of $\mathrm{Co}$ in fluids of different temperatures, $\mathrm{Co}$ is believed to be depleted in fluids with temperatures lower than roughly $310^{\circ} \mathrm{C}$. While little emphasis is intended to be placed on this actual temperature, it does suggest that cooling on the order of $50^{\circ} \mathrm{C}$ 
from end-member fluid temperatures may be sufficient to deplete a solution of Co. On the other hand, cooling from, for instance, $360^{\circ} \mathrm{C}$ to $310^{\circ} \mathrm{C}$ would cause an increase of only $0.1 \%$ in the $\delta^{34} \mathrm{~S}$ value of pyrite (Table 8 ). Although the actual temperature change is uncertain, this example demonstrates that cooling of $50^{\circ} \mathrm{C}$ from end-member fluid temperatures produces a very small change in the $\delta^{34} \mathrm{~S}$ value that is well within analytical error. Thus, it appears possible to cool end-member fluids sufficiently to produce Co values akin to those of the white smoker sample while still maintaining $\delta^{34} \mathrm{~S}$ values similar to those of black smoker, crust, and massive anhydrite samples.

The similar magnitude and degree of variance in Co data from the white smoker and mound sample is intriguing because the two sample types exhibit very distinct pyrite textures (Figures 20 and 21). Previous work on a land-based VMS deposit in Eastern Australia by Huston et al. (1995) found that Co concentrations vary as a function of pyrite texture. In this study, however, there is no clear relationship between texture and Co concentrations. Any relationship that may exist between Co concentrations and pyrite fabric and texture is obscured by other influences such as depositional temperatures.

\section{Massive Sulfide Sample}

Massive sulfide is the final sample type analyzed for Co concentrations, and the sample yields very high and variable values. The values do not appear to vary with changes in pyrite fabric. For example, sites 6,7 and 8 are all within what appears to have been an original grain boundary (boundary marked with a dashed line in Figure 22). Sites 6 and 7 yield Co ratios of the same order of magnitude, yet site 8 yields a Co ratio one order of magnitude lower, even though it nearly touches site 7.

Overall, Co ratios in the massive sulfide sample are 2 orders of magnitude greater than those in the crust and massive anhydrite samples, and 3 orders of magnitude greater than those in the white smoker and mound samples. Massive sulfide samples are thought to have originated from the interior of the TAG mound, and fluid inclusions in anhydrite minerals from inside the mound indicate deposition at temperatures as high as $388^{\circ} \mathrm{C}$ (Tivey et al., in press). These temperatures exceed measured temperatures of the hottest 
exiting end-member fluid $\left(366^{\circ} \mathrm{C}\right.$; Edmond et al,. 1995). It is not known precisely how Co concentrations change as a function of temperature, but the work by Trefry et al. (1994) suggests that Co may be depleted from a fluid rapidly with decreasing temperature. If Co concentrations decrease exponentially, rather than linearly, with decreasing temperature, then the large increase in Co values in the massive sulfide sample could solely be the product of deposition at hotter temperatures. Alternatively, the high Co values in the massive sulfide sample could be due partly to higher depositional temperatures, and partly to some effect of recrystallization. Recrystallization of pyrite could enrich the concentration of Co relative to the concentration in the original sample, and help produce the very high Co values in the massive sulfide sample. In any case, hot depositional temperatures likely account for at least a portion of the increase in $\mathrm{Co}$ values.

In contrast to the high Co values found in this study, previous analysis of the massive sulfide sample by Tivey et al. (1995) yields Co consistently below detection limits. It is not clear why the data disagree, but it may be related to the fact that the analyses in this study were conducted in a region containing abundant high-temperature chalcopyrite minerals and reworked, not primary, pyrite. 
TABLE 19. Electron Microprobe Analyses of Pyrite in Selected TAG Sulfide Samples

\begin{tabular}{llll}
\hline Sample Type & Sample Number & Co Data (wt \%) & Notes \\
\hline Crust & MIR2-75-5A2 & 0.15 & 1 of 12 analyses above mdl. \\
Massive Anhydrite & $2190-8-1 \mathrm{~A}$ & 0.05 to 0.56 & 8 of 12 analyses above mdl. \\
White Smoker & $2187-1-4 \mathrm{~A}$ & -- & All analyses below mdl. \\
Mound & $2186-1 \mathrm{~A}$ & -- & All analyses below mdl. \\
Massive Sulfide & $2183-6-1 \mathrm{~A}$ & -- & All analyses below mdl. \\
\hline
\end{tabular}

$\mathrm{mdl}=$ minimum detection limit $=0.04 \mathrm{wt} . \%$ (Tivey et al., 1995).

Data from Tivey et al. (1995) and Margaret Tivey, pers. comm. 


\section{Section 3. SUMMARY}

The 5 sample types analyzed for Co by ion probe reflect distinct and characteristic Co values. Diversity in Co by sample type indicates that depositional temperatures help produce the range of sample types on the TAG active mound. The Co data suggest that crust and massive anhydrite samples precipitate from hot but variable fluids, white smoker and mound samples are deposited from cooler fluids, and massive sulfide samples form from reworking with very hot fluids.

With the exception of the massive sulfide sample, the ion probe Co data generally resemble the electron probe data previously collected from TAG active mound samples by Tivey et al. (1995). The differences in the ability of the two instruments to measure Co highlights one of the major benefits of using the ion probe to measure trace elements. In situ analyses, small sample size, and low detection limits can make the ion probe an ideal instrument once reliable standards have been produced and necessary analytical techniques have been understood and developed. The Co analyses presented in this study are a preliminary effort towards making the ion probe a viable and reliable method for analyzing trace elements in sulfides. Future work is expected to be directed at developing standards and conducting analyses on the newer, large format Cameca IMS 1270 instrument. 


\section{Chapter 4. CONCLUSIONS}

Analyses of stable sulfur isotopes and trace cobalt in minerals from 6 surficial sample types provide information regarding the sources and temperatures of parent fluids, the genetic relationships among sample types, and the circulation of hydrothermal fluids and entrained seawater in the shallow subsurface of the active TAG mound. $\delta^{34} \mathrm{~S}$ values in sulfate and sulfide minerals dominantly reflect the relative influences of seawater $(\sim 21 \%)$ and basalt $(\sim 0 \%)$ in the formation of TAG mound minerals. Co values in pyrite primarily reflect depositional temperatures. Together, these complementary analyses help constrain the origin of each of the sample types and the processes which build and modify the TAG active mound.

Black smoker, crust, and massive anhydrite samples exhibit light $\delta^{34} \mathrm{~S}$ values, and pyrite from both the crust and massive anhydrite samples show high Co concentrations (black smoker samples were not analyzed for $\mathrm{Co}$ ). Black smoker $\delta^{34} \mathrm{~S}$ data is remarkably uniform and demonstrates that the samples precipitated directly from end-member fluids. Crust samples form from the same fluid as black smoker samples, although the $\delta^{34} \mathrm{~S}$ data and Co values suggest that the fluid may have conductively cooled slightly prior to deposition of the samples. Massive anhydrite samples form from rapid mixing between end-member fluids and entrained seawater, as shown by the disequilibrium in $\delta^{34} \mathrm{~S}$ values between sulfate and sulfide minerals and by the high Co concentrations in pyrite.

In white smoker samples, $\delta^{34} \mathrm{~S}$ values are generally heavy and Co values are low, indicative of precipitation from cooler fluids contaminated with isotopically heavy seawater-derived sulfate. Like the white smoker sample, the mound sample yields low Co values. Unlike the white smoker samples, however, the mound samples exhibit light $\delta^{34} \mathrm{~S}$ values, which indicates that the mound samples did not precipitate from fluids contaminated with reduced seawater sulfate. The combination of low Co and light $\delta^{34} \mathrm{~S}$ values suggests that mound samples were deposited from fluids which are isotopically similar to end-member fluids, but which cooled to temperatures similar to those of white smoker fluid. 
Massive sulfide samples exhibit very heavy $\delta^{34} \mathrm{~S}$ values and very high Co concentrations, and the samples likely are the result of recrystallization of previously deposited sulfides with high temperature fluids mixed with variable amounts of entrained seawater or previously precipitated anhydrite.

An interpretation of the formation of the 6 sample types derived from the $\delta^{34} \mathrm{~S}$ and Co analyses supports a model for hydrothermal circulation in the mound previously discussed by Tivey et al. (1995) and illustrated in Figure 14. Precipitation directly from end-member fluids, conductive cooling, disequilibrium mixing with entrained seawater, sulfate reduction, and reworking with hydrothermal fluids all contribute to the formation of the TAG mound deposit. The $\delta^{34} \mathrm{~S}$ and Co data supply independent and indispensable lines of evidence to describe the processes which produce the samples. The Co data presented in this paper are the result of preliminary work in developing trace element analyses of sulfides on the ion probe. The same information could not have been obtained using bulk rock techniques or another microanalytical technique such as the electron probe, and it is expected that development of ion probe analyses of $\mathrm{Co}$ and other trace elements will continue. 


\section{APPENDIX 1}

The isotopic fractionation factor $(\alpha)$ is defined as:

$$
\alpha_{\mathrm{i}-\mathrm{H} 2 \mathrm{~S}}=\left({ }^{34} \mathrm{~S} /^{32} \mathrm{~S}\right)_{\mathrm{i}} /\left({ }^{34} \mathrm{~S} /{ }^{32} \mathrm{~S}\right)_{\mathrm{H} 2 \mathrm{~S}}
$$

and using the fact that:

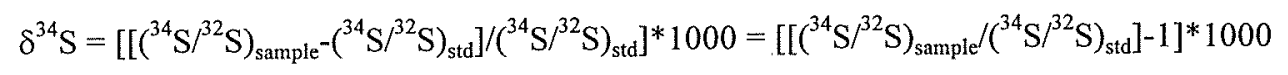

can write:

$$
\begin{aligned}
& \left({ }^{34} \mathrm{~S} /{ }^{32} \mathrm{~S}\right)_{i} /\left({ }^{34} \mathrm{~S}{ }^{32} \mathrm{~S}\right)_{\mathrm{H} 2 \mathrm{~S}}=\left[\left({ }^{34} \mathrm{~S} /{ }^{32} \mathrm{~S}\right)_{i} /\left({ }^{34} \mathrm{~S}{ }^{32} \mathrm{~S}\right)_{\mathrm{std}}\right] /\left[\left(^{34} \mathrm{~S} /{ }^{32} \mathrm{~S}\right)_{\mathrm{H} 2 \mathrm{~S}} /\left({ }^{34} \mathrm{~S} /{ }^{32} \mathrm{~S}\right)_{\mathrm{std}}\right]
\end{aligned}
$$

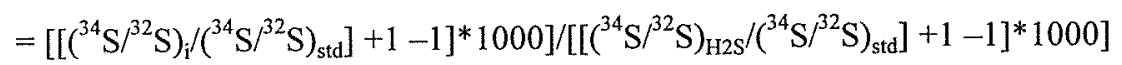

$$
\begin{aligned}
& \left.=\left[\left[\left\{\left(\left.^{34} \mathrm{~S}\right|^{32} \mathrm{~S}\right)_{i} /{ }^{34} \mathrm{~S} /{ }^{32} \mathrm{~S}\right)_{\mathrm{std}}\right]-1\right\}^{*} 1000+1000\right] /\left[\left[\left\{\left({ }^{34} \mathrm{~S} /{ }^{32} \mathrm{~S}\right)_{\mathrm{H} 22} /\left({ }^{34} \mathrm{~S} /{ }^{32} \mathrm{~S}\right)_{\mathrm{std}}\right]-1\right\}^{*} 1000+1000\right] \\
& =\left[\delta^{34} S_{i}+1000\right] /\left[\delta^{34} S_{H 2 S}+1000\right]
\end{aligned}
$$

so that:

$$
\alpha_{i-12 \mathrm{~S}}=\left({ }^{34} \mathrm{~S}^{32} \mathrm{~S}\right)_{\mathrm{i}} /\left(^{34} \mathrm{~S} /^{32} \mathrm{~S}\right)_{\mathrm{H} 2 \mathrm{~S}}=\left(1000+\delta^{34} \mathrm{~S}_{\mathrm{i}}\right) /\left(1000+\delta^{34} \mathrm{~S}_{\mathrm{H} 2 \mathrm{~S}} \mathrm{~S}\right.
$$

Reworking the equation:

$$
\begin{aligned}
& \alpha_{\mathrm{i}-\mathrm{H} 2 \mathrm{~S}}=\left(1000+\delta^{34} \mathrm{~S}_{\mathrm{i}}\right) /\left(1000+\delta^{34} \mathrm{~S}_{\mathrm{H} 2 \mathrm{~S}}\right) \\
& \alpha_{\mathrm{i}-\mathrm{H} 2 \mathrm{~S}^{*}} *\left(1000+\delta^{34} \mathrm{~S}_{\mathrm{H} 2 \mathrm{~S}}\right)=\left(1000+\delta^{34} \mathrm{~S}_{\mathrm{i}}\right) \\
& \alpha_{\mathrm{i}-\mathrm{H} 2 \mathrm{~S}} *\left(1000+\delta^{34} \mathrm{~S}_{\mathrm{H} 2 \mathrm{~S}}\right)-\delta^{34} \mathrm{~S}_{\mathrm{H} 2 \mathrm{~S}}-1000=\delta^{34} \mathrm{~S}_{\mathrm{i}}-\delta^{34} \mathrm{~S}_{\mathrm{H} 2 \mathrm{~S}} \\
& \alpha_{\mathrm{i}-\mathrm{H} 2 \mathrm{~S}} *\left(1000+\delta^{34} \mathrm{~S}_{\mathrm{H} 2 \mathrm{~S}}\right)-\left(1000+\delta^{34} \mathrm{~S}_{\mathrm{H} 2 \mathrm{~S}}\right)=\delta^{34} \mathrm{~S}_{\mathrm{i}}-\delta^{34} \mathrm{~S}_{\mathrm{H} 2 \mathrm{~S}} \\
& \left(\alpha_{\mathrm{i}-\mathrm{H} 2 \mathrm{~S}}-1\right)^{*}\left(1000+\delta^{34} \mathrm{~S}_{\mathrm{H} 2 \mathrm{~S}}\right)=\delta^{34} \mathrm{~S}_{\mathrm{i}}-\delta^{34} \mathrm{~S}_{\mathrm{H} 2 \mathrm{~S}} \\
& \left(\alpha_{\mathrm{i}-\mathrm{H} 2 \mathrm{~S}}-1\right)^{*}\left(1000+\delta^{34} \mathrm{~S}_{\mathrm{H} 2 \mathrm{~S}}\right) / 1000=\left(\delta^{34} \mathrm{~S}_{\mathrm{i}}-\delta^{34} \mathrm{~S}_{\mathrm{H} 2 \mathrm{~S}}\right) / 1000 \\
& \left(\alpha_{\mathrm{i}-\mathrm{H} 2 \mathrm{~S}}-1\right)^{*}\left(1+\delta^{34} \mathrm{~S}_{\mathrm{H} 2 \mathrm{~S}} / 1000\right)=\left(\delta^{34} \mathrm{~S}_{\mathrm{i}}-\delta^{34} \mathrm{~S}_{\mathrm{H} 2 \mathrm{~S}}\right) / 1000 \\
& 1000^{*}\left(\alpha_{\mathrm{i}-\mathrm{H} 2 \mathrm{~S}}-1\right)^{*}\left(1+\delta^{34} \mathrm{~S}_{\mathrm{H} 2 \mathrm{~S}} / 1000\right)=\left(\delta^{34} \mathrm{~S}_{\mathrm{i}}-\delta^{34} \mathrm{~S}_{\mathrm{H} 2 \mathrm{~S}}\right)
\end{aligned}
$$

Which can be approximated as:

$$
\begin{gathered}
1000^{*}\left(\alpha_{\mathrm{i}-\mathrm{H} 2 \mathrm{~S}}-1\right)^{*}\left(1+\delta^{34} \mathrm{~S}_{\mathrm{H} 2 \mathrm{~S}} / 1000\right) \sim 1000^{*}\left(\alpha_{\mathrm{i}-\mathrm{H} 2 \mathrm{~S}}-1\right) \sim 1000 \ln \left(\alpha_{\mathrm{i}-\mathrm{H} 2 \mathrm{~S}}\right) \\
\left(\delta^{34} \mathrm{~S}_{\mathrm{i}}-\delta^{34} \mathrm{~S}_{\mathrm{H} 2 \mathrm{~S}}\right) \sim 1000 \ln \left(\alpha_{\mathrm{iH} 2 \mathrm{~S}}\right)
\end{gathered}
$$




\section{APPENDIX 2}

From Bluth and Ohmoto (1979), Table 10-2:

\begin{tabular}{ll}
\hline \multicolumn{1}{c}{ Mineral Pair } & Equation \\
\hline Anhydrite - chalcopyrite & $\mathrm{T}=\left(2.85 \times 10^{3}\right) /(\Delta \pm 1)^{1 / 2}$, for $\mathrm{T}>400^{\circ} \mathrm{C}$ \\
& $\mathrm{T}=\left(2.30 \times 10^{3}\right) /(\Delta-6 \pm 0.5)^{1 / 2}$, for $\mathrm{T}<350^{\circ} \mathrm{C}$ \\
\hline Anhydrite - pyrite & $\mathrm{T}=\left(2.76 \times 10^{3}\right) /(\Delta \pm 1)^{1 / 2}$, for $\mathrm{T}>400^{\circ} \mathrm{C}$ \\
& $\mathrm{T}=\left(2.16 \times 10^{3}\right) /(\Delta-6 \pm 0.5)^{1 / 2}$, for $\mathrm{T}<350^{\circ} \mathrm{C}$ \\
\hline Pyrite - chalcopyrite & $\mathrm{T}=\left[(0.67 \pm 0.04) \times 10^{3}\right] / \Delta^{1 / 2}$ \\
\hline Pyrite - sphalerite & $\mathrm{T}=\left[(0.55 \pm 0.04) \times 10^{3}\right] / \Delta^{1 / 2}$ \\
\hline
\end{tabular}

where $T$ is in Kelvin and $\Delta=\delta^{34} S_{A}-\delta^{34} S_{B}$ for mineral pairs $A-B$.

$\Delta$ can be solved for in terms of $T$, as in the example pyrite-chalcopyrite:

where $\Delta=\delta^{34} \mathrm{~S}_{\text {pyrite }}-\delta^{34} \mathrm{~S}_{\text {chalcopyrite }}$

$$
\begin{aligned}
& \mathrm{T}=\left[(0.67 \pm 0.04) \times 10^{3}\right] / \Delta^{1 / 2} \\
& \Delta^{1 / 2}=\left[(0.67 \pm 0.04) \times 10^{3}\right] / \mathrm{T} \\
& \Delta=\left[\left[(0.67 \pm 0.04) \times 10^{3}\right] / \mathrm{T}\right]^{2}
\end{aligned}
$$

Now $\Delta$ can be calculated for any temperature $T$.

This simple derivation was used to find $\Delta$ in terms of temperature for the other 3 equations. 


\section{References}

Alt, J. C., (1995), Subseafloor processes in mid-ocean ridge hydrothermal systems, In S. E. Humphris, R. A. Zierenberg, L. S. Mullineaux, and R. E. Thomson (Eds.), Seafloor Hydrothermal Systems: Physical, Chemical, Biological, and Geological Interactions, Geophysical Monograph 91, 85-108.

Alt, J. C., E. Zuleger, and J. A. Erzinger, (1995), Mineralogy and stable isotopic compositions of the hydrothermally altered lower sheeted dike complex, Hole 504B, Leg 140, In J. Erzinger, K. Becker, H. J. B. Dick, and L. B. Stokking (Eds.), Proceedings of the Ocean Drilling Program, Scientific Results, 137/140, College Station, TX, 155-166.

Becker K., R. Von Herzen, J. Kirklin, R. Evans, D. Kadko, M. Kinoshita, O. Matsubayashi, R. Mills, A. Schultz, and P. Rona, (1996), Conductive heat flow at the TAG active hydrothermal mound: Results from 1993-1995 submersible surveys, Geophysical Research Letters, 23, 3463-3466.

Bischoff, J. L. and W. E. Seyfried, Jr., (1978), Hydrothermal chemistry of seawater from $25^{\circ}$ to $350^{\circ} \mathrm{C}$, American Journal of Science, $278,838-860$.

Blount, C. W., and F. W. Dickson, (1969), The solubility of anhydrite $\left(\mathrm{CaSO}_{4}\right)$ in NaCl$\mathrm{H}_{2} \mathrm{O}$ from 100 to $450^{\circ} \mathrm{C}$ and 1 to 1000 bars, Geochimica et Cosmochimica Acta, $33,227-245$.

Bluth, G. J., and H. Ohmoto, (1988), Sulfide-sulfate chimneys on the East Pacific Rise, $11^{\circ} \mathrm{N}$ and $13^{\circ} \mathrm{N}$ latitudes. Part II: sulfur isotopes, Canadian Mineralogist, 26, $505-$ 515.

Bowers, T. S., (1989), Stable isotope signatures of water-rock interaction in mid-ocean ridge hydrothermal systems: sulfur, oxygen, and hydrogen, Journal of Geophysical Research, 94, 5775-5786.

Brown, E., A. Colling, D. Park, J. Philips, D. Rothery, and J. Wright, (1995), In J. Wright and A. Colling (Eds.), Seawater: Its Composition, Properties and Behaviour, 2nd edition, Pergamon/Open University.

Cabri, L. J., and S. L. Chryssoulis, (1990), Advanced methods of trace-element microbeam analyses, In J. L. Jandor and D. J. Vaughan (Eds.), Mineral Association of Canada, Short-Course Handbook 17, 341-377.

Cabri., L. J., and G. McMahon, (1995), SIMS analysis of sulfide minerals for Pt and Au: methodology and relative sensitivity factors (RSF), Canadian Mineralogist, 33, 349-359.

Campbell, A. C., M. R. Palmer, G. P. Klinkhammer, T. S. Bowers, J. M. Edmond, J. R. Lawrence, J. F. Casey, G. Thompson, S. Humphris, P. Rona, and J. A. Karson, (1988), Chemistry of hot springs on the Mid-Atlantic Ridge, Nature, 335, 514-519.

Constantinou, G., and G. J. S. Govett, (1972), Genesis of sulphide deposits, ochre, and umber of Cyprus, Trans. Inst. of Mining and Metallurgy, 81, B34-B36.

Cook, N. J. and S. L. Chryssoulis, (1990), Concentrations of "invisible gold" in the common sulfides, Canadian Mineralogist, 28, 1-16.

Duckworth, R. C., R. Knott, A. E. Fallick, D. Rickard, B. J. Murton, C. Van Dover, (1995), Mineralogy and sulphur isotope geochemistry of the Broken Spur sulphides, $29^{\circ} \mathrm{N}$, Mid-Atlantic Ridge, In L. M. Parson, C. L. Walker, and D. R. Dixon (Eds.), 
Hydrothermal Vents and Processes, Geological Society Special Publication, 87, 175-189.

Edmond, J. M., A. C. Campbell, M. R. Palmer, G. P. Klinkhammer, C. R. German, H. N. Edmonds, H. Elderfield, G. Thompson, and P. Rona, (1995), Time series studies of vent fluids from the TAG and MARK sites $(1968,1990)$ Mid-Atlantic Ridge: a new solution chemistry model and a mechanism for $\mathrm{Cu} / \mathrm{Zn}$ zonation in massive sulphide orebodies, In L. M. Parson, C. L. Walker, and D. R. Dixon (Eds.), Hydrothermal Vents and Processes, Geological Society Special Publication, 87, 77-86.

Edmond, J. M., R. L. Von Damm, R. E. McDuff, and C. I. Measures, (1982), Chemistry of hot springs on the East Pacific Rise and their effluent dispersal, Nature, 297, 187191.

Edmonds, H. N., C. R. German, D. R. H. Green, Y. Huh, T. Gamo, and J. M. Edmond, (1996), Continuation of the hydrothermal fluid chemistry time series at TAG, and the effects of the ODP drilling, Geophysical Research Letters, 23, 3487-3489.

Fouquet, Y. A. Wafik, P. Cambon, C. Mevel, G. Meyer, and P. Gente, (1993), Tectonic setting, mineralogical and geochemical zonation in the Snake Pit sulfide deposit (Mid-Atlantic Ridge at 23N), Economic Geology, 88, 2018-2036.

Franklin, J. M., J. W. Lydon, and D. F. Sangster, (1981), Volcanic-associated massive sulfide deposits, Economic Geology 75th Anniversary Volume, 485-627.

Gamo, T., H. Chiba, H. Masuda, H. N. Edmonds, K. Fujioka, Y. Kodama, H. Nanba, and Y. Sano, (1996), Chemical characteristics of hydrothermal fluids from the TAG mound of the mid-Atlantic Ridge in August 1994: implications for spatial and temporal variability of hydrothermal activity, Geophysical Research Letters, 23, 3483-3486.

Goldfarb, M. S., D. R. Converse, H. D. Holland, and J. M. Edmond, (1983), The genesis of hot springs deposits on the East Pacific Rise, $21^{\circ} \mathrm{N}$, Economic Geologist Monograph, 5, 184-197.

Goodfellow, W. D., and J. M. Franklin, (1993), Geology, mineralogy, and chemistry of sediment-hosted clastic massive sulfides in shallow cores, Middle Valley, Northern Juan de Fuca Ridge, Economic Geology, 88, 2037-2068.

Goodfellow, W. D., K. Grapes, B. Cameron, and J. M. Franklin, (1993), Hydrothermal alteration associated with massive sulfide deposits, Middle Valley, Northern Juan de Fuca Ridge, Canadian Mineralogist, 31, 1025-1060.

Green, G. R., M. Solomon, and J. L. Walshe, (1981), The formation of the volcanic-hosted massive sulfide ore deposit at Rosebery, Tasmania, Economic Geology, 76, 304338.

Hannington, M. P. Herzig, S. Scott, G. Thompson, and P. Rona, (1991), Comparative mineralogy and geochemistry of gold-bearing sulfide deposits on the mid-ocean ridges, Marine Geology, 101, 217-248.

Hannington, M. D., M. K. Tivey, A. C. L. Larocque, S. Petersen, and P. A. Rona, (1995), The occurrence of gold in sulfide deposits of the TAG hydrothermal field, MidAtlantic Ridge, Canadian Mineralogist, 33, 1285-1310.

Humphris, S. E. et al., (1995), The internal structure of an active sea-floor massive sulphide deposit, Nature, 377, 713-716.

Huston, D. L., S. H. Sie, G. F. Sutter, D. R. Cooke, and R. A. Both, (1995), Trace elements 
in sulfide minerals from Eastern Australian volcanic-hosted massive sulfide deposits: Part I. Proton microprobe analyses of pyrite, chalcopyrite, and sphalerite, and Part II. Selenium levels in pyrite: comparison of $\delta^{34} \mathrm{~S}$ values and implications for the source of sulfur in volcanogenic hydrothermal systems, Economic Geology, 90, 1167-1196.

James, R.H. and H. Elderfield, (1996), Dissolved and particulate trace metals in hydrothermal plumes at the Mid-Atlantic Ridge, Geophysical Research Letters, 23, 3499-3502.

Janecky, D. R. and W. C. Shanks, III, (1988), Computational modeling of chemical and sulfur isotopic reaction processes in seafloor hydrothermal systems: chimneys, massive sulfides, and subjacent alteration zones, Canadian Mineralogist, 26, 805825.

Kinoshita, M., O. Matsubayashi, R. P. Von Herzen, (1996), Sub-botton temperature anomalies detected by long-term temperature monitoring at the TAG hydrothermal mound, Geophysical Research Letters, 23, 3467-3470.

Knott, R., A. E. Fallick, D. Rickard, and H. Backer, (1995), Mineralogy and sulphur isotope characteristics of massive sulphide boulder, Galapagos Rift, $85^{\circ} 55^{\prime} \mathrm{W}, \operatorname{In} \mathrm{L}$. M. Parson, C. L. Walker, and D. R. Dixon (Eds.), Hydrothermal Vents and Processes, Geological Society Special Publication, 87, 207-222.

Knott, R., Y. Fouquet, J. Honorez, S. Petersen, and M. Bohn, (in press), Petrology of hydrothermal mineralization: a vertical section through the TAG mound, In P. M. Herzig, S. E. Humphris, R. Zierenberg, D. J. Miller (Eds.), Proceedings of the Ocean Drilling Program, Scientific Results, 158, Texas A\&M University.

Koski, R. A., D. A. Clague, and E. Oudin, (1984), Mineralogy and chemistry of massive sulfide deposits from the Juan de Fuca Ridge, Geologic Society of America Bulletin, 95, 930-945.

Lalou, C., G. Thompson, M. Arnold, E. Brichet, E. Druffel, and P. A. Rona, (1990), Geochronology of TAG and Snake Pit hydrothermal fields, Mid-Atlantic Ridge: Witness to a long and complex hydrothermal history, Earth and Planetary Science Letters, 97, 113-128.

Lalou, C., J. L. Reyss, E. Brichet, M. Arnold, G. Thompson, Y. Fouquet, and P. Rona, (1993), New age data for Mid-Atlantic Ridge hydrothermal sites: TAG and Snake Pit chronology revisited, Journal of Geophysical Research, 98, 9705-9713.

Larocque, A. C. L., C. J. Hodgson, L. J. Cabri, and J. A. Jackman, (1995b), Ion-microprobe analysis of pyrite, chalcopyrite and pyrrhotite from the Moburn VMS deposit in northwestern Quebec: evidence for metamorphic remobilization of gold, Canadian Mineralogist, 33, 373-388.

Larocque, A. C. L., J. A. Jackman, L. J. Cabri, and C. J. Hodgson, (1995a), Calibration of the ion microprobe for the determination of silver in pyrite and chalcopyrite from the Moburn VMS deposit, Rouyn-Noranda, Quebec, Canadian Mineralogist, 33, 361-372.

McDuff, R. E., and J. M. Edmond, (1982), On the fate of sulfate during hydrothermal circulation at mid-ocean ridges, Earth and Planetary Science Letters, 57, 117-132.

Mills, R. A., T. Clayton, and J. C. Alt, (1996), Low-temperature fluid flow through sulfidic 
sediments from TAG: modification of fluid chemistry and alteration of mineral deposits, Geophysical Research Letters, 23, 3495-3498.

Mills, R. A., and H. Elderfield, (1995), Rare earth element geochemistry of hydrothermal deposits from the active TAG Mound, $26^{\circ} \mathrm{N}$ Mid-Atlantic Ridge, Geochimica et Cosmochimica Acta, 59, 3511-3524.

Mottl, M. J., (1983), Metabasalts, axial hot springs, and the structure of hydrothermal systems at mid-ocean ridges, Geological Society of America Bulletin, 94, 161-180.

Ohmoto, H. and R. O. Rye, (1979), Isotopes of sulfur and carbon, In H. L. Barnes (Ed.), Geochemistry of Hydrothermal Ore Deposits, 509-567.

Palmer, M. R., and J. M. Edmond, (1989), Cesium and rubidium in hydrothermal fluids: evidence for recycling of alkali elements, Earth and Planetary Science Letters, 95 , 8-14.

Rees, C. E., W. J. Jenkins, and J. Monster, (1978), The sulphur isotope geochemistry of ocean water sulphate, Geochimica et Cosmochimica Acta, 42, 377-382.

Rona, P. A. (1980), TAG hydrothermal field: Mid-Atlantic Ridge crest at latitude $26^{\circ} \mathrm{N}$, Journal of the Geological Society of London, 137, 385-402.

Rona, P. A., M. D. Hannington, C. V. Raman, G. Thompson, M. K. Tivey, S. E. Humphris, C. Lalou, and S. Petersen, (1993) Active and relict sea-floor hydrothermal mineralization at the TAG hydrothermal field, Mid-Atlantic Ridge, Economic Geology, 88, 1989-2017.

Rona, P. A. and R. P. Von Herzen, (1996), Introduction to special section on measurements and monitoring at the TAG hydrothermal field, Mid-Atlantic Ridge $26^{\circ} \mathrm{N}, 45^{\circ} \mathrm{W}$, Geophysical Research Letters, 23, 3427-3430.

Sakai, H., D. J. Des Marais, A. Ueda, and J. G. Moore, (1984), Concentrations and isotope ratios of carbon, nitrogen, and sulfur in ocean-floor basalts, Geochimica et Cosmochimica Acta, 48, 2433-2441.

Seyfried, W. E., and J. L. Bischoff, (1977), Hydrothermal transport of heavy metals by seawater: the role of seawater/basalt ratio, Earth and Planetary Science Letters, 34, 71-77.

Seyfried, W. E., and J. L. Bischoff (1979), Low temperature basalt interaction with seawater: an experimental study at $70^{\circ} \mathrm{C}$ and $150^{\circ} \mathrm{C}$, Geochimica et Cosmochimica Acta, 43, 1937-1947.

Shanks, W. C., III, J. K. Bohlke, and R. R. Seal II, (1995), Stable isotopes in mid-ocean ridge hydrothermal systems: interactions between fluids, minerals, and organisms, In S. E. Humphris, R. A. Zierenberg, L. S. Mullineaux, and R. E. Thomson (Eds.), Seafloor Hydrothermal Systems: Physical, Chemical, Biological, and Geological Interactions, Geophysical Monograph 91, 194-221.

Shanks, W. C., III, and W. E. Seyfried, (1987), Stable isotope studies of vent fluids and chimney minerals, Southern Juan de Fuca Ridge: sodium metasomatism and seawater sulfate reduction, Journal of Geophysical Research, 92, 11,387-11, 389.

Shima, M., W. H. Gross, and H. G. Thode, (1963), Sulfur isotope abundances in basic sills, differentiated granites, and meteorites, Journal of Geophysical Research, 68, 28352847.

Shimizu, N., and S. R. Hart, (1982), Applications of the ion microprobe to geochemistry and cosmochemistry, Annual Reviews of Earth and Planetary Science, 10, 483-526. 
Smitheringale, W. G. and M. L. Jensen, (1963), Sulfur isotopic composition of the Triassic igneous rocks of eastern United States, Geochimica and Cosmochimica Acta, 27, 1183-1207.

Stein, C. A., and S. Stein (1994), Constraints on the hydrothermal heat flux through the oceanic lithosphere from global heat flow, Journal of Geophysical Research, 99 B2, 3081-3095.

Thompson, G., S. E. Humphris, B. Schroeder, M. Sulanowska, and P. A. Rona, (1988), Hydrothermal mineralization on the Mid-Atlantic Ridge, Canadian Mineralogist, 26, 697-711.

Thompson, G., M. J. Mottl, and P. A. Rona, (1985), Morphology, mineralogy and chemistry of hydrothermal deposits from the TAG area, $26^{\circ} \mathrm{N}$ Mid-Atlantic Ridge, Chemical Geology, 49, 243-257.

Tivey, M. K., R. A. Mills, and D. A. H. Teagle, (in press), Temperature and salinity of fluid inclusions in anhydrite as indicators of seawater entrainment and heating in the TAG active mound, In S. E. Humphris, P. M. Herzig, D. J. Miller, and R. Zierenberg (Eds.), Proc. ODP Sci. Results, 158.

Tivey, M. K., S. E. Humphris, G. Thompson, M. D. Hannington, P. A. Rona, (1995), Deducing patterns of fluid flow and mixing within the TAG active hydrothermal mound using mineralogical and geochemical data, Journal of Geophysical Research, 100, 12, 527-12,555.

Tivey, M. K., (1995), Modeling chimney growth and associated fluid flow at seafloor hydrothermal vent sites, In S. E. Humphris, R. A. Zierenberg, L. S. Mullineaux, and R. E. Thomson (Eds.), Seafloor Hydrothermal Systems: Physical, Chemical, Biological, and Geological Interactions, Geophysical Monograph 91, 158-177.

Trefry, J. H., D. B. Butterfield, S. Metz, G. J. Massoth, R. P. Trocine, and R. A. Feely, (1994), Trace metals in hydrothermal solutions from Cleft segment on the southern Juan de Fuca Ridge, Journal of Geophysical Research, 99, 4925-4935.

Von Damm, K. L., (1990), Seafloor hydrothermal activity: black smoker chemistry and chimneys, Annual Reviews of Earth and Planetary Science, 18, 173-204.

Von Damm, K. L., J. M. Edmond, B. Grant, C. I. Measures, B. Walden, and R. F. Weiss, (1985), Chemistry of submarine hydrothermal solutions at $21^{\circ} \mathrm{N}$, East Pacific Rise, Geochimica et Cosmochimica Acta, 49, 2197-2220.

Woodruff, L. G., and W. C. Shanks III, (1988), Sulfur isotope study of chimney minerals and vent fluids from $21^{\circ} \mathrm{N}$, East Pacific Rise: hydrothermal sulfur sources and disequilibrium sulfate reduction, Journal of Geophysical Research, 93, 4562-4572.

Zierenberg, R. A., W. C. Shanks III, and J. L. Bischoff, (1984), Massive sulfide deposits at $21^{\circ} \mathrm{N}$, East Pacific Rise: Chemical composition, stable isotopes, and phase equilibria, Geological Society of America Bulletin, 95, 922-929.

Zierenberg, R. et al., (in press), Deep structure of a seafloor hydrothermal deposit, Nature. 


\section{Acknowledgments}

Financial support for this work included the Cecil and Ida Green Ion Microprobe Fellowship (WHOI project 00444542) and National Science Foundation grants OCE9314005 and OCE-9314697.

I am grateful to my co-advisors Margaret Tivey and Susan Humphris for making this thesis a success through their expertise, guidance, and honesty. I thank W. C. (Pat) Shanks for providing analytical facilities, for conducting many of the sulfur isotope analyses, for allowing me to quote unpublished isotopic analyses of TAG fluids, and for engaging discussions, scientific and otherwise. It is a pleasure to acknowledge Nobu Shimizu and Graham Layne for providing me with ample hours on the ion probe, and for their knowledge, extensive technical assistance, and wonderful humor. I also appreciate the patient laboratory training and support I received from Carol Gent.

To my family, I cannot thank you enough. You helped me make some difficult decisions and supported me through rough spots. Thank you to my friend Sasha for lending a sympathetic ear and for always being on my side. I will miss you. And, of course, tremendous thanks to John. You made Boston a home to me, and your voice brightened dreary days during my months on the Cape. 